University of Rhode Island

DigitalCommons@URI

Open Access Dissertations

1972

\title{
Synthesis and Characterization of Diamond and Boron Phosphide
}

K. P. Ananthanarayanan

University of Rhode Island

Follow this and additional works at: https://digitalcommons.uri.edu/oa_diss

\section{Recommended Citation}

Ananthanarayanan, K. P., "Synthesis and Characterization of Diamond and Boron Phosphide" (1972). Open Access Dissertations. Paper 690.

https://digitalcommons.uri.edu/oa_diss/690

This Dissertation is brought to you for free and open access by DigitalCommons@URI. It has been accepted for inclusion in Open Access Dissertations by an authorized administrator of DigitalCommons@URI. For more information, please contact digitalcommons-group@uri.edu. 


\section{SYNTHESIS AND CHARACTERIZATION OF \\ DIAMOND AND BORON PHOSPHIDE}

BY

K. P. ANANTHANARAYANAN

A THESIS SUBMITTED IN PARTIAL FULFILLMENT OF THE

REQUIREMENTS FOR THE DEGREE OF

DOCTOR OF PHILOSOPHY

IN

CHEMICAL ENGINEERING 
DOCTOR OF PHILOSOPHY THESIS

OF

K. P. ANANTHANARAYANAN

Approved:

Thesis Committee:

Chairman

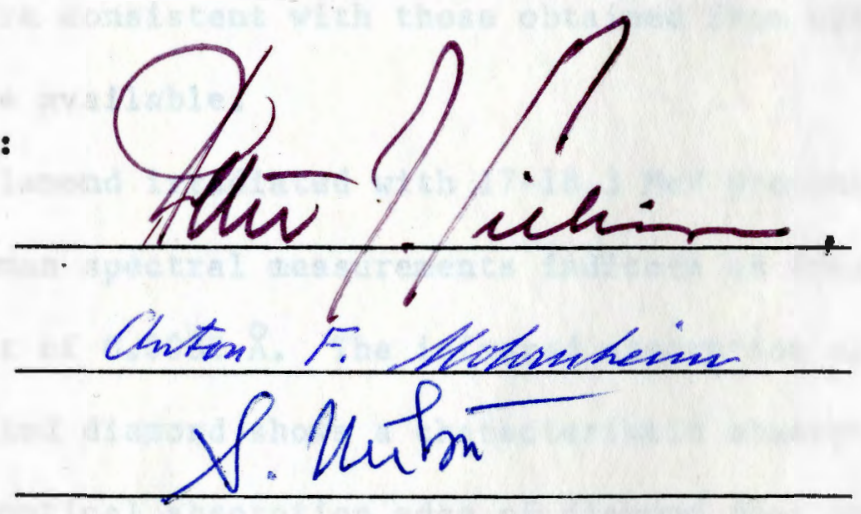

U. A kueluel

Dean of the Graduate School

UNIVERSITY OF RHODE ISLAND

1972 


\section{ABSTRACT}

Semiconducting diamond has been synthesized from carbon-metal melts in a 600 ton tetrahedral anvil press at about 60 kbar and $1400^{\circ} \mathrm{C}$. The experimental set up, pressure and temperature calibrations, and the growth region in the pressure-temperature regime are indicated. Micrographs of synthesized crystals are shown.

The semiconducting properties of diamond, doped with boron, aluminum and titanium have been interpreted using the $\log R$ versus $1 / T$ curves. In boron-doped diamond "high concentration" type impurity conduction occurs and the activation energies vary from $0.15 \mathrm{eV}$ to $0.30 \mathrm{eV}$. The activation energies for aluminum and titanium-doped samples are found to be $0.31 \mathrm{eV}$ and $0.40 \mathrm{eV}$ respectively. The results are consistent with those obtained from optical methods where data were avallable.

Properties of diamond irradiated with 17-18.3 MeV protons have been Investigated. Raman spectral measurements indicate an Increase In the lattice constant of $0.0032 \AA$. The infrared absorption spectrum of proton Irradiated diamond shows a characteristic absorption at $6.92 \mathrm{microns.} \mathrm{The} \mathrm{optical} \mathrm{absorption} \mathrm{edge} \mathrm{of} \mathrm{diamond} \mathrm{does} \mathrm{not}$ seem to be affected by the irradiation.

Boron phosphide has been synthesized from the elements at pressures and temperatures above 20 kbar and $1200^{\circ} \mathrm{C}$. The crystal growth rate has been determined as a function of temperature and pressure from which an activation energy for the process 1s derived. Optical 
and Scanning Electron Micrographs of the crystals synthesized revealed a poorly developed morphology with voids present under all conditions of pressure and temperature.

The effect of thermal neutron irradiation on the electrical conductivity of boron phosphide, hexagonal boron nitride and boron oxide $\left(\mathrm{B}_{2} \mathrm{O}_{3}\right)$ has been observed by studying the current-voltage characteristics before and during irradiation with a neutron flux of about $10^{8} \mathrm{n} / \mathrm{cm}^{2} \cdot \mathrm{sec}$. In all these compounds, currents were higher, for the same voltage setting, during irradiation. The differences observed during irradiation in current values for the three boron compounds have been explained as being due to the "boron to anion ratio" being different in them.

The Appendix to this thesis includes an introduction to the foregoing investigations and describes the equipment used with recommendations for future work. 


\section{ACKNOWLEDGMENTS}

The author is very specially indebted to his major professor, Dr. P. J. Gielisse, for the inspiring guidance, constant interest and encouragement he received during his entire graduate work. The helpful suggestions rendered by Dr. Mitra of the Electrical Engineering Department in making the optical measurements and those of Dr. Mohrnheim of Chemical Engineering in the X-ray diffraction work are sincerely appreciated. Thanks are also due to Dr. Thompson, Chairman of the Department of Chemical Engineering, for his kindness and encouragement, and to the personnel at the Rhode Island Nuclear Science Center for all assistance rendered. 
ACKNOWLEDGMENTS $\ldots \ldots \ldots \ldots \ldots \ldots \ldots \ldots \ldots \ldots \ldots \ldots \ldots \ldots \ldots \ldots \ldots$ ii

TABLE OF CONTENTS $\ldots \ldots \ldots \ldots \ldots \ldots \ldots \ldots \ldots \ldots \ldots \ldots \ldots \ldots \ldots$. 11 .

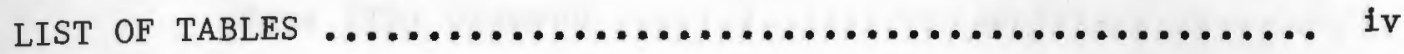

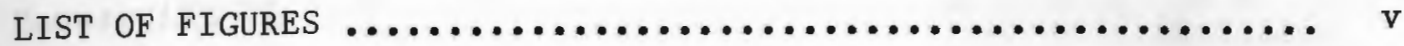

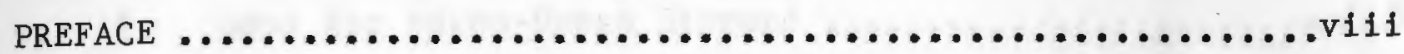

MANUSCRIPT

I. SYNTHESIS OF SEMICONDUCTING DIAMOND FOR CATHODOLUMINESCENT IMAGING TUBES $\ldots \ldots \ldots \ldots \ldots \ldots \ldots \ldots \ldots \ldots \ldots$

II. ELECTRICAL CONDUCTIVITY OF HEAVILY DOPED DIAMOND $\ldots . .20$

III. PROPERTIES OF PROTON-IRRADIATED DIAMOND $\ldots \ldots \ldots \ldots \ldots 45$

Iv. SYNTHESIS OF SINGLE CRYSTAL BORON MONOPHOSPHIDE $\ldots \ldots .61$

V. BORON COMPOUNDS FOR THERMAL NEUTRON DETECTION $\ldots \ldots \ldots .84$

$\begin{array}{ll}\text { APPENDIX } & 105\end{array}$

I. INTRODUCTION AND LITERATURE SURVEY $\ldots \ldots \ldots \ldots \ldots \ldots \ldots$

II. METHODS AND EQUIPMENT USED $\ldots \ldots \ldots \ldots \ldots \ldots \ldots \ldots \ldots \ldots \ldots$

III. SUMMARY AND PROPOSED FUTURE WORK $\ldots \ldots \ldots \ldots \ldots \ldots \ldots 121$

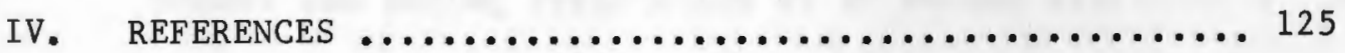




\section{LIST OF TABLES}

PAGE

Manuscript I

1. Electrical Characteristics of Semiconducting

(Type IIb) Diamond

Manuscript II

1. Data for Boron-Doped Diamond .................. 35

2. Data for Aluminum and Titanium Doped Diamond ....... 36

Manuscript IV

1. Average Crystal Size as a Function of Time, Temperature and Pressure

Manuscript V

1. Current Values for Different Voltage Settings

Before and During Irradiation of $\mathrm{BN}$ Pellet

2. Current Values for Different Voltage Settings Before and During Irradiation of Electrophoretically= Deposited BN

3. Current Values for Different Voltage Settings

Before and During Irradiation of $\mathrm{B}_{2} \mathrm{O}_{3}$ Pellet ......... 95

4. Current Values for Different Voltage Settings

Before and During Irradiation of BP Pellet. 


\section{LIST OF FIGURES}

PAGE

Manuscript I

1. TYPICAL TEMPERATURE CALIBRATION CURVE FOR SAMPLE CONFIGURATION USED IN THE EXPERIMENTS REPORTED HERE

2. TYPICAL PRESSURE CALIBRATION CURVE FOR THE 600 TON TETRAHEDRAL PRESS AND SAMPLE CONFIGURATION USED IN THE EXPERIMENTS REPORTED HERE ................... 14

3. CELL DESIGN FOR GROWTH OF DIAMOND AS USED IN OUR EXPERIMENTS $\ldots \ldots \ldots \ldots \ldots \ldots \ldots \ldots \ldots \ldots \ldots \ldots \ldots \ldots \ldots \ldots \ldots \ldots$

4. EXPERIMENTAL RESULTS IN THE DIAMOND GROWTH SYSTEM ...... 16

5. MICROGRAPH OF SYNTHESIZED DIAMOND (44X) $\ldots \ldots \ldots \ldots \ldots \ldots \ldots . . \ldots$

6. PHASE DIAGRAM OF CARBON $\ldots \ldots \ldots \ldots \ldots \ldots \ldots \ldots \ldots \ldots \ldots \ldots \ldots$ Manuscript II

1. RESISTANCE VERSUS TEMPERATURE AT VARIOUS DOPANT LEVELS FOR BORON-DOPED SEMICONDUCTING DIAMOND. DOPANT CONCENTRATION IN THE GROWTH MIXTURE OF CRYSTALS CHARACTERIZED BY CURVES 1 THROUGH 4 MAY BE OBTAINED BY REFERENCE TO

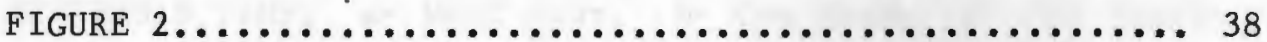

2. AVERAGE RESISTANCE AS A FUNCTION OF PERCENT BORON IN GROWTH SYSTEM COMPARED TO FIT AS SHOWN

3. RESISTANCE OF ALUMINUM-DOPED DIAMOND AS A FUNCTION OF TEMPERATURE. BEST FIT AS SHOWN .................. 40

4. RESISTANCE OF NATURAL DIAMOND (CURVE 1, INNER SCALE) AND TITANIUM-DOPED DIAMOND AS A FUNCTION OF TEMPERATURE. BEST FIT FOR TITANIUM DOPED SAMPLE IS AS SHOWN 
Manuscript III

1. X-RAY INTENSITY PROFILES AT $2 \theta=140.6$ FOR TYPE I DIAMOND BEFORE AND AFTER PROTON IRRADIATION .......... 55

2. UV ABSORPTION SPECTRA OF TYPE I DIAMOND POWDER, BEFORE AND AFTER PROTON IRRADIATION $\ldots \ldots \ldots \ldots \ldots \ldots \ldots \ldots$

3. IR ABSORPTION SPECTRA OF TYPE I SINGLE CRYSTAL DIAMOND, BEFORE AND AFTER PROTON IRRADIATION $\ldots \ldots \ldots \ldots \ldots \ldots \ldots \ldots . \ldots \ldots$

4. RAMAN SPECTRA (STOKES SIDE) OF TYPE I DIAMOND POWDER, BEFORE AND AFTER PROTON IRRADIATION $\ldots \ldots \ldots \ldots \ldots \ldots \ldots \ldots . \ldots$

5. SHIFT IN THE LATTICE VIBRATION FREQUENCY OF TYPE I DIAMOND AFTER PROTON IRRADIATION, FROM ANTI-STOKES

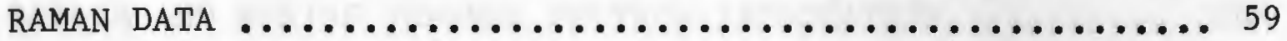

Manuscript IV

1. CELL DESIGN AS USED IN OUR EXPERIMENTS

2. CRYSTAL SIZE VERSUS SYNTHESIS TIME AS A FUNCTION OF TEMPERATURE

3. CRYSTAL SIZE VERSUS SYNTHESIS TIME AS A FUNCTION OF PRESSURE

4. MICROGRAPHS (44X) OF CRYSTALLINE BP AS A FUNCTION OF SYNTHESIS TIME. a- Half Hour, b- One Hour, c- Two Hours, d- Three Hours, e- Four Hours .................. 76

5. ACTIVATION ENERGY PLOT FOR BP SINGLE CRYSTAL GROWTH PROCESS

6. SCANNING ELECTRON MICROGRAPH (750X) OF CRYSTALLINE BP SHOWING VESICULAR STRUCTURE $\ldots \ldots \ldots \ldots \ldots \ldots \ldots \ldots \ldots \ldots \ldots \ldots \ldots \ldots \ldots$

7. UNUSUAL MORPHOLOGY OF BP CRYSTALS. SCULPTURED GROWTH FEATURES, SCANNING ELECTRON MICROGRAPH (3000X) ........ 79 
8. UNUSUAL MORPHOLOGY OF BP CRYSTALS. STEPPED COLUMNAR GROWTH FEATURES. SCANNING ELECTRON MICROGRAPH (1500X).. 80

9. TRANSMISSION SPECTRA FOR BORON PHOSPHIDE. TWO SEPARATE PRODUCT-DIFFERENTIATED MEASUREMENTS.

(For explanation see text).

Manuscript $V$

1. SKETCH OF THERMAL NEUTRON DETECTOR AS USED IN THIS INVESTIGATION $\ldots \ldots \ldots \ldots \ldots \ldots \ldots \ldots \ldots \ldots \ldots \ldots \ldots \ldots$

2. SCHEMATIC OF EXPERIMENTAL SET-UP FOR ELECTROPHORETIC DEPOSITION OF HEXAGONAL BORON NITRIDE ..............

3. CURRENT-VOLTAGE CHARACTERISTIC FOR BORON NITRIDE PELLET, BEFORE AND DURING THERMAL NEUTRON IRRADIATION......... 100

4. CURRENT-VOLTAGE CHARACTERISTIC FOR ELECTROPHORETICALLYDEPOSITED BORON NITRIDE, BEFORE AND DURING THERMAL NEUTRON IRRADIATION $\ldots \ldots \ldots \ldots \ldots \ldots \ldots \ldots \ldots \ldots \ldots \ldots \ldots$

5. CURRENT-VOLTAGE CHARACTERISTIC FOR BORON OXIDE PELLET, BEFORE AND DURING THERMAL NEUTRON IRRADIATION

6. CURRENT-VOLTAGE CHARACTERISTIC FOR BORON PHOSPHIDE PELLET, BEFORE AND DURING THERMAL NEUTRON IRRADIATION . 103 Appendix

1. TETRAHEDRAL PRESS USED IN THIS INVESTIGATION $\ldots \ldots \ldots \ldots \ldots$

2. HYDRAULIC FLOW DIAGRAM OF TETRAHEDRAL PRESS USED IN THIS STUDY $\ldots \ldots \ldots \ldots \ldots \ldots \ldots \ldots \ldots \ldots \ldots \ldots \ldots \ldots \ldots \ldots$

3. SAMPLE AND SAMPLE HOLDER AS USED IN THIS INVESTIGATION.. 117

4. TYPICAL PRESSURE CALIBRATION CURVE FOR THE 600 TON TETRAHEDRAL PRESS AND SAMPLE CONFIGURATION USED IN THE EXPERIMENTS REPORTED HERE ..................

5. TYPICAL TEMPERATURE CALIBRATION FOR SAMPLE CONFIGURATION USED IN THE EXPERIMENTS REPORTED HERE 
PREFACE

This dissertation 1s written in the "Manuscript Plan" approved by the Graduate School of the University of Rhode Island. According to this plan, this thesis is divided into two sections: five manuscripts prepared according to the format of scholarly journals and an appendix that contains an introduction to the problem, I1terature survey, and detalls of methods and equipment used with recommendation for future work.

Manuscript I has been published as part of the final report on "Research on Photoelectronic Imaging Devices" sponsored by Advanced Research Project Agency and monitored by U.S. Army Research Office. Manuscripts II and III have been accepted for publication in the "Journal of Applied Physics" and "Radiation Effects" respectively. Manuscript IV has been presented at the annual meeting of the American Ceramic Soclety, Washington, D. C., and has been submitted for publication to the "Journal of Crystal Growth". Manuscript $V$ is being finalized for publication. 
M A N U S C R I P T I 


\section{SYNTHESIS OF SEMICONDUCTING DIAMOND FOR}

CATHODOLUMINESCENT IMAGING TUBES*

K. P. Ananthanarayanan and P. J. Gielisse

Department of Chemical Engineering

University of Rhode Island

Kingston, R. I. 02881

* This research has been sponsored by Advanced Research Project Agency and monitored under contract No. DAHC 0468 C0019 by the U. S. Army Research Office, Durham, N. C. 


\section{ABSTRACT}

Semiconducting diamond, to be used as the active material in targets in cathodoluminescent imaging tubes, has been synthesized in a 600 ton tetrahedral anvil press. The experimental setup, including the temperature and pressure calibration and some of the experimental results are discussed. The growth region is indicated on a pressure-temperature diagram and micrographs of the synthesized crystals are shown. 
Introduction:

The thermodynamic calculation of the equilibrium line between graphite and diamond ${ }^{1}$ has been a major contribution towards diamond synthesis. It is in good agreement with the experimental results obtained by other workers. ${ }^{2}$ Contributions to the carbon phase diagram have been made by several investigators. ${ }^{2-4}$ The part of the diamondgraphite equilibrium line from 0 to $1200^{\circ} \mathrm{K}$ is based on moderately accurate thermodynamic data. From $1400^{\circ} \mathrm{K}$ to $2800^{\circ} \mathrm{K}$ the data is based upon experiments on the growth and graphitization of diamond. 5 It has been suggested that at pressures above 600-700 kbar diamond reduces to a dense metallic state, 15-20 percent denser than diamond. 4

Pressure equipment of various types have been designed and used for a variety of purposes. ${ }^{3,6}$ It is now possible to assess the merits and demerits of each and select the required type depending upon whether the main consideration is pressure, temperature or sample volume. The tetrahedral anvil press used in this investigation lends itself particularly well for laboratory experiments as needed in this investigation. Experimental data is available regarding the pressure and temperature at which diamond growth occurs. It varies for different catalyst systems used. ${ }^{3}$ The direct conversion of graphite to diamond (without catalyst) is also possible except that the required pressures are above 125 kbar. ${ }^{4}$ Different types of reaction cells have been devised. They can either be directly heated or indirectly heated, 2,3,6 (with a heater tube enclosing the sample). The actual transformation from carbon to diamond, when using a solvent, occurs across a very thin solvent film separating the carbon and diamond. 3 The growth region in the pressure-temperature regime is the area 
bounded by the melting point line of the solvent and the graphite diamond equilibrium line. 7

Semiconductivity in synthetic diamond is induced by introduction of specific impurities like $B e, B$ or $A$ to suitable mixtures of carbon and solvents like the transition metals iron, nickel and cobalt. ${ }^{8,9}$ The impurities may be introduced by direct addition to the growth mixture, diffusion techniques or ion bombardment. 10,11 The electrical resistivity of the crystal decreases with increasing concentration of the impurity atoms. The crystals may have resistivities as low as $10^{3} \mathrm{ohm}-\mathrm{cm}$ with activation energies for conduction lying between 0.1 and $0.35 \mathrm{ev}{ }^{9}, 12$

Electrical measurements have been made on semiconducting diamond crystals for determining Hall coefficient and temperature dependence of conductivity. ${ }^{13,14}$ It has been observed that the electrical properties can be markedly altered by subjecting the crystals to heat treatment. ${ }^{7}$ Table I shows the electrical characteristics of natural semiconducting crystals.

The effect of pressure and temperature is important not only in the actual production of semiconducting crystals but also in determining the color, size and shape of the crystals synthesized. ${ }^{15,16}$ At low pressures where nucleation is slow, it is found that cubic development is favored at the lower temperature, gradually changing to cubo-octahedra and eventually octohedra at higher temperatures. At higher pressures where nucleation is rapid, fine sized crystals are normally encountered.

Doping, apart from changing the electrical and optical properties $^{8,9}$ also influences the morphology of the crystals. For 
example, in boron doped diamond crystals the cubic habit is pronounced at boron concentrations of about 200 ppm. At concentrations around $1000 \mathrm{ppm}$ only octahedra are synthesized. Between these two levels cubo-octahedra are prevalent. ${ }^{16}$

\section{Experimental Set Up and Procedures:}

Synthesis of diamond was carried out in a 600 ton tetrahedral press. The details of construction and operation may be found elsewhere. Heating of the samples was accomplished by so-called direct heating whereby a transformer provides a low voltage, high current (600-800 amperes) which is passed via the press anvils through the sample itself. Runs were made in which the total wattage passed through the cell was monitored and the temperature read from a previously obtained calibration curve on the specific sample design used. Temperature calibrations were made using a Pt-Pt, 10\% Rh thermocouple. A typical calibration curve is shown in Figure 1. Pressure calibration is done by obtaining the relationship between ram pressure and working pressure. Known pressure values for polymorphic transition in bismuth and thallium were used. These transitions are accompanied by sharp resistivity changes in the metals. Cells containing the respective metals, which were extruded into wires from bulk form in our laboratory, are monitored for this resistivity change and the appropriate ram pressure noted. A typical calibration curve is shown in Figure 2. All runs were subsequently made by monitoring the ram pressures. No attempts were made to individually determine pressure and/or temperature in each cell. The cell design for actual crystal growth is shown in Figure 3. 
A typical growth sequence consisted of pressurizing the sample followed by gradual heating of the sample by increasing the wattage in about three minutes after which growth ensues at essentially stable conditions for about ten to fifteen minutes. At the end of the run the current is rapidly decreased, effectively quenching the sample, after which the pressure is gradually decreased. After removal of the sample and the surrounding pyrophyllite pressurizing medium, the cell is "cleaned" to yleld the desired end product. Cleaning is done by dissolution and oxidation processes in a variety of baths. The sequence of events is as follows:

The cell is first broken up mechanically and observed under the microscope. The sample holder material (pyrophyllite) ${ }^{*}$ is carefully removed as much as possible without losing any of the diamond crystals.

The material is then transferred to a clean $250 \mathrm{cc}$ beaker. To this 1 s added $150 \mathrm{cc}$ of a saturated solution of sodium or potassium dichromate in concentrated sulfuric acid. This solution is now reddish brown in color. It is carefully heated at about $60^{\circ} \mathrm{C}$ for half an hour. Stirring is done by means of a glass coated magnetic stirrer.

When the solution turns blulsh green in color, no further reaction takes place and the heating is stopped. The mixture is allowed to settle. The clean solution is carefully decanted and the materlal washed with water and decanted again. This step is repeated until all acid is fully diluted. If graphite is still left,

\footnotetext{
*See page 115 of Appendix.
} 
the above procedure is repeated.

Aqua regia ( 3 volumes of conc. $\mathrm{HCl}$ and 1 volume of conc. $\mathrm{HNO}_{3}$ ) is used to remove the metal. The solution and the sample is allowed to boil for about an hour or so using the magnetic stirrer, until all metal has dissolved. It is allowed to settle, decanted and washed repeatedly.

Some of the pyrophyllite which may still remain is dissolved by adding hydrofluoric acid to the residue in a teflon beaker. The solution is heated gently for about one half hour, allowed to cool and then decanted and washed with water as often as necessary. The only residue is now pure diamond.

\section{Results and Discussion:}

Figure 4 graphically shows the conditions at which semiconducting diamond was obtained. The experiments were primarily directed at determining the conditions of synthesis at which the material of the desired size and morphological development could be obtained. Several large crystals of boron doped diamond were selected for property determinations.

All synthetic diamond that are semiconducting are p-type and show unusual electrical conductivity properties. Thermistor devices made from this material display a negative coefficient of resistivity over a useful, continuous temperature range of -200 to $+800^{\circ} \mathrm{C}$. Typical zem-power resistance is $30,000 \mathrm{ohms}$ at $25^{\circ} \mathrm{C}$ and the resistance ratio $R_{25} / R_{125}=3$. They also have a favorable dissipation constant and thermal time constant. Aluminum and titanium doped diamond also show similar properties. 
Growth of diamond can be accomplished at reasonably low pressures and temperatures only in the presence of a so-called cata1yst. 11 It is felt that the materials used for this purpose, primarily transition metals, act as solvents for the low pressure forms, from which the high pressure forms crystallize under conditions of pressure and temperature for which they are stable. Semiconductivity can be induced by addition of low concentration dopants (less than 0.1 per cent) to the growth mixture (solute), solvent or separately. The method used in this investigation is the addition of boron to the graphite. This is particularly suitable for the present growth purposes which have the intent of producing massive nucleation with the subsequent result of many small crystallites.

The main objective was the synthesis of small crystallites of semiconducting diamond for use as target materials in cathodoluminescent tubes. Whereas the primary task, from the experimental growth points of view, was the determination of the appropriate temperature and pressure for synthesis, a variety of parameters affect the characteristics of the end product. 'Pressure greatly influences the nucleation rate, with higher pressures inducing more and more widespread nucleation. This is an advantage since pressure can now monitor the crystal size. A disadvantage of the high pressure is, however, a generally short life of the carbide press anvils. The exact conditions of pressure and temperature furthermore influence dopant level and morphology of the crystals. Dopant level is of importance inasmuch as it fixes the resistivity of the crystals and the response time when used in detector applications. Morphology is important since growth rates on the prevalent cublc and octahedral 
faces are different. It also has an influence on the ease of fabrication of detectors. Regardless of the influence of pressure and temperature on morphology, the dopant level is of greater importance yet. In the case of diamond and for any pressure level, cubic crystals are generated at low temperatures, octahedral crystals at high temperatures, while tetrakaidecahedral (cubooctahedra) forms are observed at intermediate temperatures. Figure 5 shows the morphology of the synthesized crystals. Change of morphology as a function of boron dopant level in diamond in the pressure-temperature regime is described in reference 15.

The addition of dopants generally suppresses the equilibrium line, as shown in Figure 6, to lower pressures. The extent of the pressure reduction is dependent on the type and concentration of dopant.

It can therefore not be stressed enough that a variety of parameters can influence the characteristics of the end product. Subsequently, our growth experiments have been aimed at determing the best conditions for growth of a light-element, fine-grain-size, high-temperature stable, semiconducting product. Such material, in the form of boron doped semiconducting diamond has been delivered to the sponsor. 
TABLE 1

Anctical Characteristics of Semiconducting (Type IIb) Diamond

$$
\begin{array}{ll}
\text { Activation Energy of Acceptors } & 0.35 \mathrm{eV} \\
\text { Resistivity (at } 295^{\circ} \mathrm{K} \text { ) } & 160 \mathrm{ohm}-\mathrm{cm} \\
\text { Hall Coefficient (at } 295^{\circ} \mathrm{K} \text { ) } & 1.25 \times 10^{3} \mathrm{~cm}^{3} / \mathrm{coulomb} \\
\text { Hall Mobility of Holes (at } 295^{\circ} \mathrm{K} \text { ) } & 780 \mathrm{~cm}^{2} / \mathrm{sec-volt} \\
\text { Hole Concentration (at } \left.295^{\circ} \mathrm{K}\right) & 5.9 \times 10^{13} / \mathrm{cm}^{3} \\
\mathrm{~N}_{\mathrm{A}} \text { (Acceptor Concentration) } & 8.5 \times 10^{16} / \mathrm{cm}^{3} \\
\mathrm{~N}_{\mathrm{D}} \text { (Donor Concentration) } & 5.4 \times 10^{15} / \mathrm{cm}^{3}
\end{array}
$$

Sample Description: $2.47 \times 2.51 \times 5.81 \mathrm{~mm}$

$$
\text { Weight: } 0.63 \text { carat }(0.1265 \mathrm{~g} / 0.632 \text { carat })
$$




\section{FIGURE CAPTIONS}

Figure 1. Typlcal temperature calibration curve for sample configuration used in the experiments reported here.

Figure 2. Typical pressure calibration curve for the 600 ton tetrahedral press and sample configuration used in the experiments reported here.

Figure 3. Cell design for growth of diamond as used in our experiments.

Flgure 4. Experimental results in the diamond growth system.

Figure 5. Micrograph of synthesized diamond (44X).

Figure 6. Phase diagram of carbon ${ }^{4}$. 


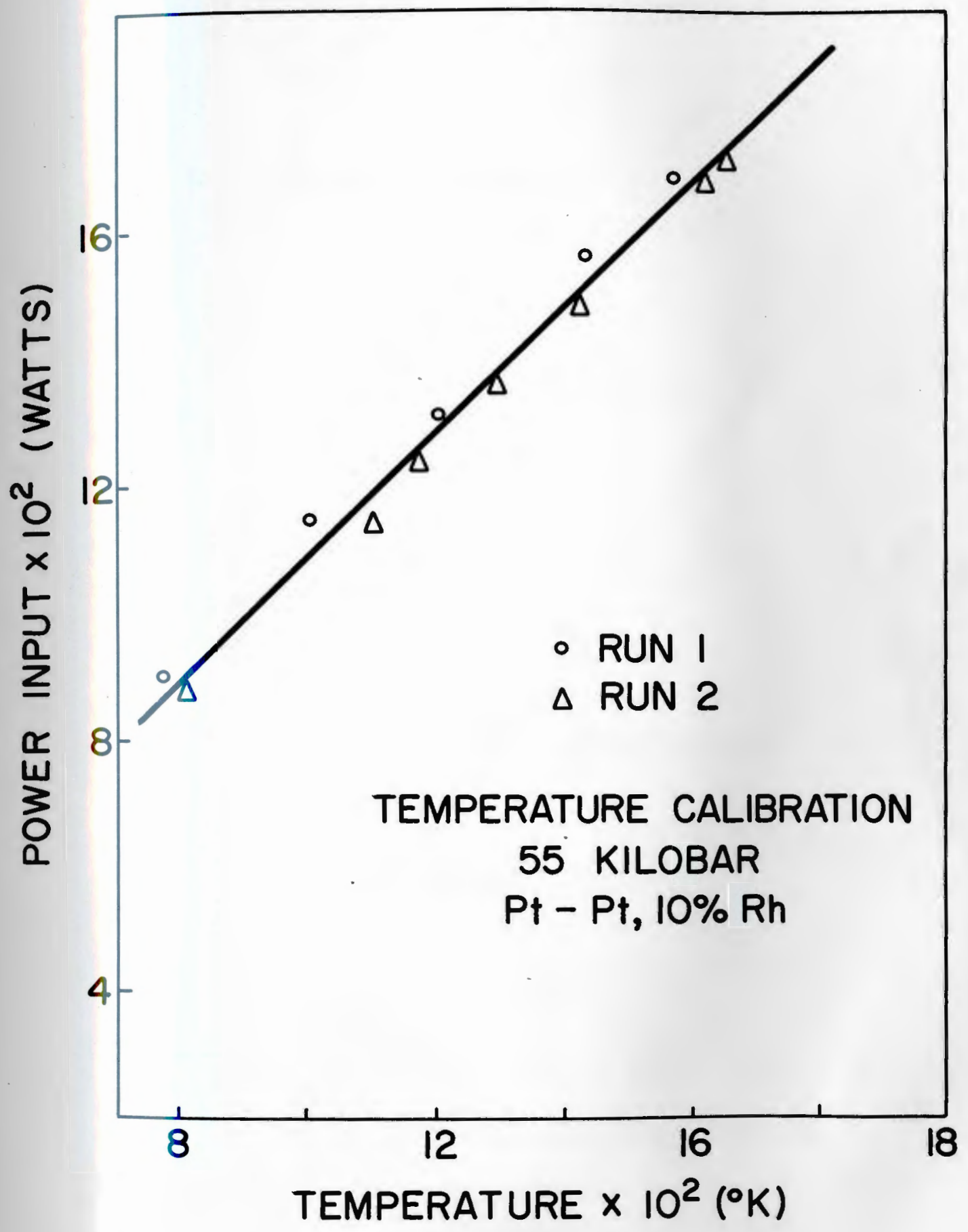




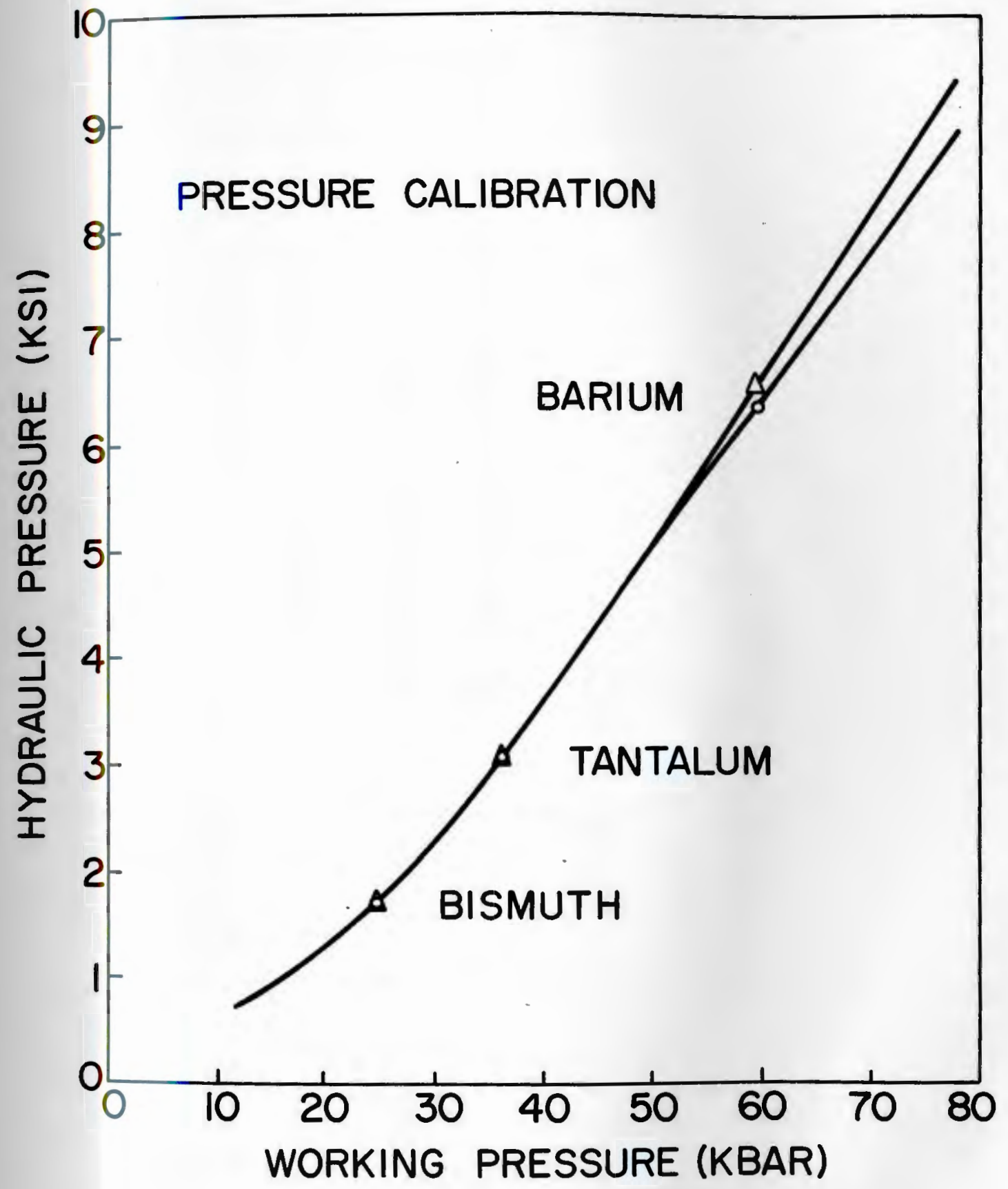




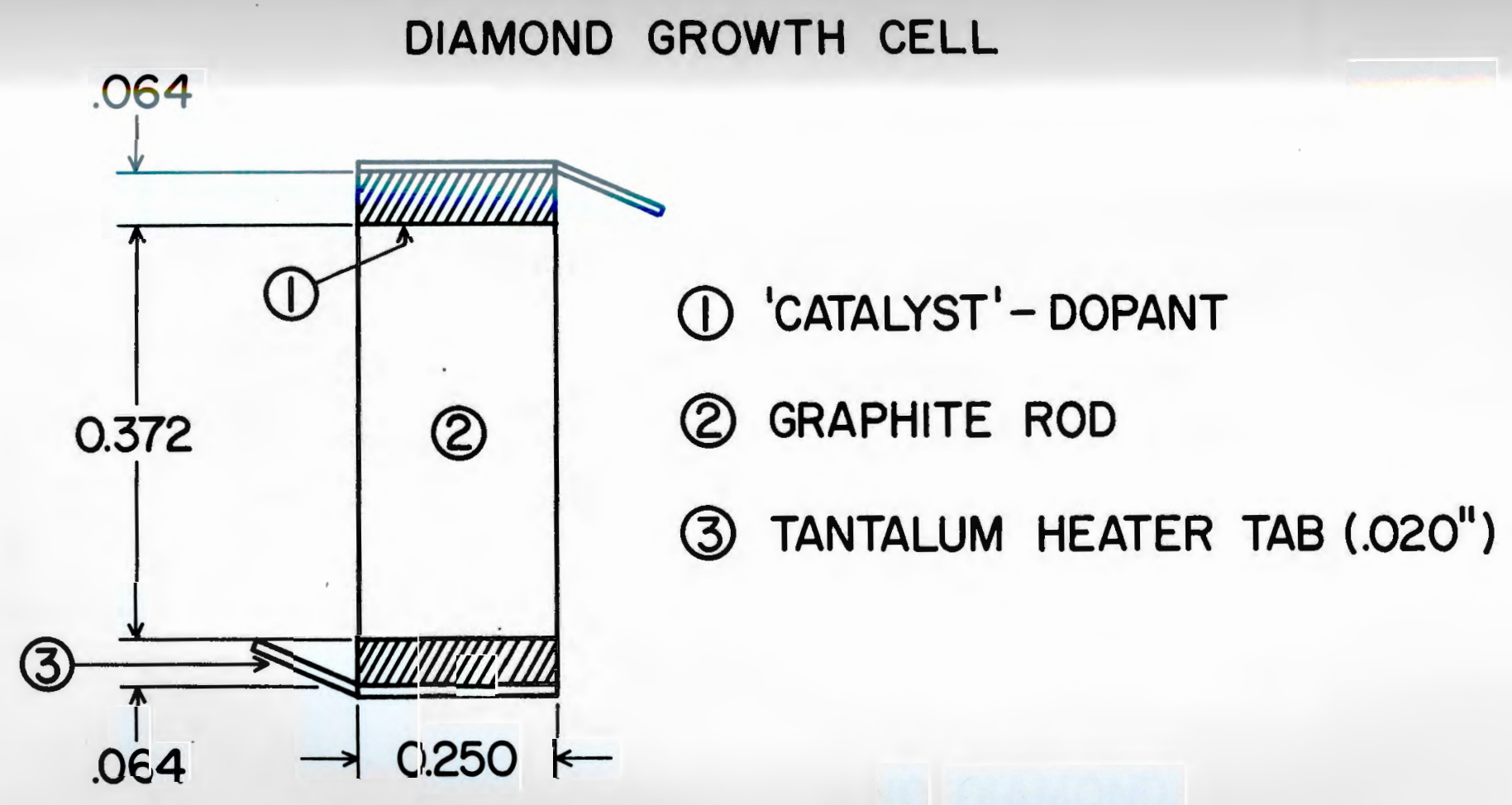




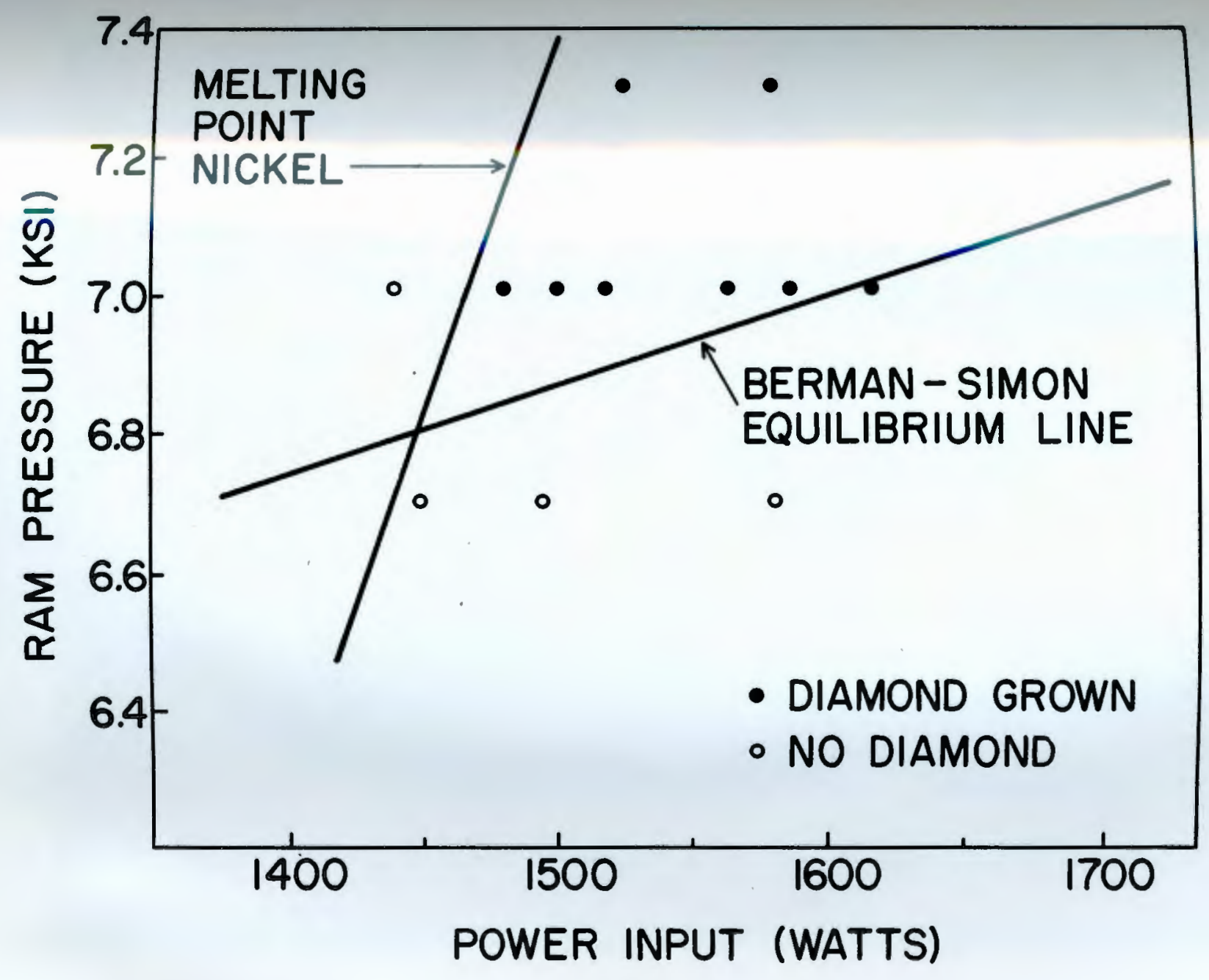




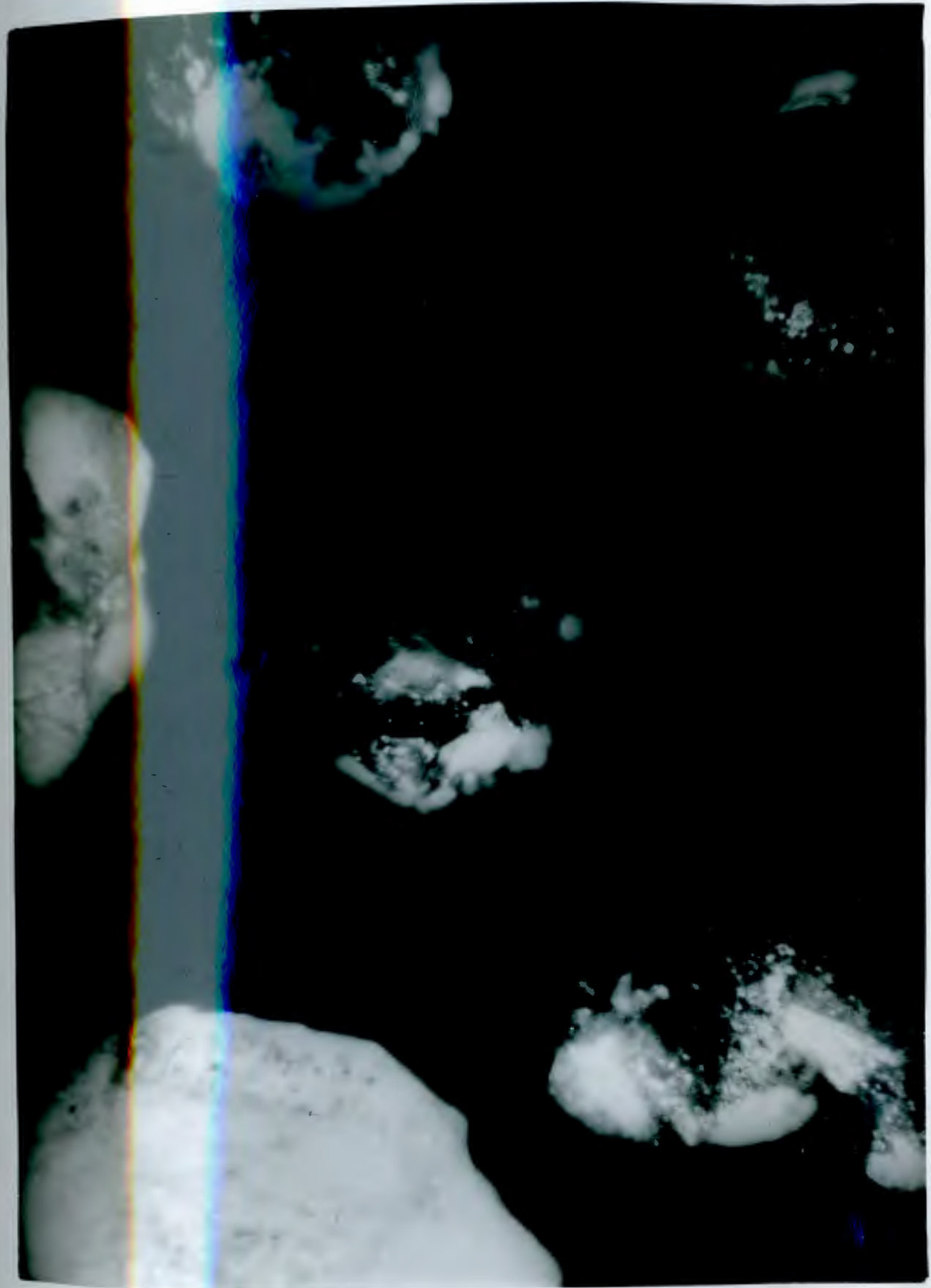




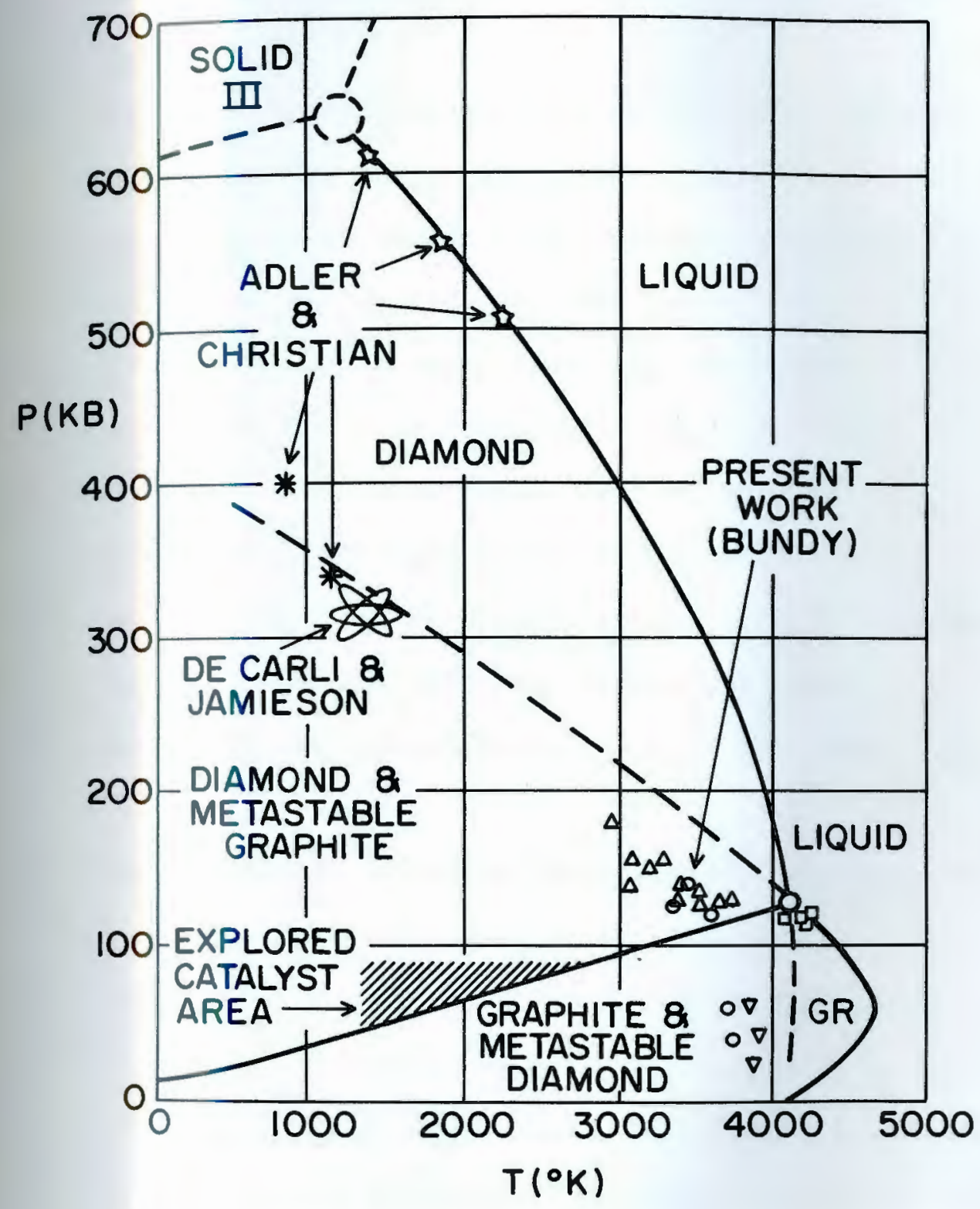




\section{References}

1. Berman, R., Sir Francis Simon, Zeitschrift fur Electrochemie, 59, $33(1955)$

2. Bundy, F. P., Bovenkerk, H. P., Strong, $H_{\bullet} M_{\bullet}$, Wentorf, R. $H_{\bullet}$ J. of Chem. Phys., 35, 383 (1961)

3. Bovenkerk, H. P., Bundy, F. P., Hall, H. T., Strong, H. M $_{*}$, Wentorf, R. H. Nature, 184, 1094 (1959)

4. Bundy, F. P. J. of Chem. Phys. 38, 631 (1963)

5. Wentorf, R. H. J. of Chem. Phys. 36, 1990 (1962)

6. Bridgman, P. W. J. of Chem. Phys. 1592 (1947)

7. Mutch, R. E., and Raal, F. A. Nature, 1857 (1959)

8. Bovenkerk, H. P. "The Physics and Chemistry of High Pressure". Society of Chemical Industry, London, 191 (1963)

9. Wentorf, R. H., Bovenkerk, H. P. J. of Chem. Phys. $\underline{36}, 1987$ (1962)

10. Vavilov, Guseva, Konorova, Krasnopevtsev, Sergienko, Tutov. Soviet Physics, Solid State, $\underline{8}$, No. 6 (1966)

11. Wentorf, R. H, and Darrow, K. A. Phys. Rev. 137, No. 5A (1965)

12. Tsay, Y. F., Ananthanarayanan, K. P., Gielisse, P. J., and Mitra, S. S. J. of Appl. Phys. May 1972 (to be published)

13. Dyer, H. B., and Wedepoh1, P. T. Proc. of Phys. Soc. 69, No. 435, Sec. B. (1956)

14. Herman, A. M., Ham, J. S. Rev. of Sc. Inst. 36, No. 11 (1965)

15. Bovenkerk, H. P. Amer. Mineralogist, $\underline{46}, 952$ (1961)

16. Gielisse, P. J. Proc. Int1. Min. Assoc. Cambridge, England $43(1966)$ 
$M A N$ U S C R I P T II 
ELECTRICAL CONDUCTIVITY OF

HEAVILY DOPED DIAMOND ${ }^{\#}$

Y. F. Tsay, ${ }^{+}$K. P. Ananthanarayanan,

P. J. Gielisse ${ }^{*}$ and S. S. Mitra ${ }^{+}$

University of Rhode Island

Kingston, R. I. 02881

"Nhis research has been supported in part by Army Electronics Command, Ft. Monmouth, N. J. and was presented at the March 1970 meeting of the American Physical Society, Dallas, Texas [Bull. Am. Phys. Soc., $15(1970)]$.

Department of Electrical Englneering

* Department of Chemical Engineering 


\section{ABSTRACT}

The semiconducting properties of boron, aluminum and titanium doped diamond have been interpreted using the $\log \mathrm{R}$ (resistance) versus $1 / T$ curves. In boron-doped diamond, "high concentration" type impurity band conduction occurs. The extrinsic ranges of the curves are analyzed with the usual model to yield the activation energies of the impurity level. The activation energies for the boron-doped samples vary from $0.15 \mathrm{eV}$ for the highest dopant concentration to $0.30 \mathrm{eV}$ for lower concentrations. For the aluminum and titanium-doped samples, the activation energies were found to be 0.31 and $0.40 \mathrm{eV}$ respectively. The results are consistent with those obtained from optical methods where data were available. An empirical formula is advanced which fits the $\log R$ versus dopant content rather well. 
I. INTRODUCTION

Stability of diamond, particularly at high temperatures, has made this material attractive from the point of view of development of special semiconductor devices. Passive diamond thermistor devices, using manufactured doped diamonds as the sensing element, have been made. ${ }^{1}$ Future development in this area depends, not only on imformation with regard to growth of the material itself, but also on an understanding or interpretation of the conduction mechanism(s) of variously doped diamond. This paper presents the dependence $\log R=f(1 / T)$ for variously doped diamonds and advances an empirical formula which fits the experimental results fairly well.

$$
\text { An inspection of the } \log \mathrm{R} \text { vs } 1 / \mathrm{T} \text { curves }^{2} \text { (e.g. see Fig. 1) }
$$

of synthesized diamond reveals that they are different from those usually observed in semiconductors at normal doping levels. For these "ordinary" semiconductors, the plot of $\log \mathrm{R}$ vs $1 / \mathrm{T}$ normally shows a minimum, which occurs at higher temperatures as the impurity concentration increases. To the low temperature side of the minimum, 1.e. in the extrinsic range, the curve is almost linear. Most of the charge carriers come from an impurity level by thermal fonization with the consequence that carrier concentration varies roughly as $\exp \left(E_{\text {lmp }} / n k T\right)$, where $E_{\text {imp }}$ is the energy level of the impurity, $\mathrm{T}$ the temperature, $\mathrm{k}$ the Boltzmann constant, and $\mathrm{n}$ is equal to 1 or 2 depending on whether the semiconductor is "strongly" compensated or not. The low temperature asymptotic slope of the plot gives the activation energy of the impurity level. The variation of these curves for different dopant levels can be explained satisfactorily and quantitatively by the usual theory for the conduction mechanism 
and Maxwel1-Boltzmann statistics. Our curves differ, however, from the usual in two ways. They don't show any tendency of reaching a minimum even at temperatures as high as $800^{\circ} \mathrm{K}$, compared to much $10 \mathrm{w}$ er temperatures at which most of the normal curves have already reached their minima, and secondly, there is a "kink" in the slope. The temperature at which this occurs is dependent upon majority impurfty concentration (Fig. 1). This kind of variation needs further explanation.

Semiconductivity may be induced in diamond in a variety of ways. The most common method is that of the introduction of specific impurities like $\mathrm{Be}, \mathrm{B}, \mathrm{Al}$ to suitable growth mixtures of carbon and solvents or by diffusion of these elements into diamond crystals at high temperatures and pressures. 3,4 Introduction of active impurities by means of ion implantation has lately received considerable attention. 5-7 The electrical resistivity of the crystals decreases wh increasing concentration of the impurity atoms (Fig. 1). Doping during growth or by diffusion has so far produced only p-type conductivity whereas ion doping (with Li, C and P) can produce n-type conductivity. ${ }^{6}$ All the results reported here refer to crystals rendered semiconductive by the growth doping technique. Doping with B and Al impurities has been reported earlier. ${ }^{4-5}$ Recently it has been found by us that the presence of titanium in the growth mixture Introduces very desirable p-type semiconductive properties. The resistivity versus temperature characteristics of this product are close to those determined on natural semiconducting diamond. This approach has not been previously reported. ${ }^{8}$ It is not known at this time whether titanium acts as an active carrier or whether the presence of 
titanium prevents or reduces the incorporation of nitrogen through gettering during the growth process. The similarity of the $\log R=f(1 / T)$ dependence for the titanium doped and the natural semiconducting diamond is of interest in this context. It is conceivable that the nitrogen level, in the presence of titanium, is sufficiently reduced to enable activation through $\mathrm{Al}$ which is normal1y present in laboratory grown diamond. The characteristics of the electrical and optical properties of natural semiconducting diamond indicate that their behavior is governed by shallow acceptor levels of $\mathrm{Al}$, which are substitutional impurities in diamond. ${ }^{9}, 10$

\section{IMPURITY CONDUCTION}

It was found by Hung ${ }^{11,12}$ that, in certain samples of germanium with decreasing temperature the resistivity as well as Hall coefficient first increased almost exponentially, as expected, but at a certain temperature the Hall coefficient reached a maximum and then decreased sharply over several orders of magnitude. At the same temperature range of the Hall coefficient maximum, the slope of the resistivity versus temperature curve changed abruptly and they became very much reduced. Recent experimental work shows the exact same behavior of the Hall coefficient and electrical conductivity in ptype semiconducting diamond doped with boron by both the ion implantation and growth-doped methods. ${ }^{7}$ Such a temperature dependence, as for the ion implanted samples, is claimed to be typical of a semiconductor with an impurity band. ${ }^{6}$ The onset of the kink was observed ${ }^{6}$ at impurity concentrations around $10^{19} \mathrm{~cm}^{-3}$ in ion doped diamond. Conwe $11^{13}$ has calculated impurity levels above which band for- 
mation is possible for several other group IV elemental semiconduetors as follows:

$(\mathrm{n}-\mathrm{Ge}) 1 \times 10^{16} \mathrm{~cm}^{-3},(\mathrm{p}-\mathrm{Ge}) 5 \times 10^{16} \mathrm{~cm}^{-3}$,

(n-Si) $1 \times 10^{17} \mathrm{~cm}^{-3},(\mathrm{p}-\mathrm{Si}) 1 \times 10^{18} \mathrm{~cm}^{-3}$.

For diamond, taking $\mathrm{m}^{*}=0.25 \mathrm{~m}$ it is found using Conwell's relation, that $2 \times 10^{18} \mathrm{~cm}^{-3}$ is sufficient for impurity band formation. Hung ${ }^{12}$ postulated originally that owing to the high impurity concentration the overlapping of impurity wave functions becomes appreciable and the 1mpurity levels broaden into a band so as to make conduction within the "1mpurity band" possible. Thus he proposed a two-conduction-band model, arguing that at high temperatures conduction takes place in the regular band while at low temperatures, when most of the charge carriers are squeezed out of the regular band, conduction via the Impurity band takes over, although with much smaller mobllity. Th1s model explains, at least qualitatively, the abrupt drop of Hall coeffictent after reaching 1 ts maximum and the "kink" of the resistivity curves; 1t also gives the criterion for the onset temperature of impurity conduction as roughly

$$
\mathrm{n}_{c} \mu_{c}=\mathrm{n}_{1 \mathrm{mp}} \mu_{\mathrm{imp}}
$$

where $n_{c}=$ carrier concentration in regular band

$$
\begin{aligned}
n_{\text {Imp }} & =\text { carrier concentration in impurity band } \\
\mu_{c} & =\text { mobility in regular band } \\
\mu_{\text {Imp }} & =\text { mobility in impurity band. }
\end{aligned}
$$


The experimental work of Fritzsche and Lark-Horovitz, ${ }^{14}$ Fritzsche 15 and Carlson ${ }^{16}$ indicate behavior similar to that described above. If the impurity conduction is primarily the result of band formation, then it should not be observed for concentrations so low that band formation is unlikely to develop. It has been suggested by Conwe $11^{13}$ and Mott ${ }^{17}$ that in the presence of minority compensations, Impurity conduction is possible at majority concentrations lower than that necessary for appreciable wave function overlapping due to the hopping of charge carriers from one occupled impurity site to a nearby one which has been made vacant by minority impurities. This has been observed by Fitzsche ${ }^{18}$ for Ge doped with $\mathrm{Sb}$ at concentrations as low as $6 \times 10^{14} / \mathrm{cm}^{3}$. The hopping mechanism was reported by Wilson ${ }^{19}$ in his attempts to interpret conductivity of variously diffusion doped diamonds. There are thus essentially two rival impurfty conduction schemes.

It is found from optical and magnetic resonance measurements 19 that in synthetic boron-doped diamond, nitrogen is the primary donor impurity, with its excess electron located in an antibond orbital where it does not contribute to conduction but may be avallable for compensation. In our samples nitrogen is not added intentionally. For convenience of calculation it is assumed that the nitrogen concentration is low and approximately constant for different boron concentration, which is also borne out by infrared measurements. The boron content is lowest in curve 1 and highest in 4 (Fig. 1 ), and the compensation ratio in the reverse order. The low temperature slopes, 1.e. low temperature activation energies, are $.0304 \mathrm{eV}$, 
$.026 \mathrm{eV}, .0219 \mathrm{eV}$, and $0.007 \mathrm{eV}$ for curves $1,2,3$, and 4 respectively. Miller ${ }^{20}$ studying the hopping mechanism in the low concentration range was able to deduce the concentration and compensation dependence of $E$, which has been confirmed experimentally at least for $\mathrm{K}=\mathrm{N}_{\mathrm{min}} / \mathrm{N}_{\mathrm{maj}}<0.6$. His findings indicate a decreasing activation energy with increasing values of $K$ at least to $K=0.5$.

It is felt ${ }^{19}$ that the $K^{\prime}$ s in our curves should not be greater than 0.1 . If the hopping process were dominant in our case, we should expect an increase in E from curves 1 to 4 . However, this is exactly contrary to what is experimentally observed. Similar experimental evidence may be found in reference 21 . This seems to rule out the possibility of a hopping mechanism and to support the band conduction scheme. Simple calculation shows that if all boron in the growth mixture goes into the diamond as an impurity, the concentrations will be $2 \times 10^{20} / \mathrm{cm}^{3}, 5 \times 10^{20} / \mathrm{cm}^{3}, 1 \times 10^{21} / \mathrm{cm}^{3}$, and $2 \times 10^{21} / \mathrm{cm}^{3}$ for curves 1, 2, 3, and 4 of Figure 1 respectively. High impurity concentrations for all four cases are, however, still indicated. The solid solubility of $B$ in $S 1$ and $G$ is of the order $5 \times 10^{21} / \mathrm{cm}^{3}$ at $1000^{\circ} \mathrm{K}$. This is considerably higher than that of other elements and is primarily due to the small radius of boron. 22 since the atomic radius of diamond is smaller than $S i$ and $G e$, we expect a lower solubility of B in diamond. But it is quite unlikely to be lower than $10^{19} / \mathrm{cm}^{3}$ because boron can still go into diamond as a substitional 1mpurity. It is therefore reasonable to expect that semiconducting diamond has impurity concentrations high enough for band conduction. 
III. ANALYSIS OF EXPERIMENTAL DATA

The analysis of the data depends on what physical model is chosen. Since the high temperature range of the curve (1.e. before the change of slope) corresponds to the extrinsic range of a regular semiconductor, a "two-impurity" model with boron as majority impurity and nitrogen, presumably as minority impurity, seems adequate. If a single acceptor energy level is also assumed, the hole concentration is given by ${ }^{23}$

$$
\mathrm{p}\left(\mathrm{p}+\mathrm{N}_{\mathrm{d}}\right) /\left(\mathrm{N}_{\mathrm{a}}-\mathrm{N}_{\mathrm{d}}-\mathrm{P}\right)=\left(2 \pi \mathrm{m}^{*} \mathrm{kT} / \mathrm{h}^{2}\right)^{3 / 2} \exp (-\mathrm{E} / \mathrm{kT})
$$

where $\mathrm{p}=$ hole concentration, $\mathrm{N}_{\mathrm{d}}=$ donor concentration, $\mathrm{N}_{\mathrm{a}}$ = acceptor concentration, $\mathrm{m}^{*}=$ effective mass, $\mathrm{k}=$ Boltzmann constant, $\mathrm{h}=$ Planck's constant, $\mathrm{E}=$ activation energy and $\mathrm{T}=$ temperature.

The resistance curves can normally be fitted as a function of temperature using $\mathrm{N}_{\mathrm{d}}, \mathrm{N}_{\mathrm{a}}, \mathrm{E}$ and $\mathrm{m}^{*}$ as parameters. This technique 24 is used when Hall coefficient data or equivalently the carrier concentration data are available, with no complication due to mobility.

The Resistance $R$ is defined as

$$
R=(\ell / A)_{p}=\ell / A(e p \mu)^{-1}
$$

where $\&, A, \rho, e, p$ are conventional terms and the mobility is

$$
\mu=1 / \mu_{\ell}+1 / \mu_{I}+1 / \mu_{N}
$$

The mobility due to lattice scattering is given by 25 


$$
\mu_{\ell}=(2 \sqrt{2 \pi} / 3)\left(\operatorname{e\hbar }^{4} c_{11} / \varepsilon_{1}{ }^{2}{ }^{* 5 / 2}\right)(1 / \mathrm{kT})^{3 / 2}
$$

where $C_{11}=$ elastic constant $=10.75 \times 10^{12}$ dyne $/ \mathrm{cm}^{2}$ for diamond (Ref. 26)

$$
\begin{aligned}
& \mathrm{m}^{\star}=\text { effective mass }=0.25 \mathrm{M}_{\mathrm{e}}(\operatorname{Ref}, 27) \\
& \varepsilon_{1}=\text { deformation potential }=30 \mathrm{eV}(\operatorname{Ref}, 26)
\end{aligned}
$$

The mobility, $\mu_{\ell}$, at $300^{\circ} \mathrm{K}$, is about $2 \times 10^{3} \mathrm{~cm}^{2} / \mathrm{V}-\mathrm{sec}$. This is in good agreement with experimental values. 28,29

The mobility due to ionized impurity scattering 25

$$
\begin{aligned}
\mu_{I}= & \left(1.65 / 10^{19} / \mathrm{N}_{i}\right)\left(\mathrm{T} / \mathrm{T}_{0}\right)^{3 / 2}\left(\varepsilon / \varepsilon_{0}\right)^{3}\left(\mathrm{~m} / \mathrm{m}^{*}\right)^{1 / 2} \\
& \left\{1 / \log \left[1+\left(10^{17} / \mathrm{p}\right)\left(\mathrm{T} / \mathrm{T}_{0}\right)^{2}\left(\varepsilon / \varepsilon_{0}\right)\right]\right\}
\end{aligned}
$$

where $\mathrm{T}_{0}=300^{\circ} \mathrm{K}, \varepsilon$ and $\varepsilon_{0}$ are the dielectric constants of the crystal and vacuum respectively and $\mathrm{N}_{i}$ is the ionized impurity concentration. Taking $\mathrm{N}_{1}=10^{18} / \mathrm{cm}^{3}=\mathrm{p}$ (for $\mathrm{p}$-type) and $\varepsilon=5.6 \varepsilon_{0}$, we have at $\mathrm{T}=300^{\circ} \mathrm{K}, \mu_{\mathrm{I}} \simeq 10^{4} \mathrm{~cm}^{2} / \mathrm{V}-\mathrm{sec}$. The mobility due to neutral impurity-scattering 30

$$
\begin{aligned}
\mu_{N} & =2 \pi^{3} m^{*}\left(e^{3} / 5 \varepsilon N_{n} n^{3}\right) \\
& =\left(10^{23} / N_{n}\right)\left(\mathrm{cm}^{2} / V-\text { sec }\right)
\end{aligned}
$$

The neutral impurity concentration $\mathrm{N}_{\mathrm{n}}=\mathrm{N}_{\mathrm{d}}+\mathrm{N}_{\mathrm{a}}-\mathrm{N}_{\mathrm{i}}$

Tak1ng $\mathrm{N}_{\mathrm{n}} \simeq 10^{19} \mathrm{~cm}^{-3}$ we have

$$
\mu_{N}=10^{4}\left(\mathrm{~cm}^{2} / \mathrm{V}-\mathrm{sec}\right)
$$


since $\mu_{\ell}<\mu_{I}$ and $\mu_{N}$ at $300^{\circ} \mathrm{K}$ and the inequalities become better for higher temperatures, $\mu \simeq \mu_{\ell}$ for $\mathrm{T} \bar{\gamma} 300^{\circ} \mathrm{K}$. The typical value is about $2 \times 10^{3} \mathrm{~cm}^{2} / \mathrm{V}-\mathrm{sec}$ as indicated above and values of the order of $1 \mathrm{~cm}^{2} / \mathrm{V}$-sec have also been reported. 21 This clearly shows that mobllity values are in fact scattered over quite a wide range depending upon the method of doping and various other factors. With $\mu \simeq \mu_{\ell}$ in Eq. (2) the only quantity needed to compute the resistance is $p$.

Case (1)

Assuming $\mathrm{p} \ll \mathrm{N}_{\mathrm{d}}<\mathrm{N}_{\mathrm{a}} \mathrm{Eq}$. (1) reduces to

$$
\begin{aligned}
\mathrm{p}\left(\mathrm{N}_{\mathrm{d}}\right) /\left(\mathrm{N}_{\mathrm{a}}-\mathrm{N}_{\mathrm{d}}\right) & =\left(2 \pi \mathrm{m}^{*} \mathrm{kT} / \mathrm{h}^{2}\right)^{3 / 2} \exp (-\mathrm{E} / \mathrm{kT}) \\
\mathrm{p} & =\left[\left(\mathrm{N}_{\mathrm{a}}-\mathrm{N}_{\mathrm{d}}\right) / \mathrm{N}_{\mathrm{d}}\right]\left(2 \pi \mathrm{m}^{*} \mathrm{kT} / \mathrm{h}^{2}\right)^{3 / 2} \exp (-\mathrm{E} / \mathrm{kT}) \\
& =(1 / \mathrm{k}-1)\left(2 \pi \mathrm{m}^{*} \mathrm{kT} / \mathrm{h}^{2}\right)^{3 / 2} \exp (-\mathrm{E} / \mathrm{kT})
\end{aligned}
$$

where $\mathrm{K}=\mathrm{N}_{\mathrm{d}} / \mathrm{N}_{\mathrm{a}}=$ compensation ratio.

It is found that the resistance curves ${ }^{31}$ (1) and (2) of

Figure (1) cannot be fitted using case (1). This probably reflects that assumption $\mathrm{p} \ll \mathrm{N}_{\mathrm{d}}$ is not fully satisfied.

\section{Csse (11)}

If the other extreme is true, i.e. $\mathrm{N}_{\mathrm{d}} \ll \mathrm{P}<\mathrm{N}_{\mathrm{a}}, \mathrm{Eq}$. (I) reduces to

$$
P=\left(N_{a}\right)^{1 / 2}\left(2 \pi m^{*} k T / h^{2}\right)^{3 / 4} \exp (-E / 2 k T)
$$


which means the mobility is proportional to $(\mathrm{kT})^{-3 / 4}$ for the high temperature region of the curves (1) and (2) of Figure 1, assuming they are strictly linear in that region and the activation energy becomes twice as large as that of case (1). This larger activation energy will reduce the hole concentration (p) of Eq. (1). This makes the assumption $\mathrm{N}_{\mathrm{d}} \ll \mathrm{P}<\mathrm{N}_{\mathrm{a}}$ less likely to be valid.

on the other hand, when the mobility $\alpha(\mathrm{kT})^{-3 / 2}$ was chosen and the corresponding activation energy used in Eq. (1), the assumption $\mathrm{p} \ll \mathrm{N}_{\mathrm{d}}<\mathrm{N}_{\mathrm{a}}$ seemed less valid. Thus it is safe to conclude that the correct activation energy lies between case ( $i$ ) and case (ii) and has been found to be 0.15 and $0.30 \mathrm{eV}$ respectively as indicated In Table 1.

Figure 2 shows the dependence of the average resistance of the boron-doped diamond at $25^{\circ} \mathrm{C}$ on percent boron content in the growth system. As can be seen from Figure 1, the temperature where the onset of impurity conduction, especially for curves 2,3 , and 4 has already occurred, is approximately $25^{\circ} \mathrm{C}$. Miller ${ }^{20}$ has given the relationship:

$p_{0}\left(N_{m a j}\right) \alpha\left(r_{0} / a\right)\left\{1+18.2\left(a / r_{0}\right)^{3 / 2}\right\} \exp \left(1.09 r_{0} / a\right)$

where $a$ = average radius of the impurity wave function $r_{0}=$ average separation between two impurity atoms = $\left(3 / 4 \pi \mathrm{N}_{\mathrm{maj}}\right)^{1 / 3}$, and $\rho_{0}\left(N_{m a j}\right)=$ resistivity at a fixed temperature. This expression is derived for the low temperature resistivity of the hopping type of impurity conduction. No theory on the majority 
Impurity concentration dependence of resistivity, at temperatures where transition from normal to impurity conduction occurs, has been given. However, guided by Miller's relation, we found that the expression $A \exp \left(B / X+C X^{1.5}\right)$ with $A=45.0 \Omega, B=0.695$, $c=-1.005$ and $X$ the percentage boron in the growth system can $f i t$ the experimental curve very well. The above expression is also plotted in Figure 2.

For Al and Ti doped diamond, the experimental curves can be fitted quite well with $\mathrm{Eq} .(1)$ and the lattice scattering mobility $\mu=$ constant $\times T^{-3 / 2}$. This good fit is due to the fact that the $\mathrm{R}$ versus $1 / \mathrm{T}$ curves are normal with no "kink" up to $1000 / \mathrm{T} \simeq 5$. Experimental data and the fits obtained are shown in Figures 3 and 4. For comparison, the curve for natural diamond is also included in Figure 4. If the constant preceding the $T^{-3 / 2}$ term is set equal to the numerical value given by Eq. (2'), then the two curves can be fitted with $\mathrm{E}, \mathrm{N}_{\operatorname{maj}}, \mathrm{K}$ as 1 isted in Table 2 to within a constant factor of about 10 in both cases. This constant factor could only come in due to the uncertainty of the crystal dimensions. In the above fittings, we assumed the diamond crystals to be cubic with a 250 micron $^{32}$ edge. All the data are contained in Tables 1 and 2.

\section{DISCUSSION AND CONCLUSIONS}

Among the data given in Table 1 and Table 2, the activation energies are thought to be the most reliable. For boron-doped diamond, the activation energies ranging from $0.15 \mathrm{eV}$ to $0.30 \mathrm{eV}$ are probably quite good, since electroluminescence methods show the boron level in the synthetic diamond to be at about $0.19 \mathrm{eV}$ at 
$150{ }^{\circ} \mathrm{K}$ and at about $0.3 \mathrm{eV}$ at $300^{\circ} \mathrm{K} .{ }^{33}$ Furthermore, Conwe $11^{24}$ has shown that as the impurity concentration increases, the "effective" activation energy (that is the single energy level assumed in deriving Eq. (1)), decreases because of the formation of an impurity band.

For aluminum and titanium doped diamonds, (Figures 3 and 4 ) the low impurity concentrations are in qualitative agreement with the fact that they don't show any "anomalies" down to $200^{\circ} \mathrm{K}$, where the "anomalies" of boron-doped crystals already occur. An activation energy of about $0.30 \mathrm{eV}$ for $\mathrm{Al}$ is considered good and may be compared with a value of $0.35 \mathrm{eV}$ as obtained from electroluminescence measurements. 33

In the presence of impurity conduction, even if analysis is done on the extrinsic range of the Hall coefficient curve to extract $E, N_{m a j}, K$, the result obtained is accurate only when the extrinsic range (which is not affected by impurity conduction) is large enough. ${ }^{18}$ This occurs only at low enough impurity concentrations. The analysis given above, especially for boron-doped crystals, indicates the difficulties encountered in interpreting conductivity in heavily doped diamond. 
TABLE 1

DATA FOR BORON-DOPED DIAMOND*

\begin{tabular}{|c|c|c|c|c|}
\hline \multirow[b]{2}{*}{ Curves } & \multicolumn{2}{|c|}{$\begin{array}{c}\text { Fit With } \\
\sigma=C_{1} \exp \left(-\frac{E_{1}}{k T}\right)+C_{3} \exp \left(-\frac{E_{3}}{k T}\right)\end{array}$} & \multicolumn{2}{|c|}{$\begin{array}{l}\text { With Approximation Made } \\
\text { On Equation (1) For } \\
\text { Curves (1) } \delta(2) \\
\text { Of Fig. } 1\end{array}$} \\
\hline & $E_{1}(e V)$ & $\mathrm{E}_{3}(\mathrm{eV})$ & $\begin{array}{l}\text { Mobility } \\
\text { Variation }\end{array}$ & $\begin{array}{l}\text { Activation } \\
\text { Energy of the } \\
\text { Impurity Level }\end{array}$ \\
\hline 1 & 0.152 & 0.0304 & $\begin{array}{l}\text { Case (i) } \\
\mu \alpha(T)^{-3 / 2}\end{array}$ & $0.15 \mathrm{eV}$ \\
\hline 2 & 0.168 & 0.026 & $\begin{array}{l}\text { Case (ii) } \\
\mu \alpha(T)^{-3 / 4}\end{array}$ & $0.30 \mathrm{eV}$ \\
\hline 3 & -- & 0.0219 & -- & -- \\
\hline 4 & -- & 0.007 & -- & -- \\
\hline
\end{tabular}

*Figure 1 
TABLE 2

DATA FOR ALUMINUM AND TITANIUM DOPED DIAMOND ${ }^{a}$

Best fit of the extrinsic range with a two-impurity model and $\mu \alpha \mathrm{T}^{-3 / 2}$

\begin{tabular}{|c|c|c|c|}
\hline $\begin{array}{l}\text { Activation Energy } \\
\text { of Impurity Leve1 }\end{array}$ & $\mathrm{N}_{\mathrm{maj}}$ & $\mathrm{K}=\mathrm{N}_{\mathrm{min}} / \mathrm{N}_{\mathrm{maj}}$ \\
\cline { 2 - 4 } $\mathrm{Al}$ & $0.31 \mathrm{eV}$ & $\sim 2.5 \times 10^{16} / \mathrm{cm}^{3}$ & $\sim 0.05$ \\
\hline $\mathrm{T} 1$ & $0.40 \mathrm{eV}$ & $\sim 3 \times 10^{17} / \mathrm{cm}^{3}$ & $\sim 0.01$ \\
\hline
\end{tabular}

Figures 3 and 4 


\section{Figure Captions}

Figure 1 Resistance versus temperature at various dopant levels for boron-doped semiconducting diamond. Dopant concentration in the growth mixture of crystals characterized by curves 1 through 4 may be obtained by reference to Figure 2 .

Figure 2 Average resistance as a function of percent boron in growth system compared to fit as shown.

Figure 3 Resistance of aluminum doped diamond as a function of temperature. Best fit as shown.

Figure 4 Resistance of natural diamond (curve 1, inner scale) and titanium doped diamond as a function of temperature. Best fit for titanium doped sample is as shown. 


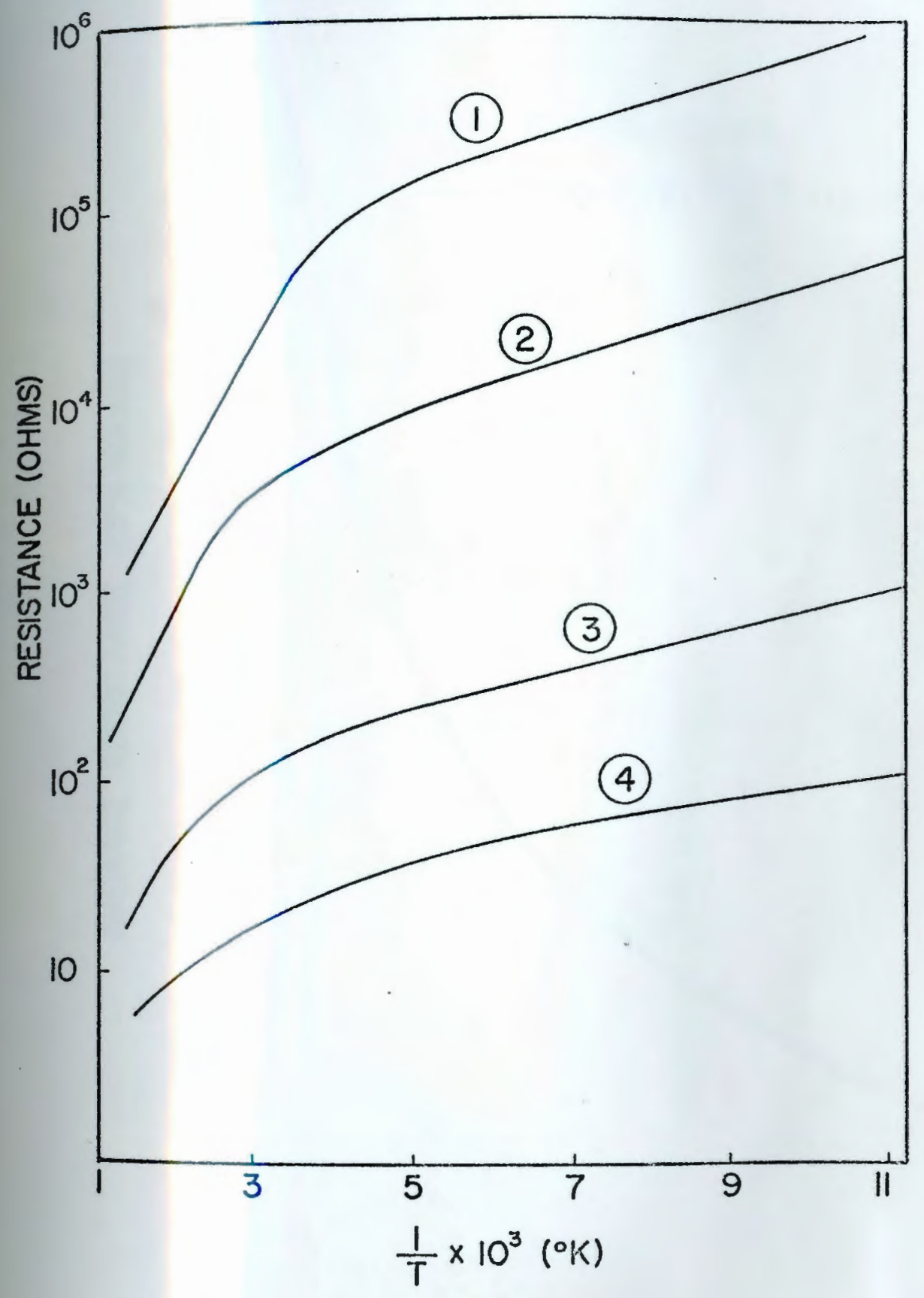




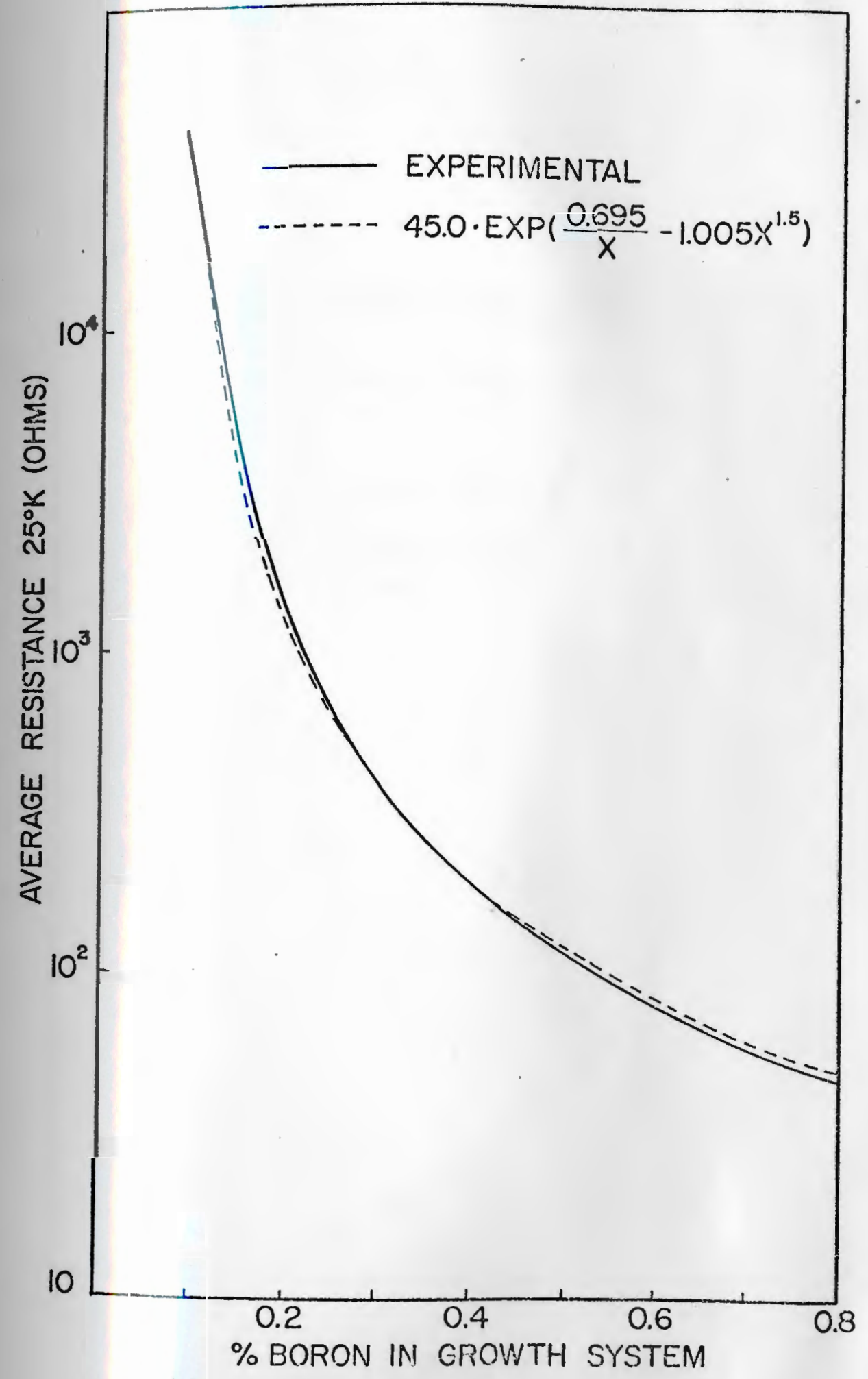




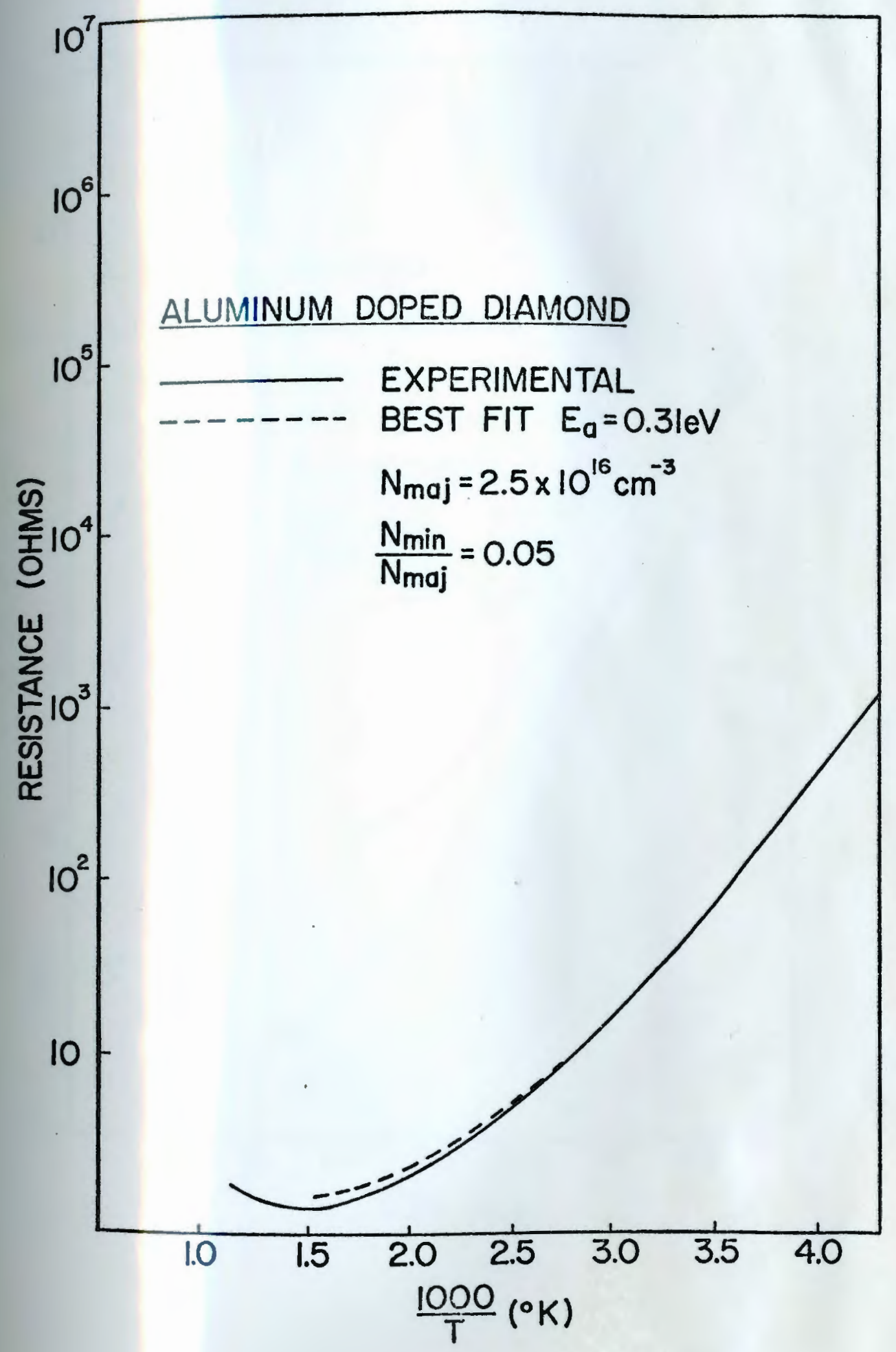




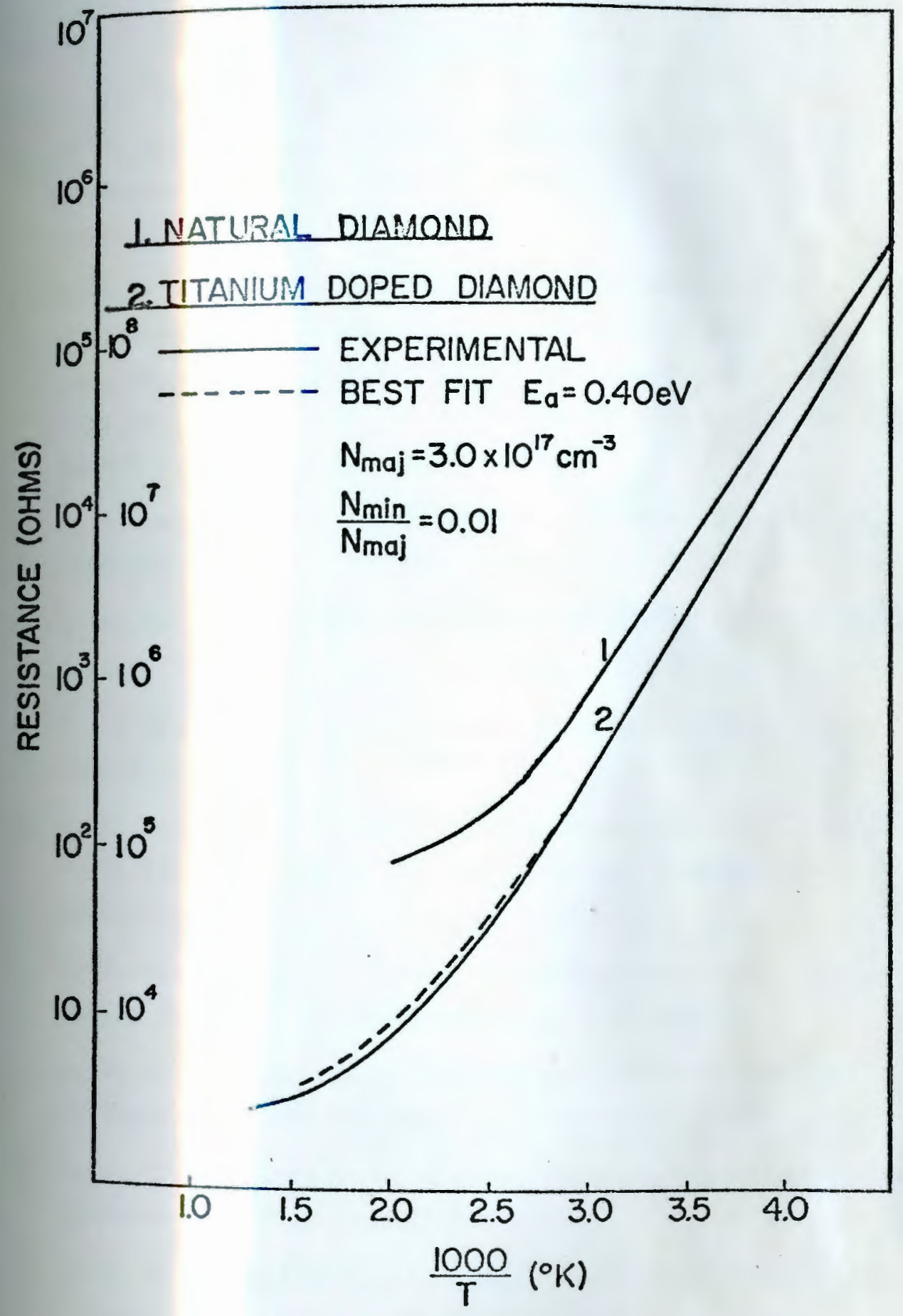




\section{REFERENCES}

1. P. J. Gielisse and M. Doser. "Thermistor Device and Method of Producing Said Device" U. S. Patent No. 3,435, 399 March 25, 1969.

2. Because of the irregularity in shape and actual contact area, Fig. 1 is plotted in terms of resistance. Taking the average size of the diamond cubes as 250 microns on side, resistivities at $303^{\circ} \mathrm{K}$ are $0.5,3.25,95$ and $825 \mathrm{ohm}-\mathrm{cm}$ for the curves marked $4,3,2$ and 1 , respectively.

3. R. H. Wentorf and H. P. Bovenkerk, J. Chem. Physics, 36 , 1987-1990 (1962).

4. H. P. Bovenkerk. "The Physics and Chemistry of High Pressures" Soclety of Chemical Industry, London, 191-195 (1963).

5. R. H. Wentorf and K. A. Darrow. Physical Review, 137, $1614-1616$ (1965).

6. V. S. Vavilov, M. I. Guseva, E. A. Konorova, V. V. Krasnopevtsev, V. F. Sergienko and V. V. Tutov. Soviet Physics, Solid State, $\underline{8}$, $1560-1561$ (1966).

7. V. V. Vavilov, M. I. Guseva, E. A. Konorova, and V. F. Sergienko. Soviet Physics - Semiconductors, 4, 6-11 (1970).

A. W. S. Williams, E. C. Lightowlers and A. T. Collins.

J. Phys. C: Solid St. Phys., 3, 1727-1735 (1970).

8. P. J. Gielisse and G. M. Kibler. General Electric Company, Worthington, Ohio, unpublished data.

9. I. G. Austin and R. Wolfe. Proc. Phys. Soc. (London) B69, 329 (1956). 
10. P. J. Dean, E. C. Lightowlers, and D. K. Wight. Phys. Rev. 140 , A352 (1965).

11. C. S. Hung and J. R. Gliessman. Phys. Rev. 79, 726 (1950).

12. C. S. Hung. Phys. Rev. 79,727 (1950).

13. E. Conwe11. Phys. Rev, 103, 51 (1956).

14. H. Fritzsche and K. Lark-Horovitz, Physica, 20, 834 (1954).

15. H. Fritzsche. Phys. Rev. 99, 406 (1955).

16. R. O. Carlson. Phys, Rev. 100, 1075 (1955).

17. N. F. Mott. Can. J. Phys, 34, 1356 (1956).

18. H. Fritzsche. J. Phys. Chem. Solids, $\underline{6}, 69$ (1958).

19. W. B. Wilson. Phys. Rev. 127, 1549 (1962).

20. A. Miller and E. Abrahams. Phys. Rev. 120, 745 (1960).

21. G. N. Bezrukov, V. P. Butuzov, N. N. Gerasimenko, L. V. Lezheiko, Yu. A. Litvin, and L. S. Smirnov. Soviet Physics - Semiconductors, $\underline{4}$, 587-590 (1970).

22. F. A. Trumbore. Bel1 System Technical Jour. 39, 205 (1960).

23. S. Wang. "Solid State Electronics" 157, New York N. Y.: McGraw H111 (1966).

24. P. P. Debye and E. M. Conwe11. Phys. Rev. 93,693 (1954).

25. Shyh Wang. "Solid-State Electronics" 225, New York, N. Y.: McGraw Hill (1966).

26. J. Bardeen and W. Shockley. Phys. Rev. $\underline{80}, 72$ (1950).

27. P. T. Wedepoh1. Proc. Phys. Soc. London, 70, 177 (1957).

28. R. T. Bate. Proc. Phys. Soc., Vol, LXXIV, 363 (1959).

29. G. Redfield. Phys. Rev. 94,526 (1954).

30. C, Erginsoy. Phys. Rev. 79, 1013 (1950).

31. Resistance curves (3) and (4) of Figure 1 have not been analyzed here due to the inconspicuous nature of the high temperature region. 
32. It is approximately the dimensions of the diamonds from which the experimental data were obtained.

33. E. C. Lightowlers, A. T. Collins, P. Denham and P. S. Walsh. "Dfamond Research" 11 (1968) Industrial Diamond Information Bureau, London. 
M A N U S C R I P T III 
PROPERTIES OF PROTON-IRRADIATED DIAMOND ${ }^{\#}$

K. P. Ananthanarayanan ${ }^{*}$

W. J. Borer ${ }^{\text {tx }}$

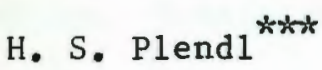

P. J. Gielisse

"This research has been supported in part by the National Science Foundation, Grant No. NSF-GP-25974 and the Air Force Office of Scientific Research Grant No. AF-AFOSR-69-1674.

* Department of Chemical Engineering, University of Rhode Island, Kingston, R. I. 02881 .

** Department of Electrical Engineering, University of Rhode Island, KIngston, R. I. 02881 .

Present Address: Swiss Aluminum Ltd., Research Institute, Neuhausen, Switzerland.

$\hbar * *$.

Department of Physics, Florida State University, Tallahassee, Plorida. 32306. 
ABSTRACT

Properties of diamond 1rradiated with 17-18.3 MeV protons have been investigated. Raman spectral measurements indicate an increase in the lattice constant of $0.0032 \AA$. The infrared absorption spectrum of proton irradiated diamond shows a characteristic absorption at 6.92 microns. The optical absorption edge of damond does not seem to be affected by the irradiation. 
Radiation-induced changes in the properties of diamond are of considerable interest, both from the practical and theoretical point of view. The effect of irradiation by energetic electrons or neutrons on diamond has been studied with respect to changes in 1 ts electrical properties. ${ }^{1,2}$ Investigations have also been made recentIy on neutron irradiation effects in graphite, ${ }^{3}$ again only with respect to changes in electrical properties. The optical absorption of electron-1rradiated type I diamond has been found to show an extra band at $3.1-3.8 \mathrm{eV} .4$ Gamma-radiation induces fluorescence in the UV region. 5 It has also been found that optical transmission can be fncreased by annealing neutron irradiated type I diamond. ${ }^{6}$ However, apparently no information has been published on the determination of changes in proton-1rradiated diamond.

The irradiations were carried out in the proton beam from a tandem van de Graaff accelerator (High Voltage Engineering Corporation Model Super FN). The targets consisted of natural type I diamond. Both powder (6-10 microns in size) and a single crystal (equilateral triangle with $0.25^{\prime \prime}$ edge, $50 \mathrm{mil}$ thick) were used. The powder sample was packed ( $50 \%$ theoretical density) into a $0.5^{\prime \prime}$ diameter, $23 \mathrm{mil}$ thick cavity in a nickel holder and covered with a . $0.5 \mathrm{mil}$ thick nickel foll. Both samples were exposed to $\sim 10^{4} \mu \mathrm{Coul}$ or $10^{17}$ protons and the average proton beam flux in both irradiations was of the order of $10^{13}$ protons $/ \mathrm{sec} \mathrm{cm}^{2}$.

X-ray diffraction analysis (Genera1 Electric XRD-5D/S diffractometer) 1nvolved scanning from low to high Bragg angles using the counting technique to gain precision in measuring intensity. 
Pptical absorption measurements were made using a Cary 14 spectrophotometer in the visible and the UV region using a quartz substrate. No spectrum in the visible region could be obtained due to the opaque nature of the diamond powder. Infrared absorption in the fundamental vibration region $(2.5 \mu \mathrm{m}$ and $15.4 \mu \mathrm{m})$ was recorded using a Perkin Elmer 521 instrument. Raman spectra of the powdered diamond were taken with a RCA-LD2140 $200 \mathrm{~mW}$ argon ion laser tuned to the $4880 \AA$ ine.

The $x$-ray diffraction counting was done only at a high angle position since such an angular position is more sensitive to a given change in plane spacing. 7 The results of the counting technique on the nominally $2 \theta=140.6^{\circ}$ diffraction peak are shown in Figure 1. It indicates the difference in the peak positions which amounts to a $\Delta(2 \theta)=0.0375$ degrees. For a cubic system, ${ }^{7}$

$$
\Delta a / a=\Delta d / d=-(\cot \theta) \Delta \theta
$$

where $a$ is the lattice constant, $d$ the interplanar spacing and $\theta$ the Bragg angle. Using this relationship, the change in the lattice constant was calculated to be $0.0238 \AA$.

The absorption spectra in the UV, before and after irradiation, show little difference and are shown in Figure 2. Proton irradiation does not seem to affect the value of the direct bandgap in diamond. In addition to the fundamental bandedge absorption, a broad low intensity absorption peak is shown centered at $2400 \AA$. It is likely that the observed edge absorption position contains a contribution from the quartz substrate. Quantitative comparisons with bandgap 
ralues for diamond would be warranted only with irradiated single crystals and not with powders as used here. However, the data do show an overall increase in absorption after irradiation. The IR absorption spectra on single crystal diamond are shown in Figure 3. Both samples show the 4 and $8 \mu$ bands characteristic of type I diamond. The only significant difference is seen to be in the strong additional absorption peak at 6.92 microns for the sample after irradiation. This particular feature has apparently not been observed previously. In type II diamond, for which normally no absorption structure is shown in the 8 micron region, neutron irradiation induces structure normally found in type I diamond. 8 If proton irradiation has the same effect, it would not be observable in our data since we have used type I diamond as the base material. On the other hand, the observed increased resolution of the single phonon absorption structure may be a manifestation of this effect. Smith and Hardy ${ }^{8}$ did not observe the strong absorption at 6.92 microns. It is possible, therefore, that there exists a fundamental difference in the type of imperfections created in proton irradiated versus neutron Irradiated diamond.

The ant1-Stokes Raman spectrum was used as the basis for comparison of position and width of the first-order Raman lines in both samples since a large luminescence background prevented analysis on the Stokes side. Typical Raman spectra are shown for the Stokes side in Figure 4. The line shift resulting from the analysis of the anti-Stokes side is shown in Figure 5. For this case there was almost no background in the spectrum of diamond before irradiation; however, 
some background had to be deducted in the spectrum of diamond after irradiation. Comparison of the data for the samples before and after Irradiation (Figure 5) shows that the position of the Raman line is Ignificantly different, amounting to a shift of $\sim 4 \mathrm{~cm}^{-1}$ or $0.32 \%$. The line width, however, is the same for both cases.

The question now arises whether any conclusion can be drawn from this shift in position of the Raman line and the nature of the changes produced by proton irradiation. The shift in the lattice mode frequency can be related to the change in the lattice constant via the Grlneisen constant,

$$
\gamma=-\frac{d \ln w}{d \ln V}=-\frac{d \ln w}{3 d \ln a}
$$

where $\omega$ is the lattice mode frequency, $V$ the volume and a the lattice constant. Mathematical transformation yields

$$
\frac{\Delta \mathrm{a}}{\mathrm{a}}=-\frac{\Delta \omega}{\omega} \frac{1}{3 \gamma}
$$

For diamond, ${ }^{9} \gamma=1.20$, therefore an $0.32 \%$ decrease of $w$ will correspond to an increase of a by $0.089 \%$, 1.e. by $0.0032 \AA$. It may be seen that the change in lattice constant based on spectral frequency shift and calculated from the Grlueisen relationship is much smaller than that obtained from the $x$-ray data. Due to the much higher accuracy of the Raman frequency shift measurement, it is felt that an estimate of the change in lattice constant of $0.0032 \AA$ as a result of proton irradiation is the more reliable value. Since the irradiations were carried out at incident proton 
energies of 17.0 and $18.3 \mathrm{MeV}$, no significant amount of nuclear transnutation could take place. Of the four proton-induced transmutation reactions on ${ }^{12} \mathrm{C}$ that have thresholds below $18.3 \mathrm{MeV}$, the proton capture reaction leads to ${ }^{13} \mathrm{~N}$ which decays with a $10 \mathrm{~min}$. halflife to ${ }^{13} \mathrm{C}$ and the $(\mathrm{p}, \alpha)$ reaction leads to a highly unstable product nucleus,

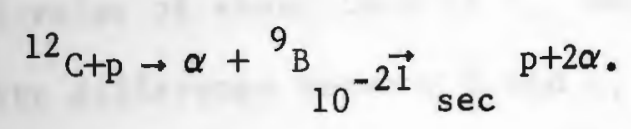

Only the $(p, d)$ and $(p, 2 p)$ reactions result in a product that can affect the properties of the crystal, if produced in sufficient quantity:

$$
\begin{aligned}
& { }^{12} \mathrm{C}+\mathrm{p} \rightarrow \mathrm{d}+{ }^{11} \mathrm{C}_{20.3} \stackrel{\beta^{+}}{\rightarrow} \min \\
& { }^{12} \mathrm{C}+\mathrm{p} \rightarrow 2 \mathrm{~B},
\end{aligned}
$$

Although these reactions should, from the energy point of view, begin to occur at any energy above the thresholds 17.9 and $17.3 \mathrm{MeV}$ respectively, the outgoing charged particles need additional energy to overcome the nuclear Coulomb barrier. Hence the reaction cross sections begin to become effective for transmutation only at several MeV above threshold energies. Experiments are presently being conducted at higher energies on single crystal diamond to determine the feasibility of inducing conductivity in diamond through boron doping by transmutation.

If in spite of these nuclear considerations, some transmutation has taken place, the occurrence of the sharp band at 6.92 microns 
may be explained as being due to a localized vibrational mode of boron impurity in the diamond host lattice. Such boron impurities may be produced from the nuclear transmutation of carbon during the Irradiation process. A simple harmonic oscillator model without incorporating any force constant change around the impurity predicts a local mode frequency of $B$ in diamond to be $1404 \mathrm{~cm}^{-1}$ compared to an observed value of about $1440 \mathrm{~cm}^{-1}$. Because of the mass and electronegativity difference between $B$ and $C$, such a mode may be electric dpole-active and thus observable in infrared transmission, in spite of the fact that the long-wavelength optic phonon of diamond (type II) itself is not infrared active.

At this stage it can be concluded that proton irradiation of type I diamond at energies used here, leads to an additional absorption band at 6.92 microns and an increase in the lattice constant. It therefore seems likely that proton irradiation results in imperfections of the vacancy type. The exact extent of the lattice constant increase may need further quantitative work because of an apparent difference between results from $x$-ray diffraction and Raman spectral analysis. There is furthermore a significant difference between the absorption in the fundamental vibration region of neutron and proton irradiated diamond. The direct bandgap is not Ignificantly affected.

alnowledgment

The assistance of $\mathrm{J}$. Villegas and $\mathrm{R}$. Holub in the irradiation work at Florida State University is gratefully acknowledged. 
FIGURE CAPTIONS

Figure 1 X-RAY INTENSITY PROF ILES AT $2 \theta=140.6$ FOR TYPE I DIAMOND BEFORE AND AFTER PROTON IRRADIATION.

Figure 2 UV ABSORPTION SPECTRA OF TYPE I DIAMOND POWDER, BEFORE AND AFTER PROTON IRRADIATION.

FIgure 3 IR ABSORPTION SPECTRA OF TYPE I SINGLE CRYSTAL DIAMOND, BEFORE AND AFTER PROTON IRRADIATION.

Tigure 4 RAMAN SPECTRA (STOKES SIDE) OF TYPE I DIAMOND POWDER, BEFORE AND AFTER PROTON IRRADIATION.

Figure 5 SHIFT IN THE LATTICE VIBRATION FREQUENCY OF TYPE I DIAMOND AFTER PROTON IRRADIATION, FROM ANTI-STOKES RAMAN DATA. 


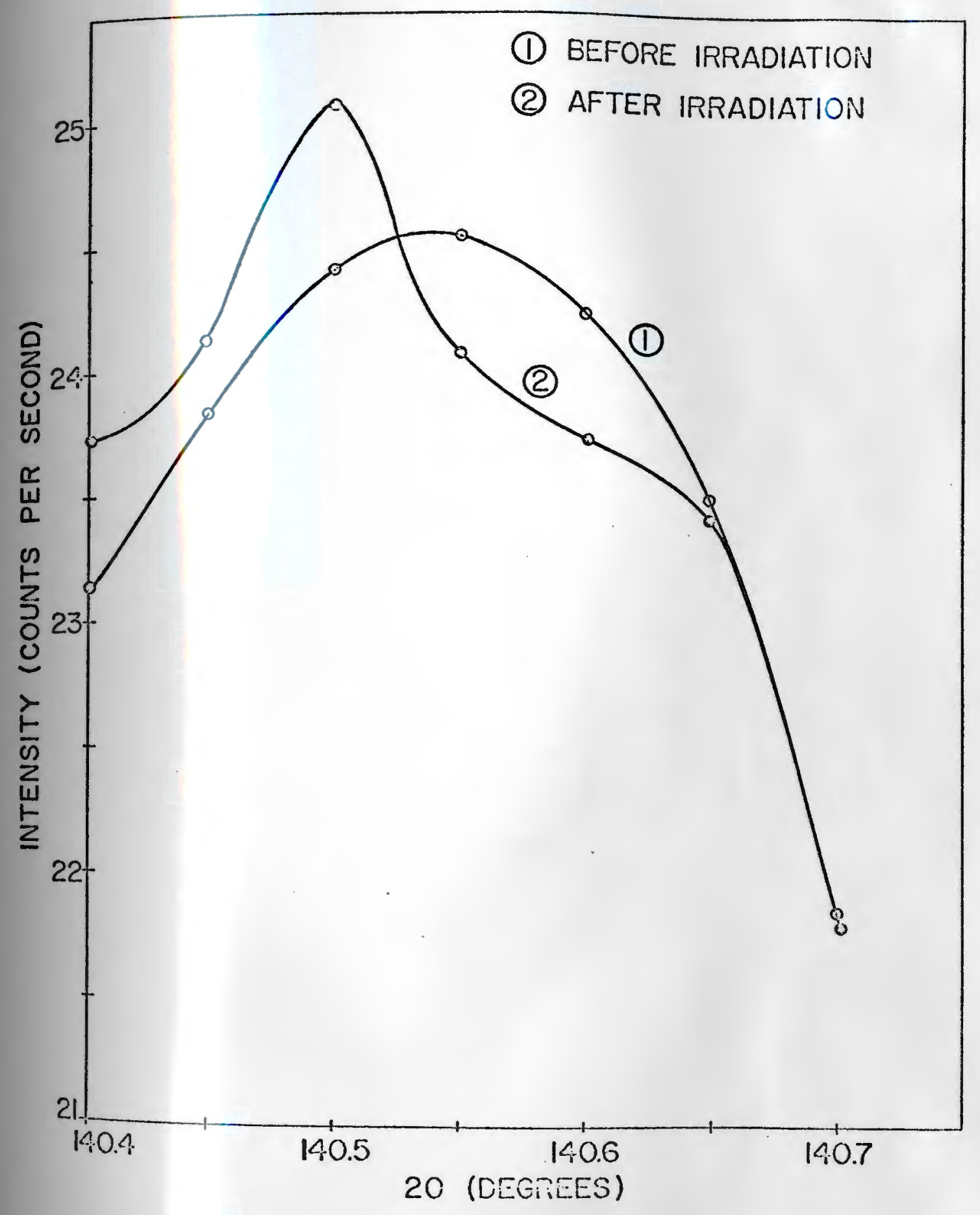




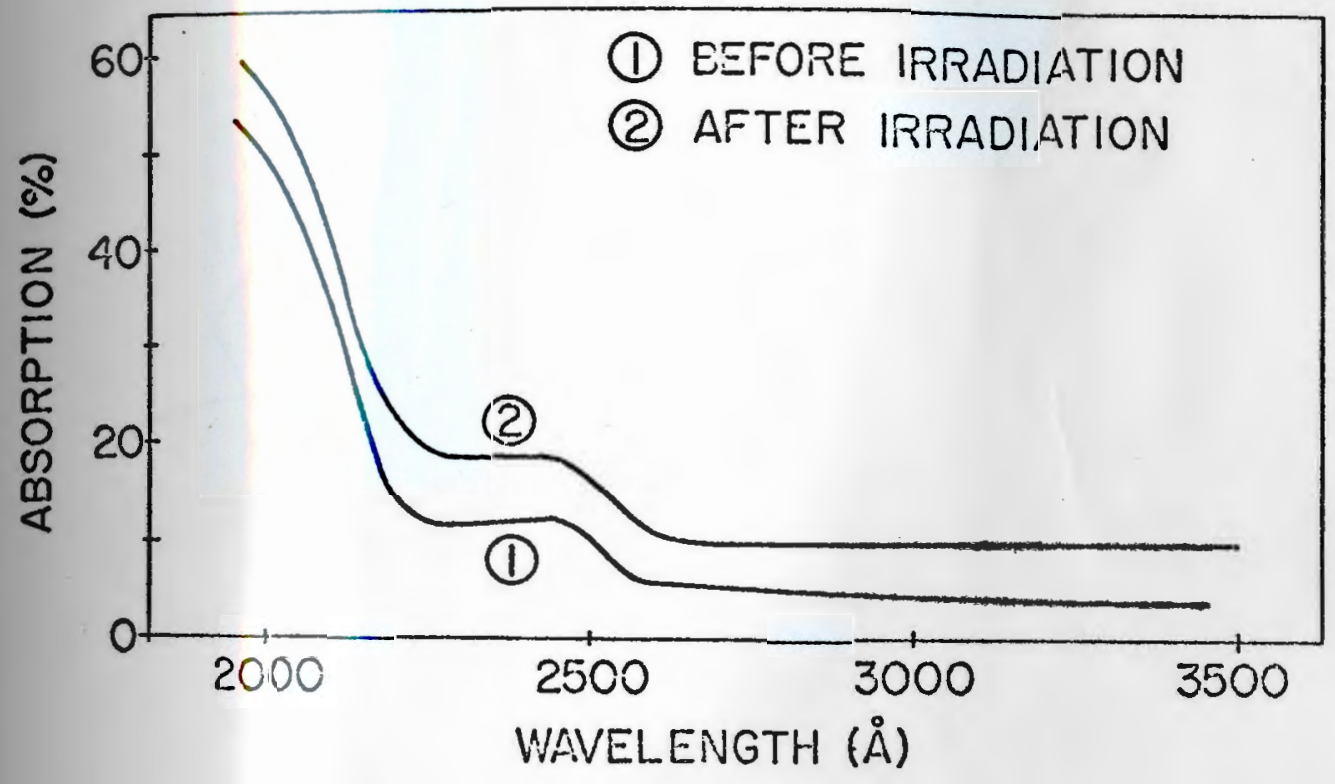




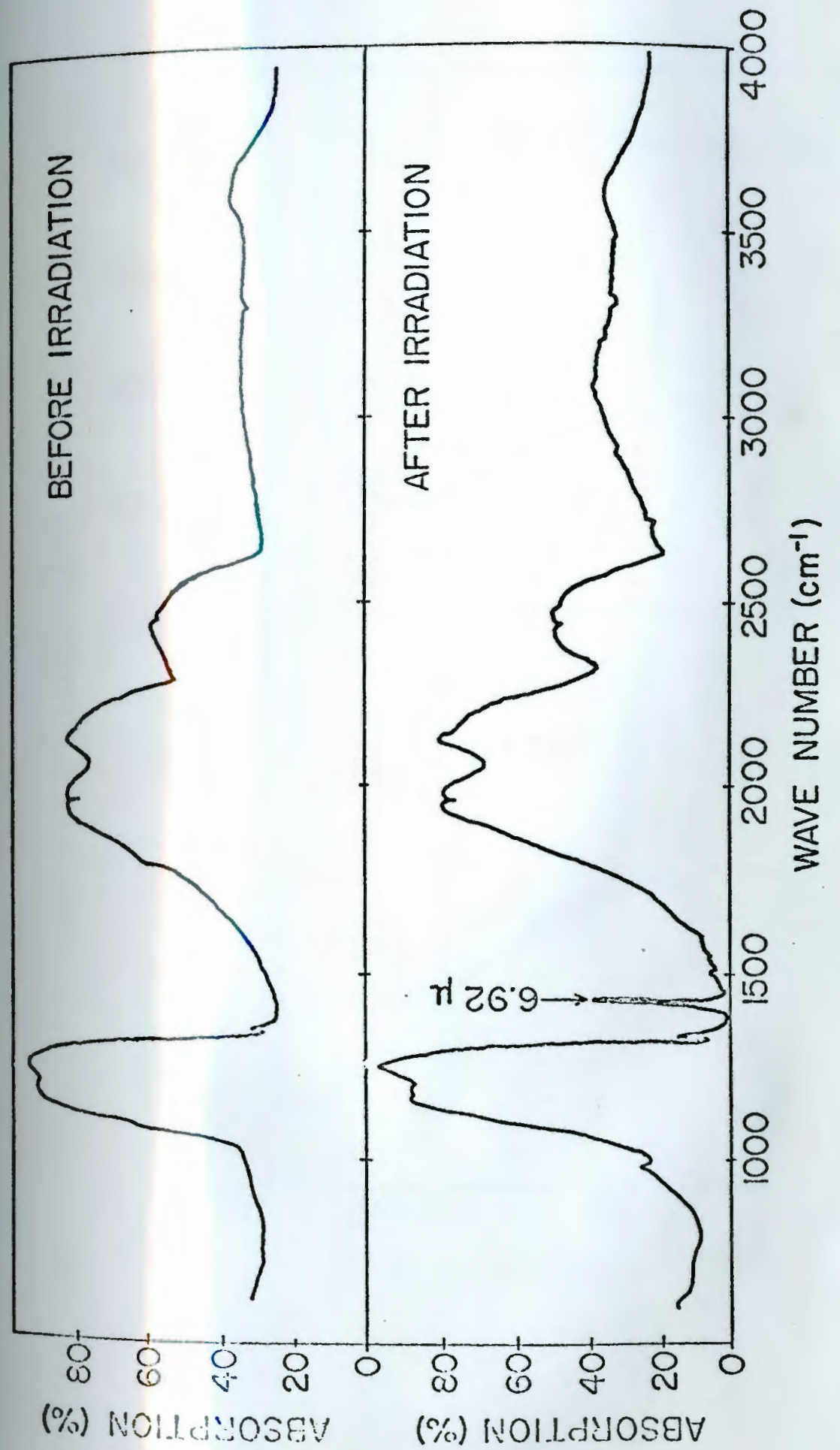




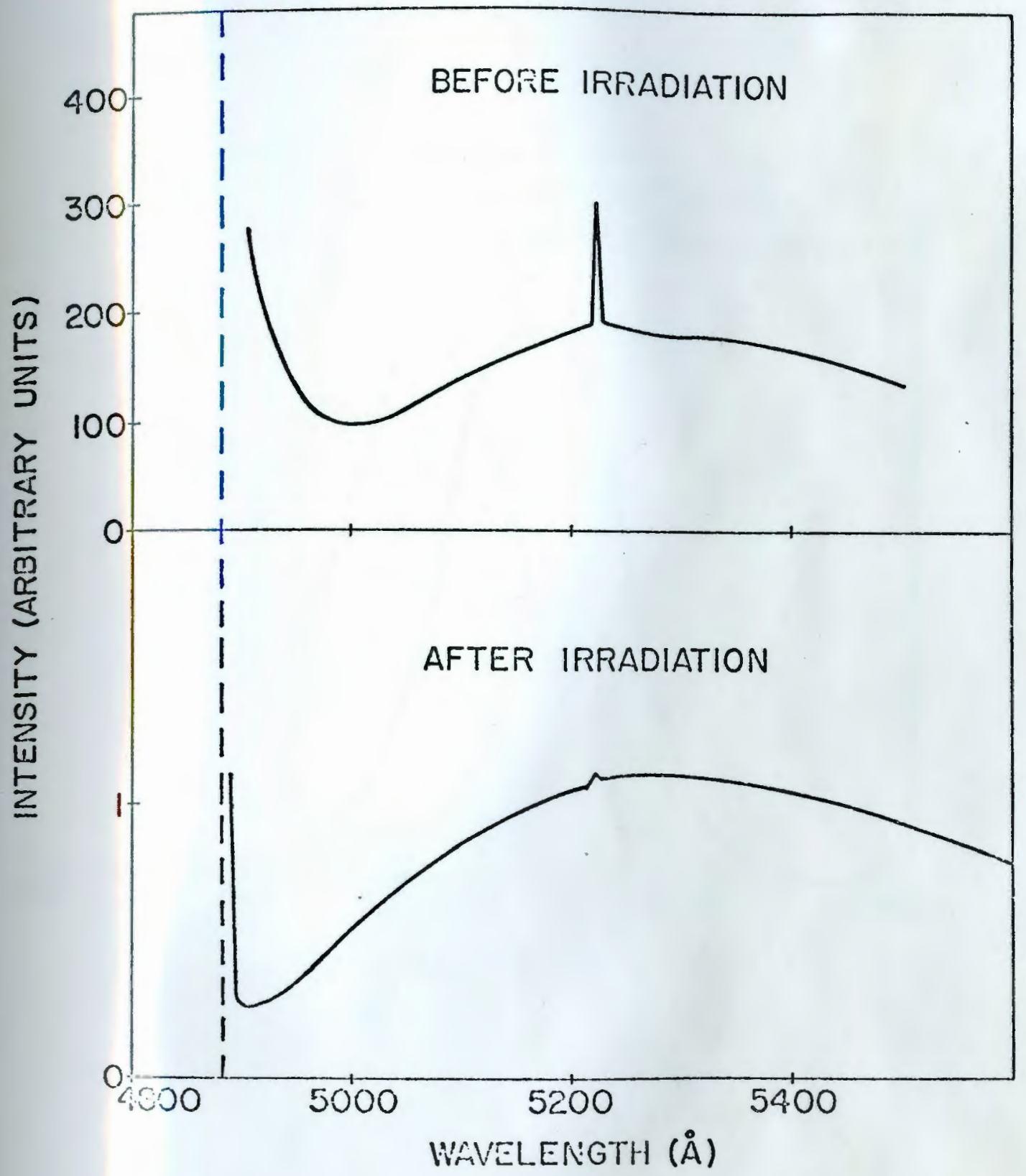




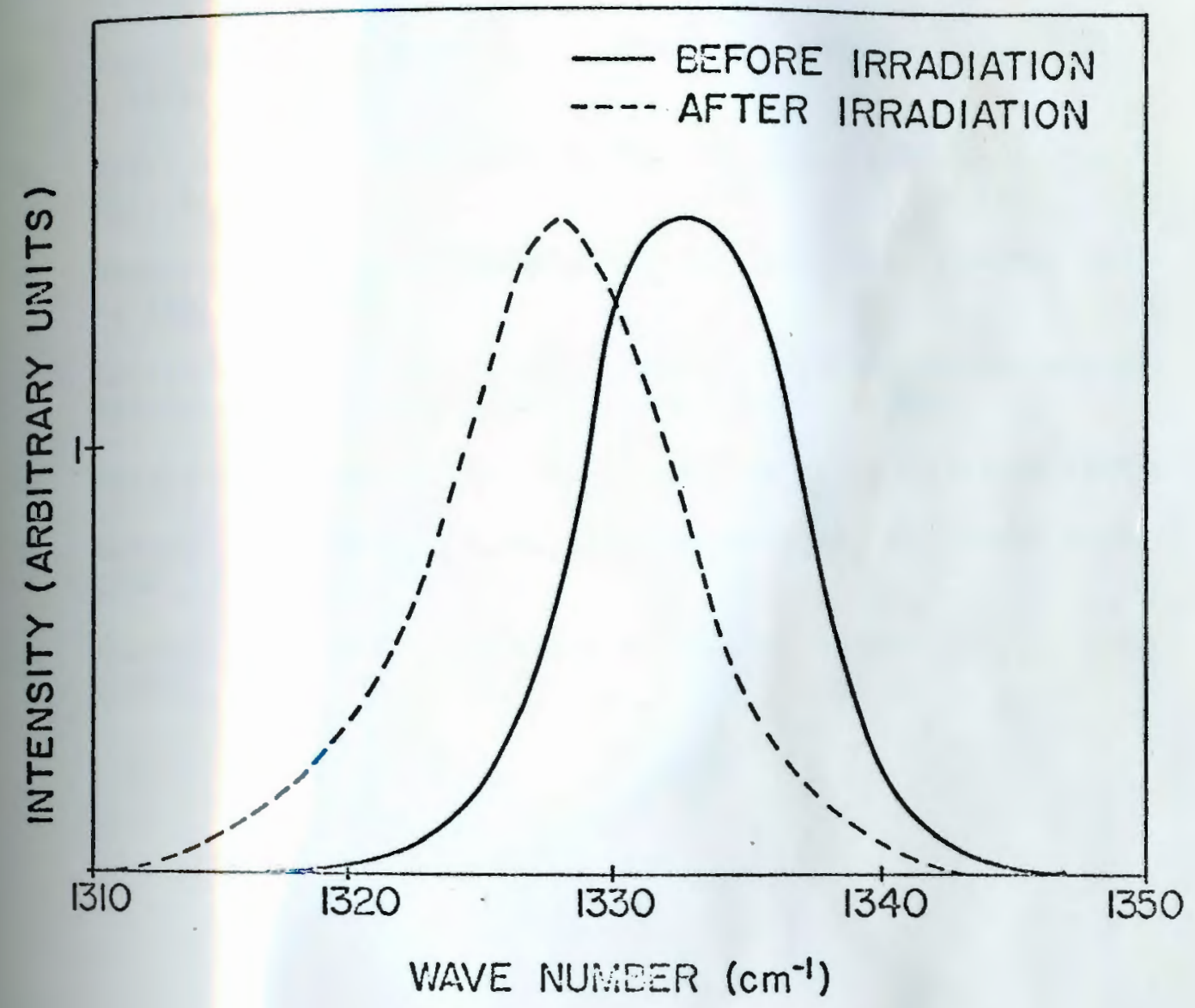




\section{REFERENCES}

1. Wedepohl, P. T., Ph.D. Thesis, University of Reading (1958). 2. Clark, C. D., Kemmey, P. J., and Mitche11, E. W. J.
Discussions of the Faraday Society, No. 31 (1961).

3. Cooper, J. D., Smith, J. P., Woore, J, and Young, D. A. J. Phys. C. (Solid St. Phys.) 4, 442 (1970).

4. Dyer, H. B., and DuPreez, L. Jour. of Chem. Phys., 42, 1898 (1965).

5. Dyer, H. B., and Matthews, I. G. Roy. Soc. London, Proc., A, 243,320 (1958).

6. Benny, A. H. B., and Champion, F. C. 1.uy. Soc. London, Proc., A, 234, 432 (1956).

7. Cullity, B. D. Elements of X-ray Diffraction, Massachusetts: Addison-Wesley Publishing Co. Inc. (1956) p. 325.

8. Smith, S. D., and Hardy, J. R. Phil. Mag., 5, 1311-14 (1960).

9. Borer, W. J., Mitra, S. S., and Namjoshi, K. V., Solid State Comm., 9, 1377 (1971).

10. American Institute of Physics Handbook, 2nd Edition, p. 4-66 (1957). 
M A N U S C R I P T IV 
SYNTHESIS OF SINGLE CRYSTAL BORON MONOPHOSPHIDE*

K. P. Ananthanarayanan and P. J. Gielisse

\author{
Department of Chemical Engineering \\ University of Rhode Island \\ Kingston, $R$. I. 02881
}

This paper has been presented at the Annual Meeting of the American Ceramic Society, Washington, D.C., May 1972. 


\section{ABSTRACT}

Boron phosphide has been synthesized from the elements at pressures and temperatures above $20 \mathrm{kbar}$ and $1200^{\circ} \mathrm{C}$. The growth rate of crystals has been determined as a function of temperature and pressure and an activation energy of $49.27 \mathrm{kcal} / \mathrm{mole}$ has been obtained for the process. Optical transmission measurements made on these crystals indicate the fundamental absorption edge to lie around $5 \mathrm{eV}$. Optical and Scanning Electron Micrographs have been made to study the crystal morphology. 


\section{INTRODUCTION}

The semiconducting properties evidenced in the III-V compounds, particularly the phosphides, arsenides and antimonides of boron, gallium and indium have generated considerable interest in their synthesis. Boron Monophosphide is of special interest because it has a large band gap. ${ }^{1}$ Yet it has not been previously produced as either colorless or transparent. ${ }^{2}$ The color could be due to impurities in the growth system which end up in the crystals; hence the synthesis of purer crystals may provide more information on this aspect. The high hardness and temperature stabllity also contribute to the interest in this material particularly for device and abrasive applications.

Most of the earlier synthesis of BP was carried out in evacuated tubes containing boron and red phosphorus heated to $1000^{0}-1100^{\circ} \mathrm{C}^{3-5}$ The replacement reaction of $\mathrm{BCl}_{3}$ or $\mathrm{BBr}_{3}$ and $\mathrm{Br}_{3} \mathrm{P}_{2}$ at $1000^{\circ} \mathrm{C}$ in an argon atmosphere, results in microcrystalline boron phosphide. Other phosphorus halides have also been used with boron halides in the preparation of $\mathrm{BP} .6,7$ The rapid heating of pressed pellets of boron and phosphorus ${ }^{8}$ and the action of phosphine on boron powder yield BP, 9 again in powder form.

Pressure synthesis has been successful at 100 atmospheres and $1000-1600^{\circ} \mathrm{C} .10$ High purity stoichiometric crystals of BP have been reported to crystallize from solutions under high pressure in an autoclave, ${ }^{11}$ at about $1500 \mathrm{kbar}$ and temperatures between $1000-1500^{\circ} \mathrm{C}$; 
pure boron and pure phosphorus in admixture were used as the reactants with the boron content varying between $5-20$ per cent by weight. Largest crystals are reported to be obtained at process temperatures between 1200 and $1300^{\circ} \mathrm{C}$; slow cooling had no effect on the crystal growth but prolonged reaction times produced larger crystals. It is further claimed ${ }^{11}$ that the crystallization was due to the temperature gradient within the sample chamber. The reaction between boron and phosphorus achieves its top rate at temperatures above $1200^{\circ} \mathrm{C}$ and at pressures above $10,000 \mathrm{kbar} .12$

It is interesting to note however, that so far the kinetics of BP growth under high pressure has not yet been studied. It was the purpose of this investigation to study the rate of growth of BP as a function of pressure, temperature and time.

\section{EXPERIMENTAL PROCEDURES}

Details of the 600 ton tetrahedral anvil press used in these experiments may be found elsewhere. ${ }^{13}$ The cell in which the boron phosphide crystals have been grown is illustrated in Figure 1 . It consists of a graphite heater tube containing the charge which is $20 \%$ boron and $80 \%$ phosphorus by weight. The ends of the tube are plugged with graphite and tantalum discs with tantalum tabs for electrical conduction. The entire cell is placed in a pyrophyllite tetrahedron. The sample is directly heated by a transformer which provides a low voltage, high current via the press anvils. In all runs the total wattage passed through the cell was monitored and the tomperature determined from a standard calibration curve which had 
jreviously been constructed for this cell geometry using a Pt-Pt $10 \%$ Rh thermocouple. A pressure calibration using standard reference points ${ }^{14}$ provided the relation between the ram pressure and actual cell pressure.

For each Individual run, the sample was first pressurized to the desired level and subsequently heated to the required temperature and held for the appropriate length of time.

The cleaning of the crystals involved removing the unreacted Phosphorus as the first step, using nitric acid. This was followed by treating the charge in chromic acid and hydrofluoric acid to remove graphite and pyrophylite particles respectively. The cleaned crystals were identified by X-ray diffractometry initially and later by light tcroscopy, size permitting.

Particle size determination was accomplished with the use of a polarizing microscope equipped with a filar micrometer. The "size" of a crystal was established as the average of the largest dimensions "a" and " $\mathrm{b}$ " measured in mutually perpendicular directions. The average crystal size of each run was obtained by dividing the sum total of "size" by the number of crystals measured in each case and this was taken as representative of the run. Standard deviation calculations have borne out the validity of this approach. Approximately fifty crystals were measured per run to arrive at the average crystal size.

Table 1 shows the average crystal size for different growth times, temperatures and pressures. The average size has been plotted as a function of time for various temperatures in Figure 2 and for 
varlous pressure levels in Figure 3. Scanning electron micrographs and optical absorption measurements have been made on the synthesized crystals. The absorption measurements were carried out on $B P$ crystals from different runs, using a LiF substrate.

\section{EXPERIMENTAL RESULTS AND DISCUSSION}

A set of growth experiments, with temperature and pressure as the system's variants, have been conducted, in an attempt to determine the crystal growth rate. In growth systems with massive, essentially uncontrolled, heterogeneous nucleation it is not normally possible to obtain separate and accurate nucleation and growth rates. For the same reason an average crystal size had to be determined as described in the previous section.

It may be observed from the data of Figure 2 that average crystal size increases as a function of temperature. From a kinetic point of view, this can be expected, since higher temperatures normally enhance the rate of reaction. The curves for $1370^{\circ} \mathrm{C}$ and $1275^{\circ} \mathrm{C}$ exhibit similar trends and are offset by a small size difference only. The maxima in these curves occur at a total synthesis time of approximately two hours. A large difference is seen, both with regard to value and position of the maximum in the $1450^{\circ} \mathrm{C}$ curve. Overall, the duration of the run seems to have a definite effect on the crystal size; initially, the average size increases with time till a maximum is reached after which it actually decreases. This may be the result of dissolution of crystals or increasingly high nucleation rates. The former process can be ruled out since, although the average 
crystal size decreases, the size of any one crystal continues to Increase with time. This may be seen from Figure 4. An explanation may be found in the fact that the processes of nucleation and growth take place simultaneously and continually with the growth process dominant until such time as the maximum in the curves is reached. After that the new nucleation becomes more substantial causing an actual decrease in average crystal size. The reason for this may Fobably be found in the development of temperature and/or composition gradients in the cell which become more marked as time increases. As more and more crystals form, the resistance of the growth mixture changes favoring the development of temperature gradients in the partially self heated cell. Alternatively composition gradients may occur as a result of out-diffusion of phosphorus driving the growth composition towards a boron richer region. Loss of phosphorus, through the vapor phase, seems unlikely at 20 kbar.

Pressure appears to have an effect on size similar to that of temperature, though not to the same extent (see Figure 3). An increase in pressure increases average crystal size. The data shows that the rate is, however, decreased as a result of higher nucleation.

The values of the positive slopes of the curves shown in Pigure 2 (obtained by the least square method) were used to develop an Arrhenius rate equation plot as shown in Figure 5. From the slope of this plot, the activation energy was determined to be $49.27 \mathrm{kcal} / \mathrm{mole}$. For reasons previously given, no attempt was made to determine activation energies separately for nucleation and growth. 
The activation energy reported here can only represent the activation energy for the total process. Although no data of this nature appears to have been reported before, it should be kept in mind that activation energies measured in this way are often much larger than those predicted by Eyring's theory. ${ }^{15}$ An explanation for such a deviation is given by Turnbul1 16 and Mott. 17

One aspect which is not evident from optical microscopic examination, has been brought out with the aid of a scanning electron acroscope; virtually all crystals have a vesicular structure. Figure 6 is a scanning electron micrograph illustrating this feature. Almost all of the crystals synthesized contain spherical or semiapherical volds regardless of the conditions of temperature and pressure. The extent of occurrence and individual size of the voids would seem to be more a function of temperature than pressure. Few crystals show distinct morphological features. They are generally anhedral in shape, orange in color, mostly translucent and only a few distinctly transparent. Unusual growth features such as the sculptured growth and stepped columnar growth, shown in Figures 7 and 8 respectively, are relatively rare occurrences. No plausible explanation for the occurrence of the volds can be advanced at this time.

The bandgap of boron phosphide has varlously been reported as $2 \mathrm{ev}^{2,18}$ and $6 \mathrm{eV} .^{1}$ These measurements were made on products from totally different growth methods. This could possibly explain the discrepancy in the bandgap values. The transmission spectra on our boron phosphide crystals are shown in Figure 9. The fundamental absorption edge lies at around $5 \mathrm{eV}$. The $5 \mathrm{eV}$ value results from meas- 
urements made on boron phosphide from different runs. The upper curve of Figure 9 shows the absorption edge to lie at $2300 \AA(5.4 \mathrm{eV})$ and the lower one at $2700 \AA(4.6 \mathrm{eV})$. Whereas these measurements clearly show the fundamental edge for the product as synthesized by us, it cannot yet be concluded that a corresponding bandgap is either direct or indirect. The shift in the fundamental absorption edge, from $5.4 \mathrm{eV}$ to $4.6 \mathrm{eV}$, could be due to a difference in the crystalline product from the different runs. More extensive experiments are presently being conducted with products from one run only. This refinement should lead to a more accurate value for the fundamental absorption edge and an indication of whether this value is due to direct or indirect band transitions. 
TABLE 1

AVERAGE CRYSTAL SIZE AS A FUNCTION OF TIME, TEMPERATURE \& PRESSURE

\begin{tabular}{|c|c|c|c|c|}
\hline \multirow{2}{*}{$\begin{array}{l}\text { TIME } \\
\text { (hours) }\end{array}$} & \multicolumn{4}{|c|}{ AVERAGE CRYSTAL SIZE (microns) } \\
\cline { 2 - 5 } & $1275^{\circ} \mathrm{C}$ & $1370^{\circ} \mathrm{C}$ & $1450^{\circ} \mathrm{C}$ & $1370^{\circ} \mathrm{C}$ \\
\hline $1 / 2$ & 6.58 & 7.72 & 14.40 & 16.65 \\
1 & 11.82 & 13.36 & 16.70 & 17.03 \\
2 & 18.10 & 22.07 & 31.99 & 24.23 \\
3 & 16.50 & 20.00 & 89.36 & 34.53 \\
4 & 13.36 & 16.25 & 48.33 & 23.06 \\
\hline
\end{tabular}


FIGURE CAPTIONS

1. CELL DESIGN AS USED IN OUR EXPERIMENTS.

2. CRYSTAL SIZE VERSUS SYNTHESIS TIME AS A FUNCTION OF TEMPERATURE.

3. CRYSTAL SIZE VERSUS SYNTHESIS TIME AS A FUNCTION OF PRESSURE.

4. MICROGRAPHS (44X) OF CRYSTALLINE BP AS A FUNCTION OF SYNTHESIS TIME. a - HALF HOUR, b - ONE HOUR, c - TWO HOURS, d - THREE HOURS, e - FOUR HOURS.

5. ACTIVATION ENERGY PLOT FOR BORON PHOSPHIDE SINGLE CRYSTAL GROWTH PROCESS.

6. SCANNING ELECTRON MICROGRAPH (750X) OF CRYSTALLINE BP SHOWING VESICULAR STRUCTURE.

7. UNUSUAL MORPHOLOGY OF BP CRYSTALS. SCULPTURED GROWTH FEATURES, SCANNING ELECTRON MICROGRAPH (3000X).

8. UNUSUAL MORPHOLOGY OF BP CRYSTALS. STEPPED COLUMNAR GROWTH FEATURES. SCANNING ELECTRON MICROGRAPH (1500X).

9. TRANSMISSION SPECTRA FOR BORON PHOSPHIDE. TWO SEPARATE PRODUCT-DIFFERENTIATED MEASUREMENTS.

(For explanation seé text). 


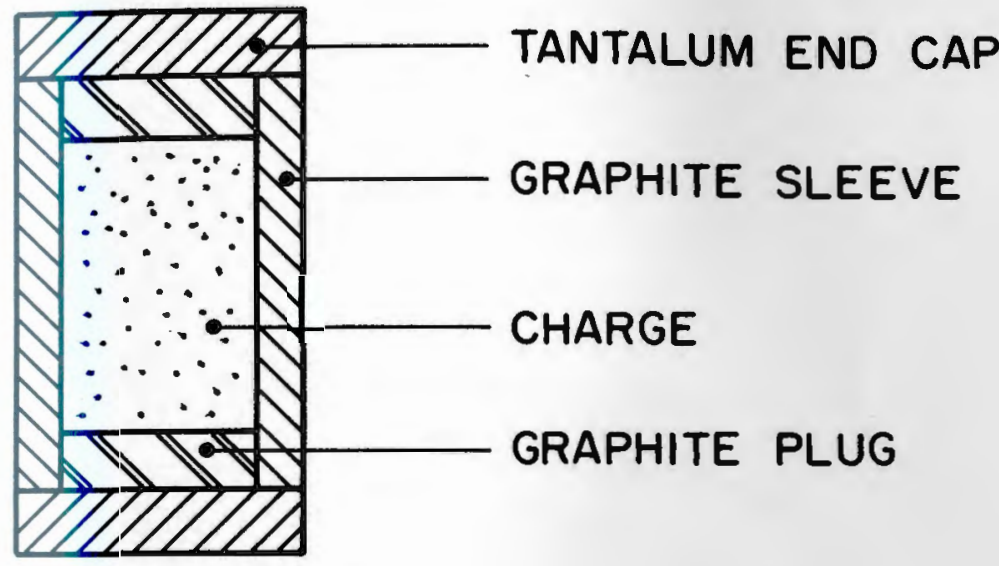




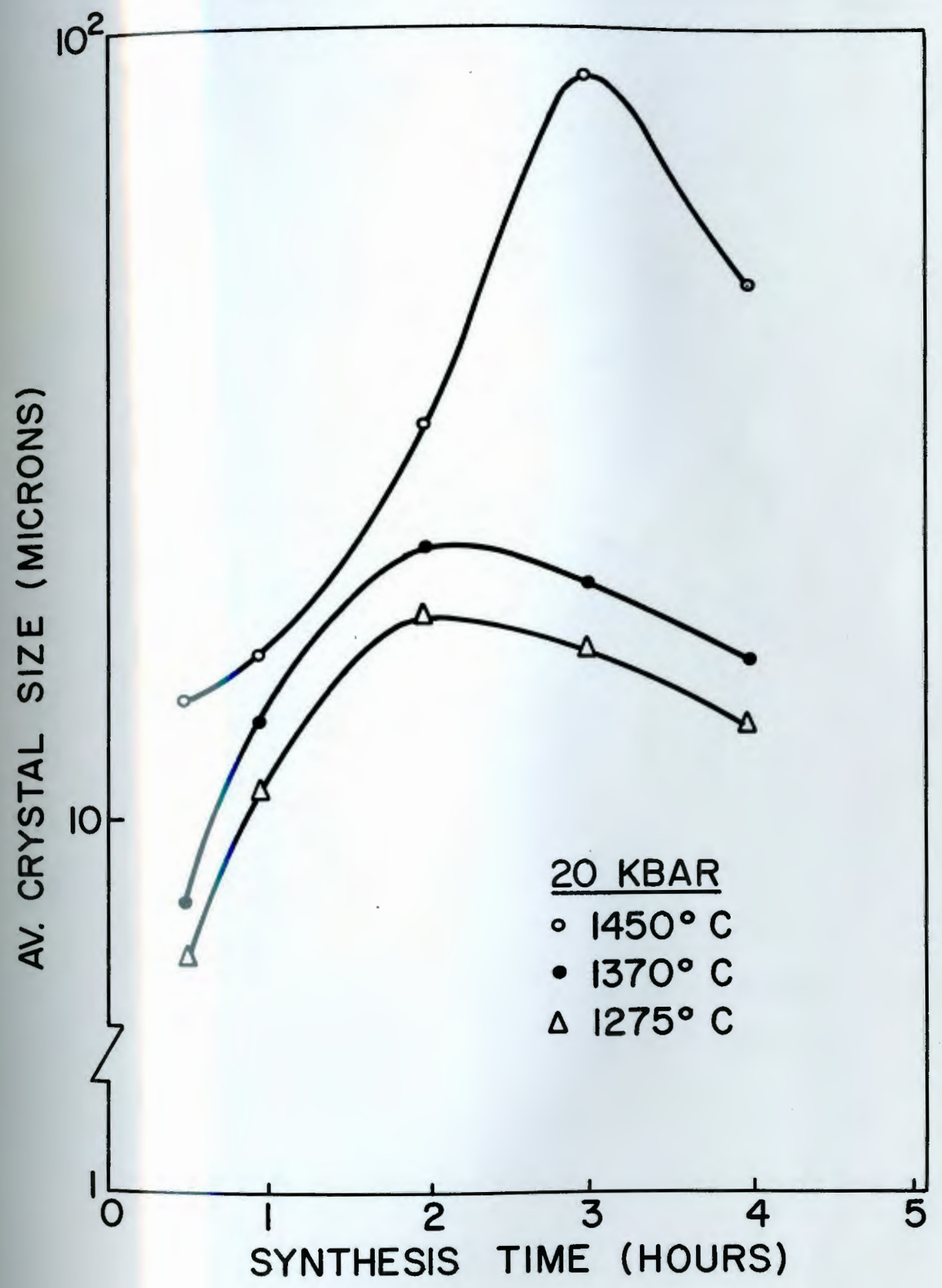




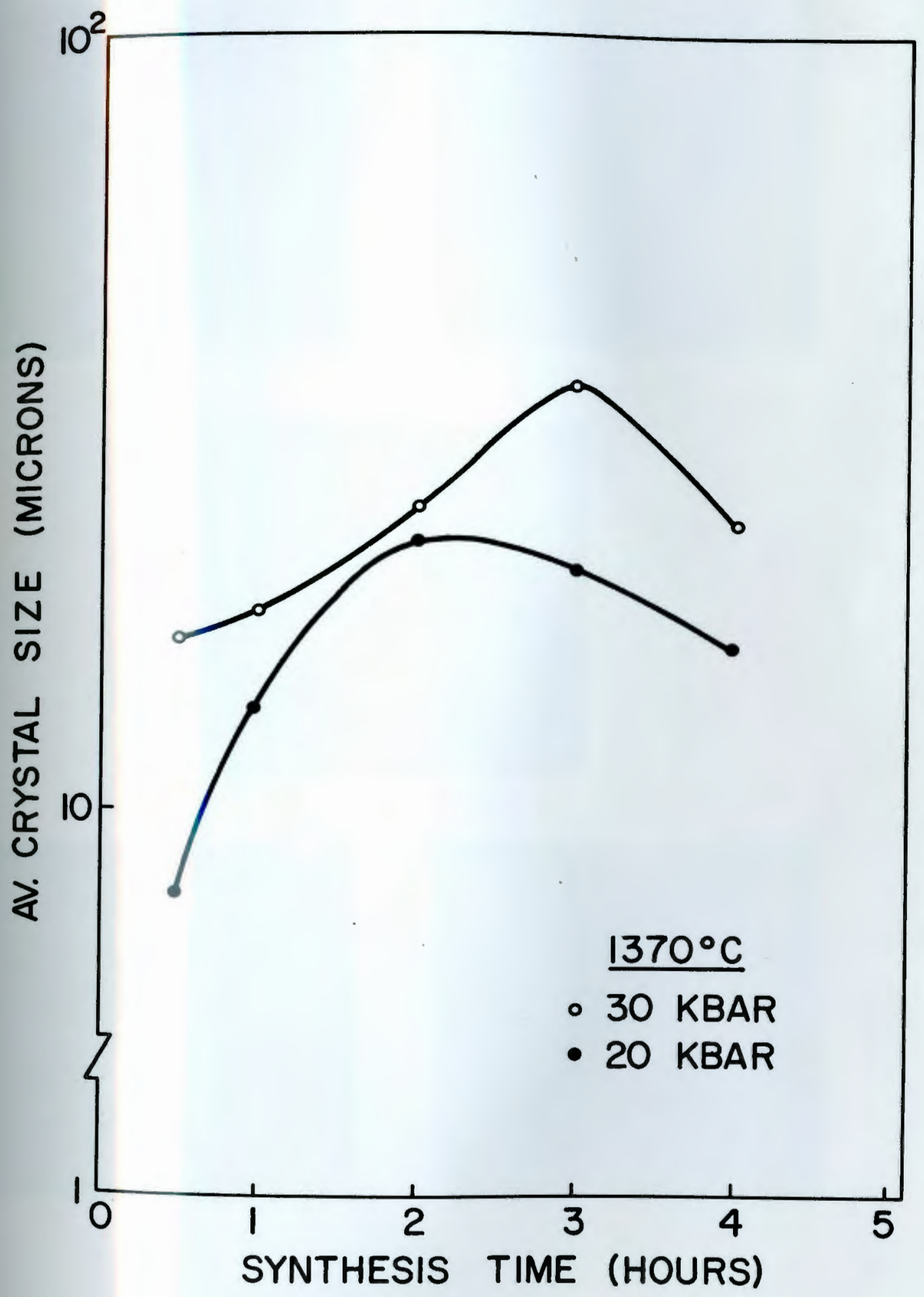




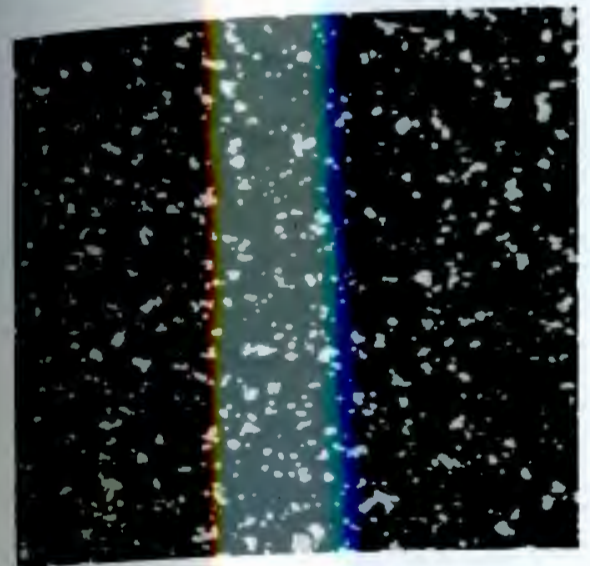

a.

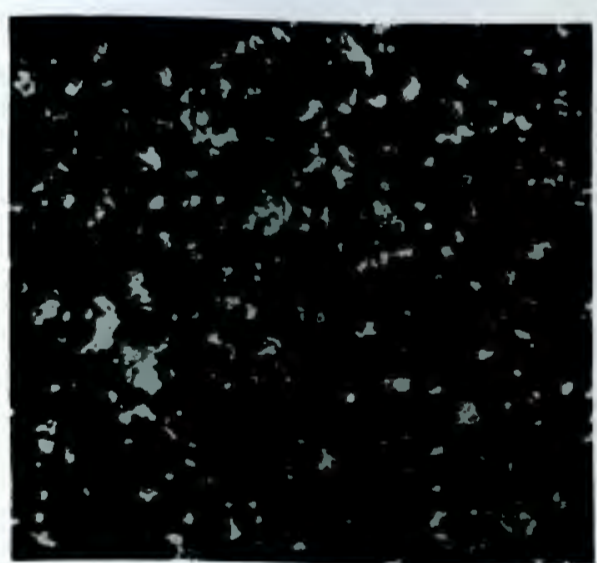

b.

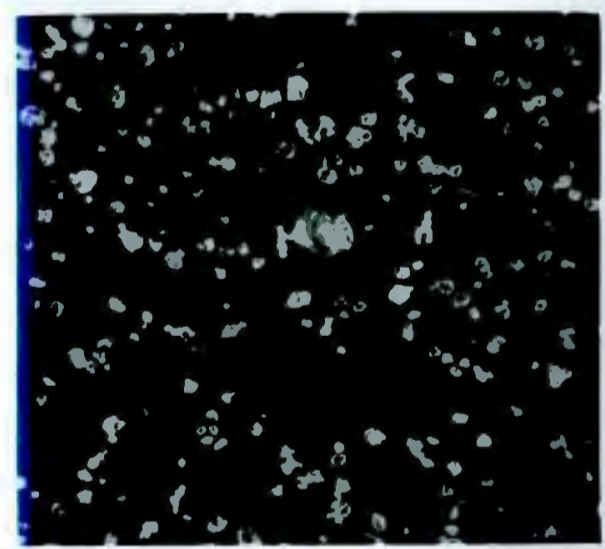

c.

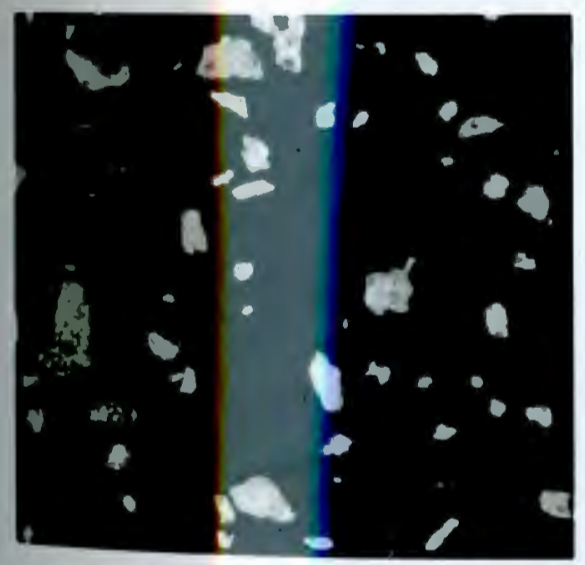

d.

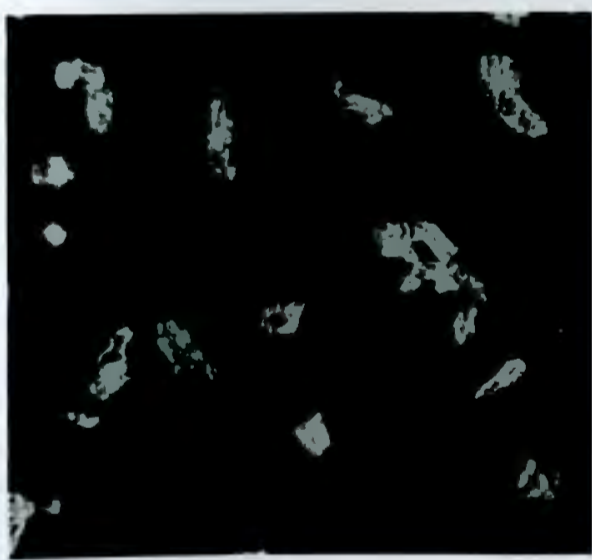

e. 
77

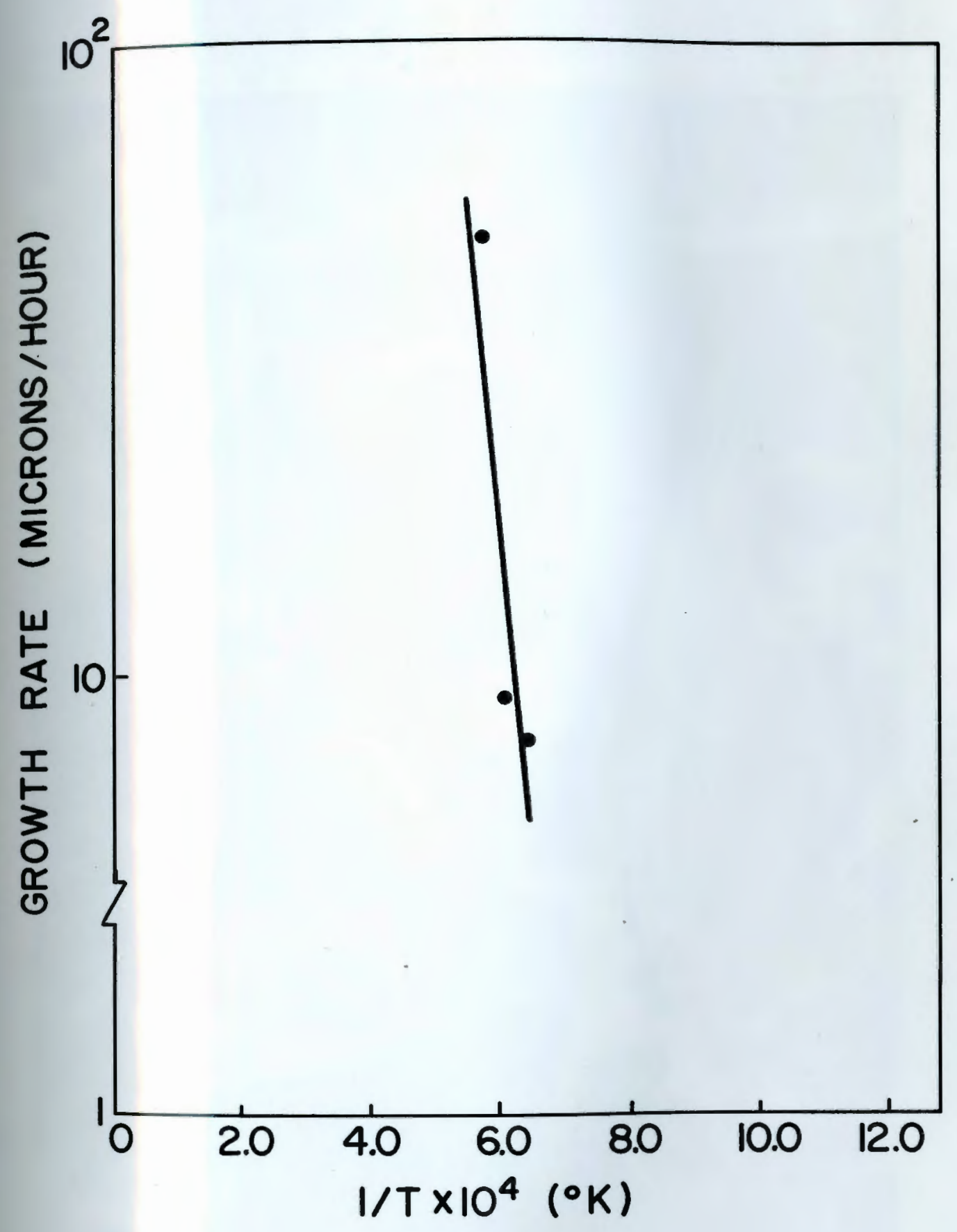




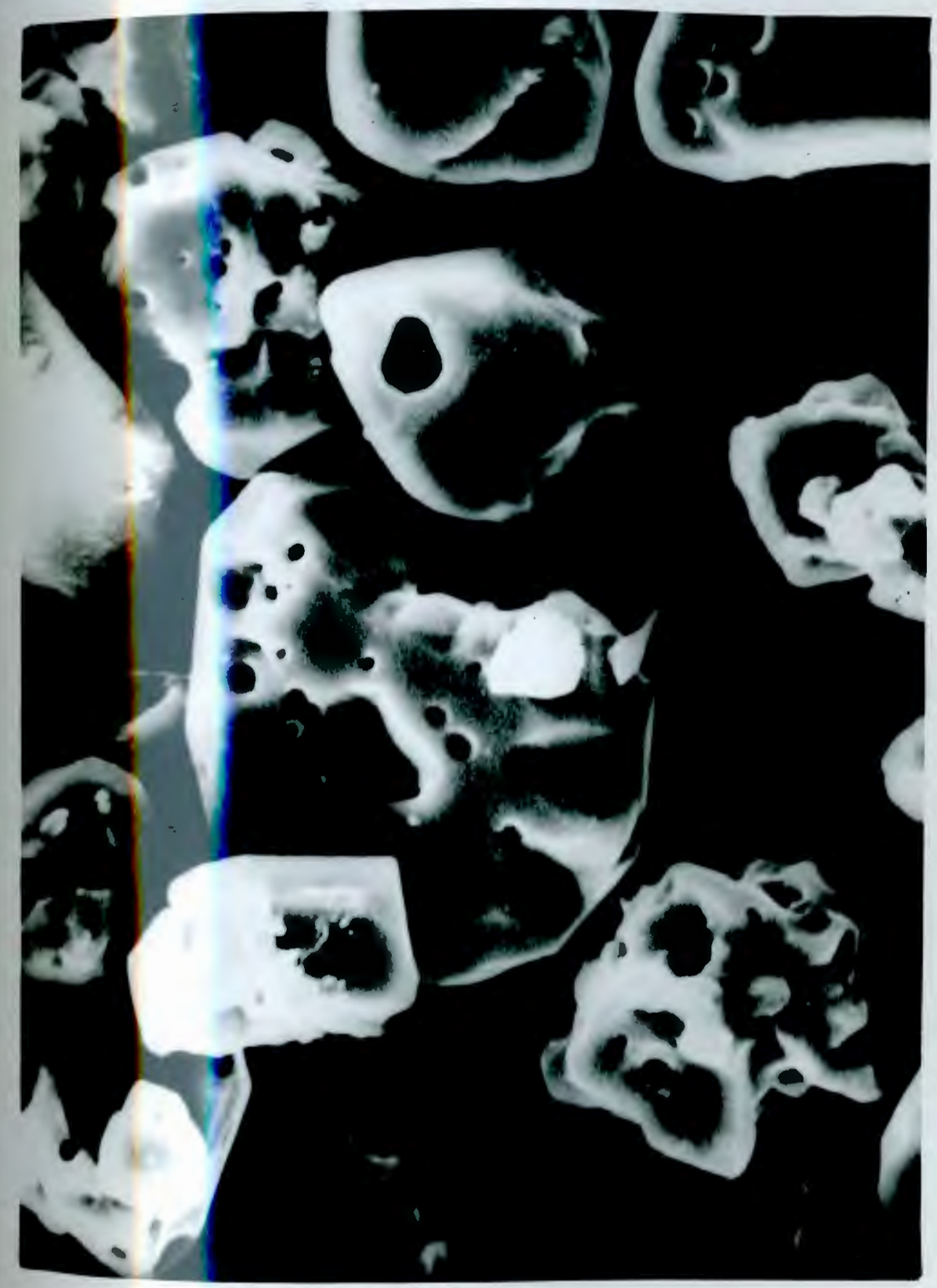




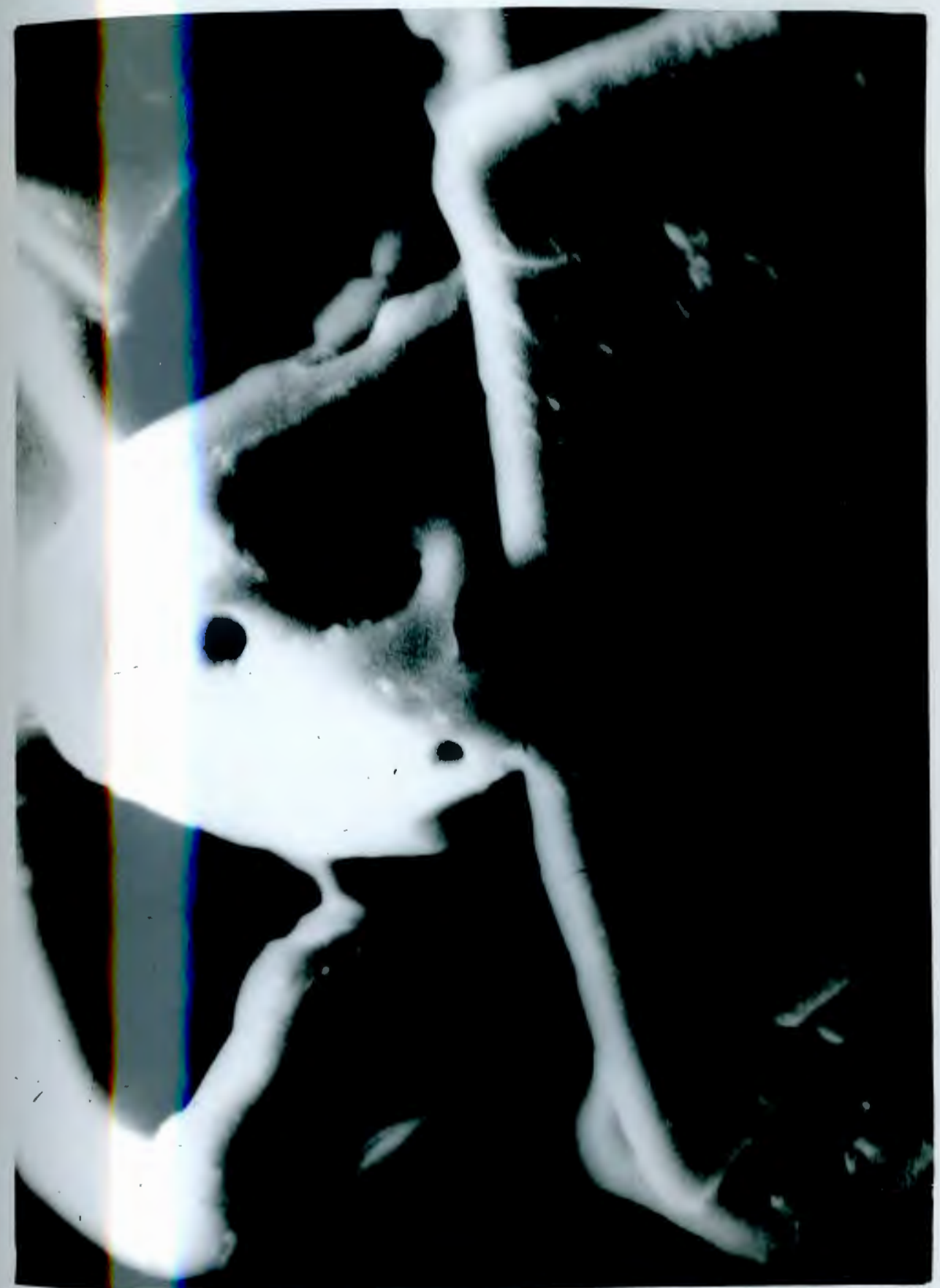




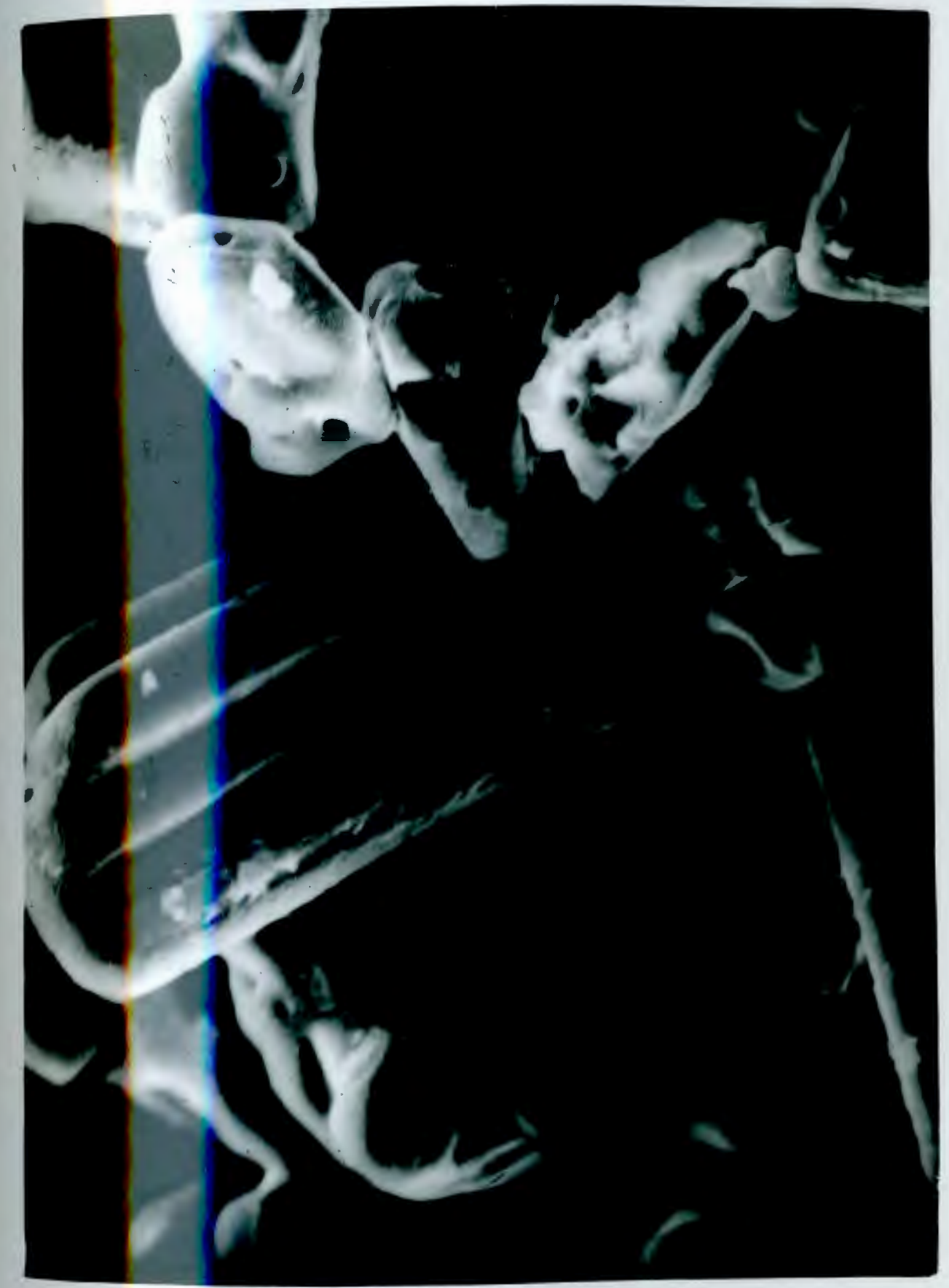




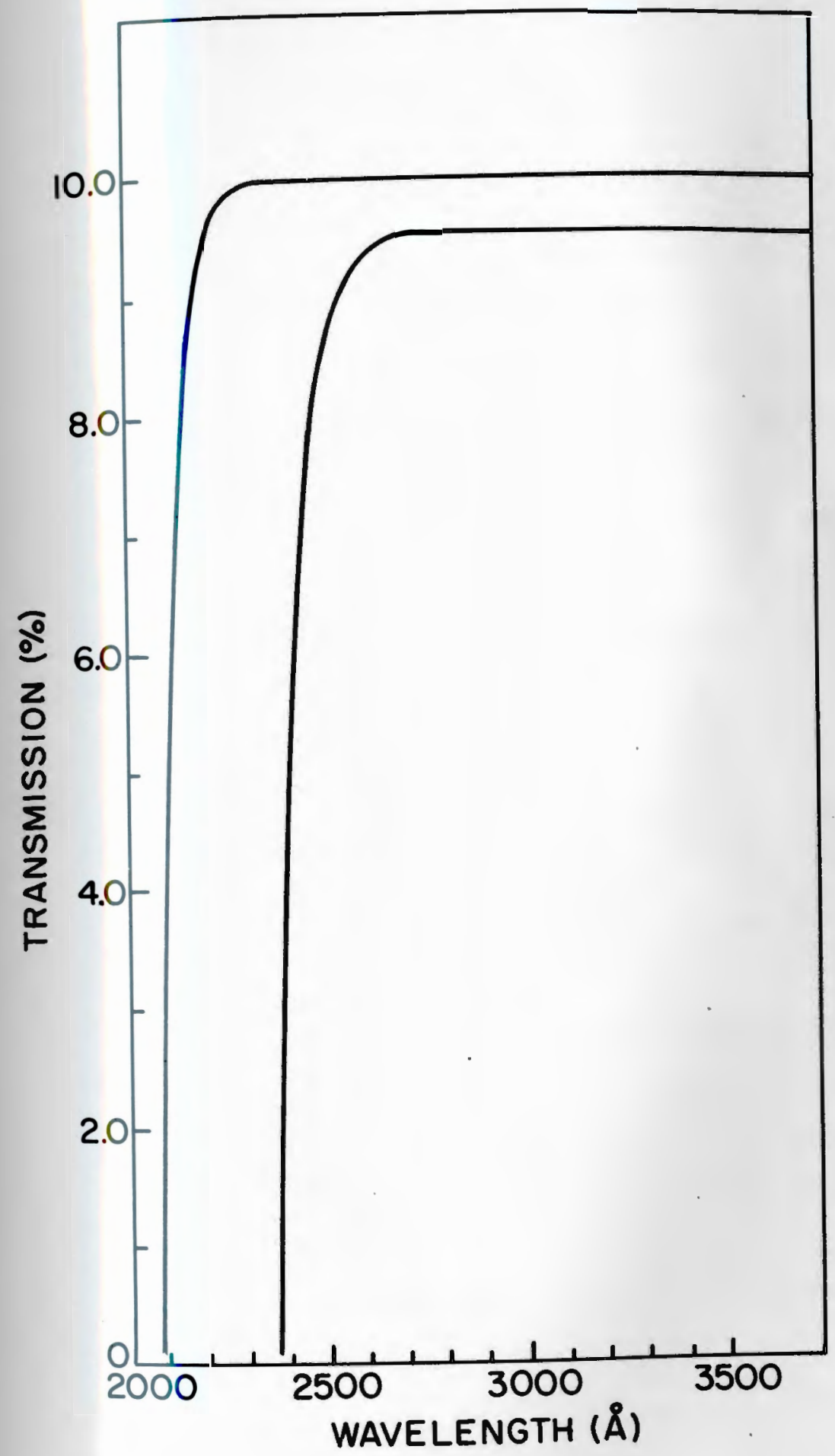




\section{REFERENCES}

1. Stone, B. and Hill, D. Phys. Rev. Lett., No. 6, 282 (1960)

2. Wang, C. C., Cardona, M., and Fischer, A. G. RCA Review, 25, 159 (1964)

3. Popper, P. and Ingles, T. A. Nature, 179, 1075 (1957)

4. Williams, F. V., and Ruehrwein, R. A. J. Am. Chem. Soc., $\underline{82}$, $1330(1960)$

5. Perri, J. A., La Placa, S., and Post, B. Acta Cryst., 11, 310 (1958)

6. Armington, A. F., Weiner, J. R. and Moates, G. H, Inorg. Chem., $\underline{5}, 483(1966)$

7. Vickery, R. C. Nature, 184, 268 (1959)

8. Matkovich, V. I. and Peret, J. L. "Method of Preparing Cubic Boron Phosphide", U.S. Patent No. 3,251,651, May 17, 1966.

9. Samsonov, G. V., and Titkov, Yu, B., Translated from Zhurnal Prikladno1 Khimil, $\underline{36}, 669$ (1963)

10. Grayson, P. E, Buford, J. T., and Armington, A. F. Electrochem. Tech., 3, 338 (1965)

11. Niemyski, T., Mierzcjewska-Appenheimer, S., and Majewski, J. Proc. of the Intl. Conf, on Crystal Growth, ed. by H. Peiser, p. 585 (1966)

12. Zass1, N. K. J. Chem. Soc. Japan, 85, 183 (1964)

13. Hal1, H. T. Sc1. Amer., 201, 61 (1959)

14. Kennedy, G. C., and LaMori, P. N. "Progress in Very High Pressure Research" Wiley, New York, p. 304 (1961) 


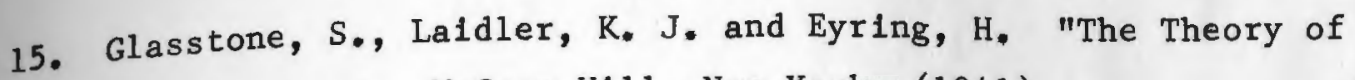
Rate Processes, McGraw-Hi11, New York (1941)

16. Turnbul1, D. Trans. Am. Inst. Min. (Metal1.) Engrs, 191, 661 (1951)

17. Mott, N. F. Proc. Phys. Soc., 60, 391 (1948)

18. Archer, R. J., Koyama, R* Y., Loebner, E, E, and Lucas, R* C. Phys. Rev. Lett., 12, 538 (1964). 
M A N U S C R I P T V 
BORON COMPOUNDS FOR THERMAL NEUTRON DETECTION

K. P. Ananthanarayanan *

A. Choudry

and P. J. Gielisse ${ }^{*}$

* Department of Chemical Engineering, University of Rhode Island, Kingston, R. I. 02881

Bepartment of Physics, University of Rhode Island, Kingston, R. I. 02881 . 


\section{ABSTRACT}

Pressed pellets of hexagonal boron nitride (BN), boron oxide $\left(\mathrm{B}_{2} \mathrm{O}_{3}\right)$, boron phosphide (BP), as well as electrophoretically deposited $B N$ have been evaluated as detectors for thermal neutrons. The current versus voltage characteristic was studied for each of these materials before and during irradiation with a neutron flux of about $10^{8} \mathrm{n} / \mathrm{cm}^{2} \mathrm{sec}$. The dark current was lowest in the $\mathrm{B}_{2} \mathrm{O}_{3}$ pellets and highest in the $\mathrm{BP}$ pellets with that of $\mathrm{BN}$ lying intermediate, as might be expected from their forbidden gaps. The differences observed during irradiation in the current values for the three boron compounds have been explained as being due to the "boron to anfon" atomic weight ratio being different in them. 


\section{INTRODUCTION}

Neutrons can be counted only by means of detecting secondary charged particles which they release in passing through matter, or by other secondary processes which produce ionizing radiations. The secondary charged particles may be protons released by collisions of neutrons with hydrogen nuclei; they may be the direct result of nuclear disintegration produced by neutrons or they may be the radioactive radiations from product nuclei which become radioactive as a result of neutron capture. The approach to detecting neutrons is controlled by the requirement that measurable lonization effects be produced.

In the present case, since thermal neutrons do not produce protons on collision with hydrogen nuclei ${ }^{1}$ and since radioactive products are undesirable because of safety considerations and also from the point of view of remnant radioactivity, the choice of detection is restricted to the release of the $\alpha$ particle. The reaction may be written as ${ }^{2}$

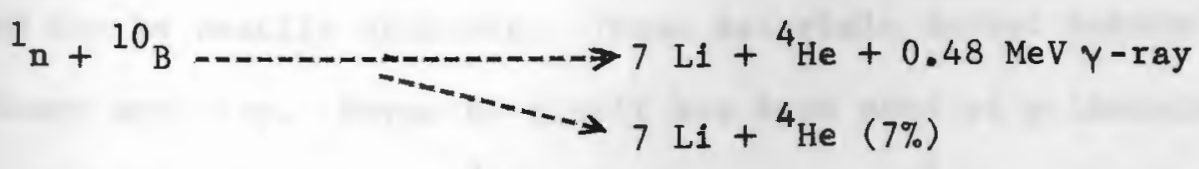

Many instruments are used for thermal neutron detection presently: the boron trifluoride $\left(\mathrm{BF}_{3}\right)$ filled proportional counter, the helium-3 filled proportional counter and boron or lithium (with zinc sulfide) seintillation detectors, to name a few. The helium-3 
filled counters are superior to the $\mathrm{BF}_{3}$ filled counters because the neutron absorption of helium-3 is greater than $\mathrm{BF}_{3}$ for the same length and pressure of the gas. ${ }^{2}$ However, helium- 3 occurs naturally as only one part in a million of natural helium and even though the isotope has been made avallable by irradiation of 1ithium- 6 which results in tritium decaying in 12.3 years half life to helium-3, the chemical separation of helium-3 from the parent tritium has to be done under extreme care to remove this background source in detectors. In scintillation detectors which absorb a large fraction of the neutrons, most neutrons are absorbed on the side of the detector from which neutrons arrive. The resulting light flashes must pass through the rest of the detector to reach the photosensitive face of the photomultiplier. For low neutron energies (larger absorption cross section) the mean position of interaction is further from the photosensitive surface and this may reduce the overall detection efficiency. Secondly, the fabrication of scintillation detectors keeping in mind the optimum thickness and the amount of phosphor to be added to the neutron absorbing element may not be easy.

The boron compounds studied in this investigation may eliminate some of the existing problems since they are solids with large band gaps and may be readily obtained. These materials do not retain any significant activity. Boron by itself has been used as a thermistor for sensing thermal neutrons. ${ }^{3}$ It is also reported that the $\mathrm{B}_{2} \mathrm{O}_{3}$ content on the scintillation properties in lithium borosilicate-cerium activated-glasses does not affect the behavior of the luminescence centers but hinders the energy transfer process. At present there is 
apparently no avallable information on the use of boron compounds, such as those investigated here, as possible neutron detector materials. Guided by the optical and electrical properties of these materials, ${ }^{5-8}$ it is felt that they may lend themselves suitably for such an investigation.

\section{EXPERIMENT}

Microcrystalline $\mathrm{BN}, \mathrm{BP}$ and $\mathrm{B}_{2} \mathrm{O}_{3}$ (10-20 microns in size) were pressed into pellet form in a standard laboratory hand press to a pressure of $5000 \mathrm{psi}$. The pellets were $6.35 \mathrm{~mm}$ in diameter and $1 \mathrm{~mm}$ thick. Pressure contact was made by means of a spacer-separated spring loaded plunger and the assembled detector is shown in Figure 1. The thickness of the detector plate was chosen such that the incoming neutrons are not absorbed.

The reactor power level was maintained at $2 \mathrm{MW}$ throughout the investigation and the neutron flux encountered by the detector was about $10^{8} \mathrm{n} / \mathrm{cm}^{2}$. sec. A DC power supply capable of delivering $200 \mathrm{milli-}$ amperes and 400 volts was used as the power source and a solid state electrometer ${ }^{*}$ was used to measure the current through the detector. The voltage was monitored from $0-100$ volts and the corresponding current was noted, first in the absence of the neutrons and then during Irradiation, unt1l reproducibility was achieved within experimental error. Tables 1, 2, 3 and 4 show the current values for each voltage setting, before and during irradiation for the various targets. The electrophoretic technique ${ }^{9}$ used in the deposition of hex-

\footnotetext{
*Keithley Instruments Inc., Cleveland, Ohio
} 
agonal boron nitride proved to be simple and rapid and provided a uniform deposit of about 200 microns in thickness. The substrate chosen for the deposition was a cathode of aluminum metal in the form of a plunger indicated in Figure 1. An aluminum disc, $38 \mathrm{~mm}$ in diameter and $1.7 \mathrm{~mm}$ thick, was used as the anode. A schematic of the experimental set-up for deposition is shown in Figure 2.

The suspension for the deposition was prepared as follows: Two stock solutions were required; A, lanthanum nitrate $(0.5 \mathrm{~g})$, aluminum nitrate $(0.25 \mathrm{~g})$, isopropyl alcohol $(50 \mathrm{ml})$ and distilled water ( $3 \mathrm{ml})$; B, equal parts by volume of glycerol and 1sopropyl alcohol. About 50 glass balls of $1 / 8$ " diameter were put 1nto a 150-ml stoppered flask and $1 \mathrm{ml}$ of solution B, 2 drops of solution $\mathrm{A}$ and 350-400 $\mathrm{mg}$ of boron nitride (10-20 microns) were added. The mixture was rotated for about 5 minutes to disperse the powder into a thin viscous cream. The presence of a small quantity of glycerine at this stage and in the final suspension helped to reduce flocculation. The following solution was added to the viscous cream; isopropyl alcohol $(100 \mathrm{ml})$, solution $\mathrm{A}(2 \mathrm{ml})$ and distilled water $(5 \mathrm{ml})$. The suspension was shaken thoroughly and subjected to ultrasonic agitation for 3-5 minutes. This suspension had a limited active life and had to be used within 12 hours of preparation. The electrophoretic deposition was carried out with the substrate held horizontally in the suspension which was contained in a glass beaker. The deposition was carried out with an anode-to-cathode separation of $15 \mathrm{~mm}$ and with a current of 6 milliamperes supplied from a stabilized DC power unit for about an hour. 
After deposition the target was carefully removed and dried. A thin film of aluminum was evaporated on to the target in order to establish uniform contact.

\section{RESULTS AND CONCLUSION}

Using the data given in Table 1, a semilog plot of current versus voltage is made for $B N$ pellet as indicated in Figure 3. The increase in current during irradiation follows a reducing trend towards higher voltages. This may approach saturation if carried further. The increase in conductivity during irradiation is contrary to what is usually observed. 10 It can be argued here that defects are created in the crystal lattice as a result of irradiation and on a band model these defects represent trapping levels between the valence band and the conduction band. For large band gap material such as those investigated here, these traps lie very close to the valence band and thus enable electron transfer. As a result of this, hole conduction becomes possible.

For electrophoretically deposited BN'Figure 4 is drawn using Table 2 data. The dark current is two orders of magnitude smaller than that of the $\mathrm{BN}$ peliet. This could be due to the smaller thickness of the deposit as compared to the pellet. The current seems to saturate at relatively low voltages. Some of the other advantages of the electrophoretically deposited target are that the dark currents observed here are close to those normally encountered in neutron detection. Secondly, the material thickness plays an important part in the relaxation time and since electrophoretic deposits can 
be made in the range of microns they may prove superior to other forms of target making where evaporation is not quite so straightLorward.

The current voltage plot for boron oxide is shown in Figure 5. The trend seems to be similar to that of the BN targets except that the increase in current is much less. The increase in conductivity 1s governed to a large extent by the neutron interaction with the target material and this interaction increases with increasing boron concentrations in the host crystal since neutrons interact mostly only with the boron atoms present in these compounds. Hence it may be said that the boron concentration being less in $\mathrm{B}_{2} \mathrm{O}_{3}$ than in $\mathrm{BN}$ is the cause for the lowered increase in current.

Figure 6 for BP shows quite a high dark current as compared to that of $\mathrm{BN}$ and $\mathrm{B}_{2} \mathrm{O}_{3}$ and this may be due to 1 ts smaller band gap. The interesting feature of this plot is the fact that the increase in current during irradiation is more pronounced at higher voltages and this material may therefore be more suited for those targets which have to operate at high fields.

From this preliminary investigation it appears as though these materials may be promising from the point of view of thermal neutron detectors. However, more precise quantitative measurements are needed in order to make any conclusive statement. 
TABLE 1

CURRENT VALUES FOR DIFFERENT VOLTAGE SETTINGS BEFORE AND DURING IRRADIATION OF BN PELLET

\begin{tabular}{cll}
$\begin{array}{c}\text { VOLTAGE } \\
\text { (VOLTS) }\end{array}$ & $\begin{array}{l}\text { CURRENT (AMPERES) } \\
\text { BEFORE IRRADIATION }\end{array}$ & $\begin{array}{l}\text { CURRENT (AMPERES) } \\
\text { DURING IRRADIATION }\end{array}$ \\
\cline { 2 - 3 } 0 & 0 & 0 \\
10 & $5.5 \times 10^{-12}$ & $1.1 \times 10^{-10}$ \\
20 & $1.5 \times 10^{-11}$ & $1.6 \times 10^{-10}$ \\
30 & $2.8 \times 10^{-11}$ & $2.2 \times 10^{-10}$ \\
40 & $4.3 \times 10^{-11}$ & $2.6 \times 10^{-10}$ \\
50 & $6.4 \times 10^{-11}$ & $3.1 \times 10^{-10}$ \\
60 & $8.5 \times 10^{-11}$ & $3.7 \times 10^{-10}$ \\
70 & $1.3 \times 10^{-10}$ & $4.2 \times 10^{-10}$ \\
80 & $1.8 \times 10^{-10}$ & $4.9 \times 10^{-10}$ \\
90 & $2.3 \times 10^{-10}$ & $5.4 \times 10^{-10}$ \\
100 & $3.0 \times 10^{-10}$ & $6.1 \times 10^{-10}$
\end{tabular}


TABLE 2

CURRENT VALUES FOR DIFFERENT VOLTAGE SETTINGS

BEFORE AND DURING IRRADIATION OF

ELECTROPHORETICALLY DEPOSITED BN

VOLTAGE

0

5

10

15

20

25

30
CURRENT (AMPERES)

BEFORE IRRADIATION

0

$2.8 \times 10^{-10}$

$9.7 \times 10^{-10}$

$2.2 \times 10^{-9}$

$3.0 \times 10^{-9}$

$3.8 \times 10^{-9}$

$4.5 \times 10^{-9}$

\section{CURRENT (AMPERES)}

DURING IRRADIATION

0

$5.4 \times 10^{-9}$

$1.0 \times 10^{-8}$

$1.5 \times 10^{-8}$

$1.9 \times 10^{-8}$

$2.1 \times 10^{-8}$

$2.3 \times 10^{-8}$ 
TABLE 3

CURRENT VALUES FOR DIFFERENT VOLTAGE SETTINGS BEFORE AND DURING IRRADIATION OF $\mathrm{B}_{2} \mathrm{O}_{3}$ PELLET

VOLTAGE

(VOLTS)

0

10

20

30

40

50

60

70

80

90

100
CURRENT (AMPERES)

BEFORE IRRADIATION

0

$9.0 \times 10^{-12}$

$2.2 \times 10^{-11}$

$3.5 \times 10^{-11}$

$5.0 \times 10^{-11}$

$6.4 \times 10^{-11}$

$8.0 \times 10^{-11}$

$9.6 \times 10^{-11}$

$1.1 \times 10^{-10}$

$1.3 \times 10^{-10}$

$1.5 \times 10^{-10}$
CURRENT (AMPERES)

DUR ING IRRADIATION

0

$3.5 \times 10^{-11}$

$6.7 \times 10^{-11}$

$1.1 \times 10^{-10}$

$1.4 \times 10^{-10}$

$1.8 \times 10^{-10}$

$2.0 \times 10^{-10}$

$2.3 \times 10^{-10}$

$2.5 \times 10^{-10}$

$2.9 \times 10^{-10}$

$3.1 \times 10^{-10}$ 
TABLE 4

CURRENT VALUES FOR DIFFERENT VOLTAGE SETTINGS BEFORE AND DURING IRRADIATION OF BP PELLET

\begin{tabular}{ccc}
$\begin{array}{c}\text { VOLTAGE } \\
\text { (VOLTS) }\end{array}$ & $\begin{array}{l}\text { CURRENT (AMPERES) } \\
\text { BEFORE IRRADIATION }\end{array}$ & $\begin{array}{l}\text { CURRENT (AMPERES) } \\
\text { DURING IRRADIATION }\end{array}$ \\
\cline { 2 - 3 } 0 & 0 & 0 \\
10 & $1.3 \times 10^{-6}$ & $2.3 \times 10^{-6}$ \\
20 & $3.5 \times 10^{-6}$ & $5.6 \times 10^{-6}$ \\
30 & $5.5 \times 10^{-6}$ & $1.0 \times 10^{-5}$ \\
40 & $7.6 \times 10^{-6}$ & $1.6 \times 10^{-5}$ \\
50 & $1.0 \times 10^{-5}$ & $2.1 \times 10^{-5}$ \\
60 & $1.3 \times 10^{-5}$ & $2.5 \times 10^{-5}$ \\
70 & $1.5 \times 10^{-5}$ & $3.0 \times 10^{-5}$ \\
80 & $1.7 \times 10^{-5}$ & $3.4 \times 10^{-5}$ \\
90 & $1.8 \times 10^{-5}$ & $3.9 \times 10^{-5}$ \\
100 & $1.9 \times 10^{-5}$ & $4.4 \times 10^{-5}$
\end{tabular}




\section{FIGURE CAPTIONS}

1. SKETCH OF THERMAL NEUTRON DETECTOR AS USED IN THIS INVESTIGATION.

2. SCHEMATIC OF EXPERIMENTAL SET-UP FOR ELECTROPHORETIC DEPOSITION OF HEXAGONAL BORON NITRIDE,

3. CURRENT-VOLTAGE CHARACTERISTIC FOR BORON NITRIDE PELLET, BEFORE AND DURING THERMAL NEUTRON IRRADIATION.

4. CURRENT-VOLTAGE CHARACTERISTIC FOR ELECTROPHORETICALLYDEPOSITED BORON NITRIDE, BEFORE AND DURING THERMAL NEUTRON IRRADIATION.

5. CURRENT-VOLTAGE CHARACTERISTIC FOR BORON OXIDE PELLET, BEFORE AND DURING THERMAL NEUTRON IRRADIATION.

6. CURRENT-VOLTAGE CHARACTERISTIC FOR BORON PHOSPHIDE PELLET, BEFORE AND DURING THERMAL NEUTRON IRRADIATION. 

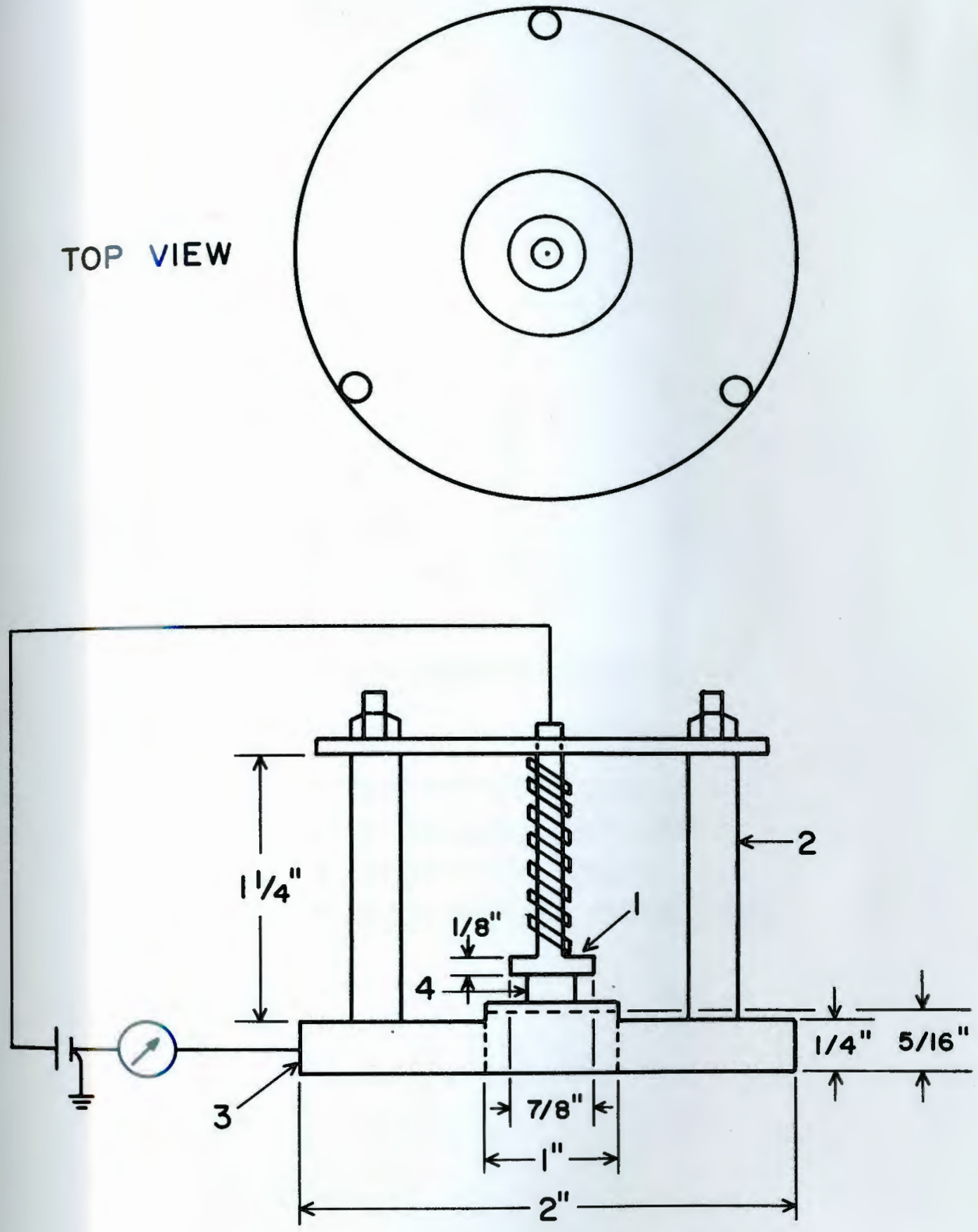

I SPRING - LOADED PLUNGER

2 SPACERS

3 BACK PLATE

4 DETECTOR PELLET 


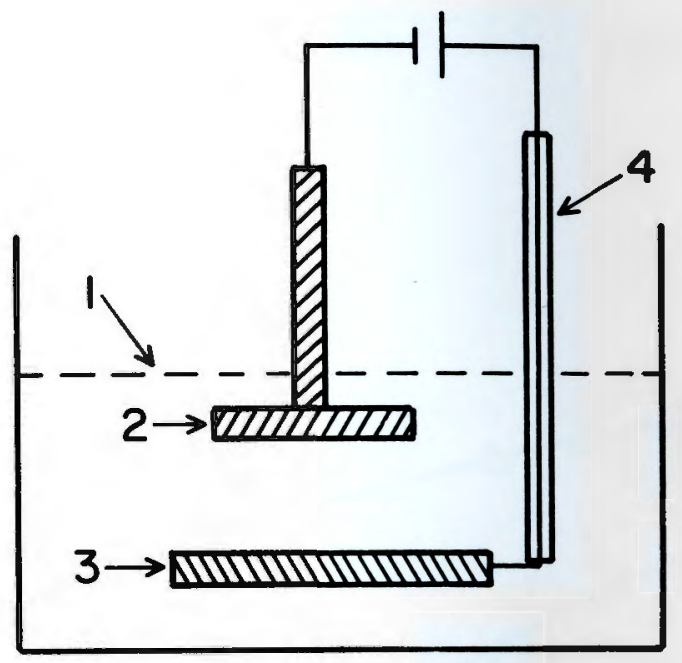

I SUSPENSION LEVEL

2 ALUMINUM CATHODE

3 ALUMINUM ANODE

4 ELECTRICAL INSULATOR 


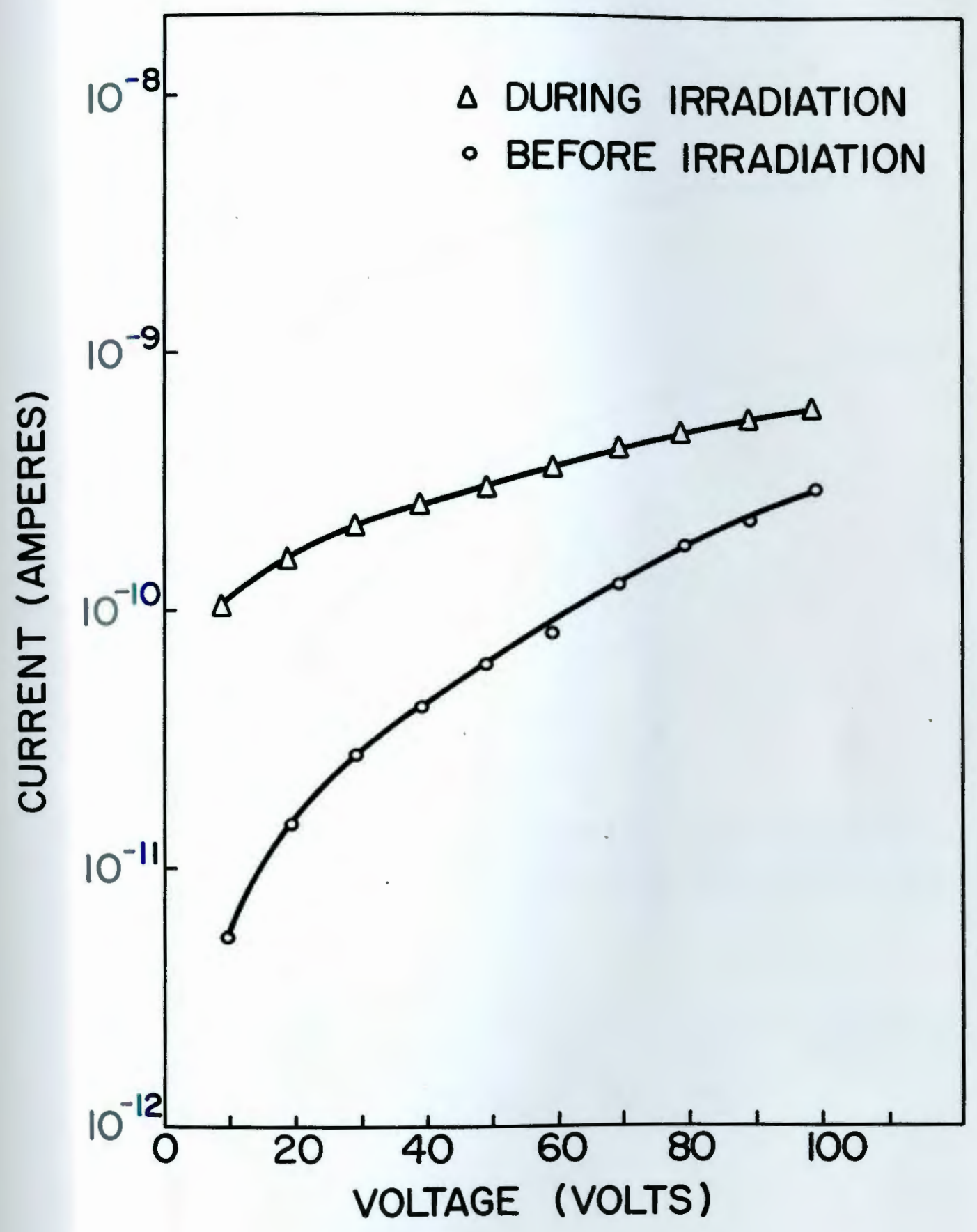




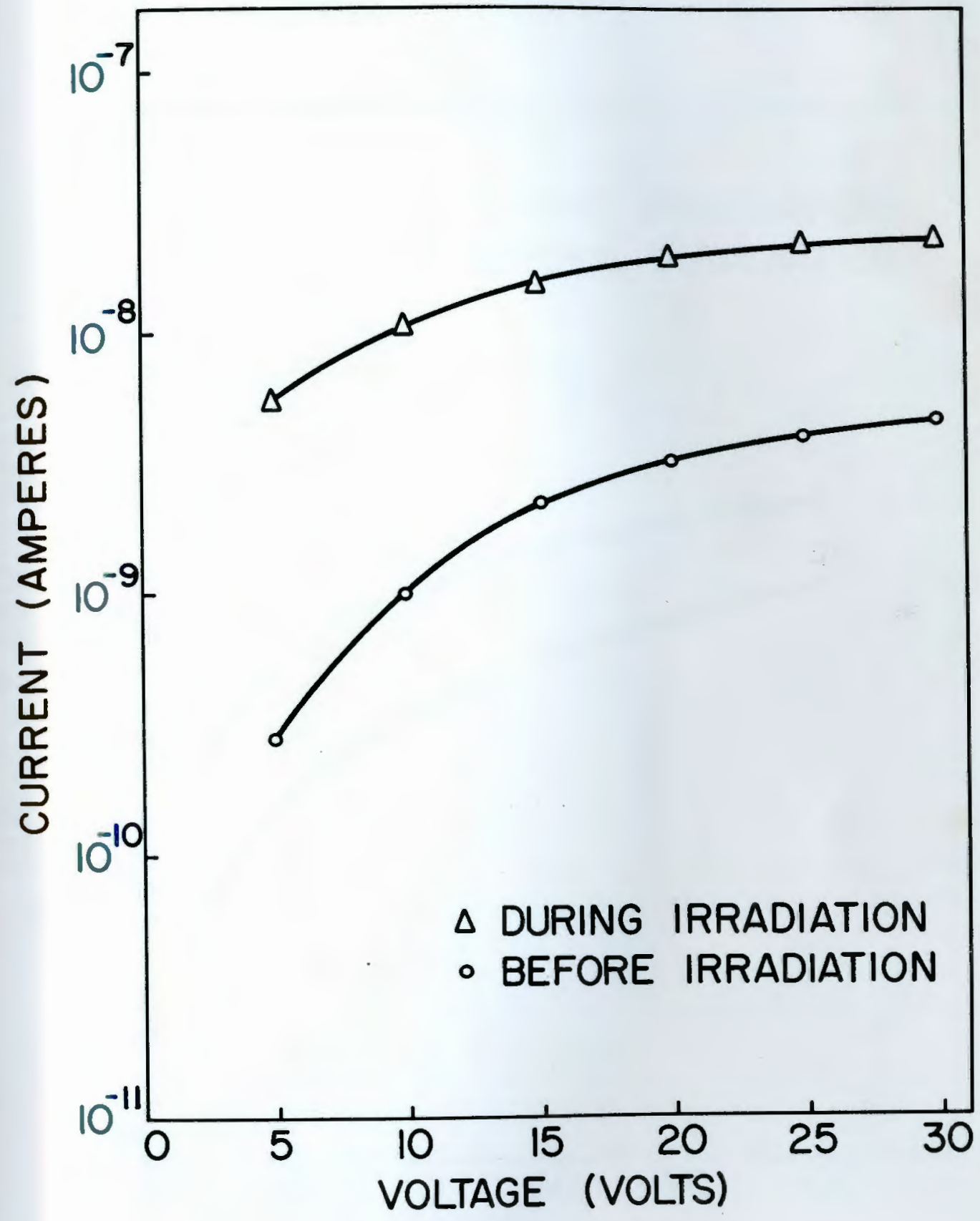




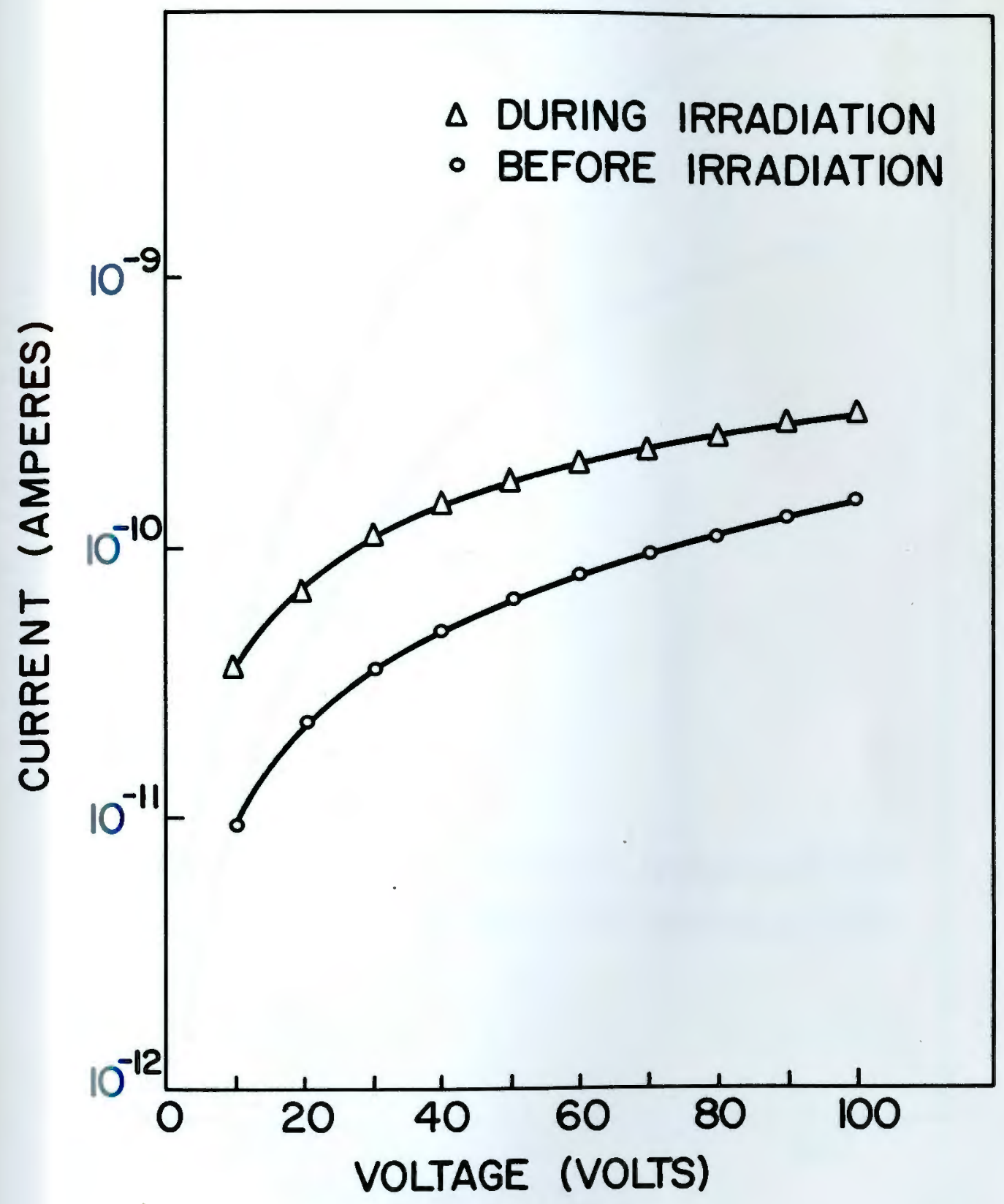




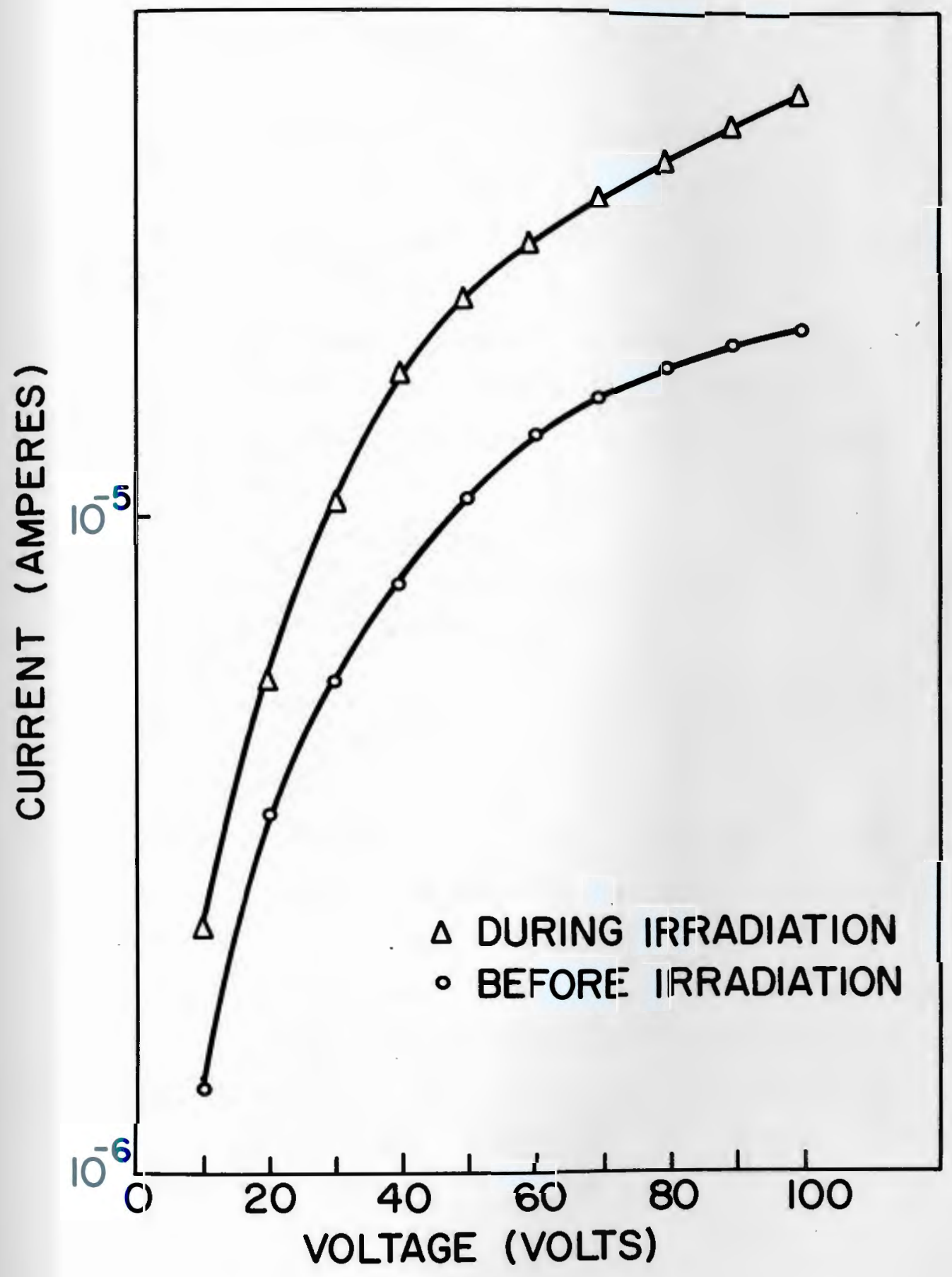




\section{REFERENCES}

1. Curtiss, L. F. "Introduction to Neutron Physics" New York, N. Y.: Van Nostrand Co. Inc. (1959) 144.

2. Egelstaff. "Thermal Neutron Scattering" New York, N. Y.: Academic Press (1962) 171.

3. Gaule, G. K. "Boron - Preparation, Properties and Applications" New York, N. Y.: Plenum Press 2, 318 (1965)

4. Bertozzi, G., Coceva, C., and Pissini, S. Energia Nucleare, 9, $164(1962)$

5. Frederickson, J. E., Redanz, W. H, Boron Nitride for Aerospace Applications, Southern Materials Conf., American Society for Metals, Orland, Florida (1964)

6. Gielisse, P. J., Mitra, S. S., Plendl, J. N., Griffis, R. D., Mansur, L. C., Marshall, R., and Pascoe, E. A. Phys. Rev., 155, 1039 (1967)

7. Stone, B., and Hill, D. Phys. Rev. Lett., 4, 282 (196)

8. Wang, C. C., Cardona, M*, and Fischẹ,, A, G. RCA Rev., 159 (1964)

9. Linden, B. R. "Advances in Electronics and Electron Physics" New York, N. Y.: Academic Press 16, 311 (1962)

10. Kemmey, P. J., and Mitchell, E. W. J. Proc. of the Intl. Conf. on Semiconductor Physics, New York, N. Y.: Academic Press, p. 919 (1961) 
A P P E N D I X 


\section{INTRODUCTION AND LITERATURE SURVEY}

During the past decade, there has been a great interest in the development of new materials and in improving the properties of existing materials. This is particularly so in the field of semiconductors. It is mainly due to the fact that since the development of the transistor, semiconductors have been put to a variety of sophisticated applications which call for very specific properties. The use of a semiconductor laser, which emits a narrow band, and which can be attuned to the absorption frequency of the crystal laser, can result in an overall increase in conversion efficiency. Tuning is made possible by varying the composition of the alloys. Since this type of laser can be tallored to emit a range of frequencles, another use would be as a high resolution monochromatic source for spectroscopy. ${ }^{1}$ Semiconductors are also sought after for making solar cells and temperature sensing devices. Since the major use of the solar cell is as a power source for space vehicles, there is considerable interest in semiconductors with a high temperature capability and greater resistance to high energy particles. For a good temperature sensing device, the semiconductor in question must have a fairly large temperature range over which it is capable of being operated. Diamond thermistors are ideally suited for this. Devices such as cathodoluminescent imaging tubes, based on optoelectronic principles, also make for significant interest in new semiconductor materials. 
The work in this thesis has been concerned with the synthesis, characterization, and applications of some of the important members of the family discussed above, specifically diamond and boron phosphide. This appendix gives an overview of the relevant literature and background on these materials in the two separate sections following.

\section{A. Diamond and Semiconducting Diamond}

The graphite-diamond equilibrium line, calculated from thermodynamic concepts, ${ }^{3}$ has been a major contribution for all diamond synthesis work. Subsequently a phase diagram has been reported ${ }^{4}$ for carbon extending up to $5000^{\circ} \mathrm{K}$ and $800 \mathrm{kbar}$. Phase equilibria for "indirect" formation of diamond (via a metal "catalyst" or solvent), from graphite have also been investigated ${ }^{5}$ along with nucleation and growth characteristics. For a metal solvent like nickel, the nickelcarbon phase diagram has been established. ${ }^{6}$ A method for predicting a priori the conditions for indirect diamond synthesis has been developed ${ }^{7}$ and calculations have been made for the nickel-carbon and manganese-carbon phase equilibria. The lower pressure-temperature limits for indirect synthesis seems to be controlled by the eutectic temperature at pressure and the diamond-graphite equilibrium line. ${ }^{7}$ The direct conversion of carbon into diamond requires pressures, static or dynamic, in excess of $130 \mathrm{kbar}$ and hence is seldom used.

There are two points of view on the graphite-diamond transition. According to one, it is due to rupture of the crystal lattice of graphite and transfer of free carbon atoms, in a melt of "solvent catalyst", to the growth surface of the diamond by diffusion. $8-10$ 
others consider the transition to involve reconstruction of the graphite lattice without breakup into individual atoms (solid-state mechanism). 11-12 The diffusion mechanism seems to be the more prominent one ${ }^{13}$ though 1 t does not exclude the possibility of the solid-state mechanism.

The introduction of semiconductivity in diamond is a relatively easy task and can be accomplished in a variety of ways. The most common method is that of the introduction of specific dopants like $\mathrm{Be}, \mathrm{B}, \mathrm{Al}$ efther through addition to growth mixtures of carbon and solvents or through diffusion of these elements into diamond crystals at high temperatures and pressures. ${ }^{14-16}$ Introduction of active impurities by means of ion implantation has lately received considerable attention. ${ }^{17-19}$

This investigation has been concerned with the semiconducting properties and mechanism of conduction in diamond brought about by impurities or dopants. For most semiconductors, the plot of $\log R$ versus $1 / T$ normally shows a minimum, which occurs at increasingly higher temperatures as the impurity concentration increases. To the low temperature side of the minimum, that is in the extrinsic range, the curve is almost linear. The low temperature asymptotic slope of the plot gives the activation energy of the 1mpurity leve1. The curves obtained in our investigation do not reach a minimum even at $800^{\circ} \mathrm{K}$ and secondly there is a "kink" in the slope. In a similar vein 1 t has been reported 20,21 that in certain germanium samples, the resistivity as well as Hall Coefficient first increase almost exponentially with decreasing tem- 
perature, but that at a certain temperature the Hall Coefficient reaches a maximum and then decreases sharply over several orders of magnitude. Such a temperature dependence is clatmed to be typical of a semiconductor with an impurity band. ${ }^{18}$ The twoconduction-band model as proposed by Hung ${ }^{21}$ explains conduction to take place at high temperatures in the regular band and at low temperatures in the impurity band. For our case this does not seem to be valid at low temperatures and low doping levels because of the inability to form impurity bands. For diamond, impurity band formation can occur at impurity levels of about $10^{18} / \mathrm{cm}^{3}$ (reference 22). The hopping mechanism suggested by Conwell 23 and Mott ${ }^{24}$ states that in the presence of minority compensations, impurity conduction is possible at majority concentrations lower than necessary for band formation due to the hopping of charge carriers from one occupied impurity site to a nearby one left vacant by minority impurities. Such a mechanism has been observed by Fritzsche ${ }^{25}$ and reported by Wilson ${ }^{26}$ in his interpretation of conductivity in variously doped diamond. A relation between ' $E$ ' the activation energy and the compensation ratio $\mathrm{K}=\mathrm{N}_{\min } / \mathrm{N}_{\operatorname{maj}}$, where $\mathrm{N}_{\min }$ and $\mathrm{N}_{\text {maj }}$ are the minority and majority concentrations respectively, has been found by Miller. ${ }^{27}$ His findings indicate a decreasing activation energy with increasing values of $K$ at least up to $K=0.5$. This means for a fixed minority concentration, once the low temperature activation energy and the dopant content are known, it may be possible to determine whether conduction is by hopping mechanism or not.

Diamond can be classified into type I and type II depending on 
the absorption in the infrared region of the electromagnetic spectrum. Type I diamond exhibits absorption in two regions: from 2 to 6 microns and from 8 to 13 microns. Type II diamond shows absorption only in the 2 to 6 micron region. The absorption in the 8 to 13 micron region for type I diamond varies from specimen to specimen and appears therefore to be an impurity or structure sensitive property. ${ }^{28}$ The absorption in the 8 to 13 micron region was found to be temperature independent whereas the bands in the 2 to 6 micron region showed a temperature dependence which was similar to that of corresponding bands in silicon and germanium. 29 This would indicate that the 2 to 6 micron absorption is related to the characteristic lattice frequencies of diamond while the other band is truly impurity related. It has been shown that the intensity of the latter band is a function of the nitrogen concentration. The absorption characteristics can also be changed by neutron ${ }^{30}$ and electron irradiations. ${ }^{31}$ In type II diamond, for which normally no absorption structure is shown in the 8 micron region, neutron 1rradiation induces structure normally found in type I diamond. 30 Electron-irradiated type I diamond has been found to show an extra band at 3.1-3.8 $\mathrm{eV}^{31}$ The infrared absorption spectrum of protonirradiated diamond shows a characteristic absorption at 6.92 microns. 32

The electrical properties of diamond are also significantly affected by energetic electrons or neutrons. 33,34 By suitable irradiation of semiconducting diamond, (with $1.5 \mathrm{MeV}$ electrons and a beam current density of $50 \mathrm{microamperes} / \mathrm{cm}^{2}$ ), the upper useful 
temperature limit for semiconductivity may be considerably increased ${ }^{35}$ at the expense of an increase in resistance.

\section{B. Boron Monophosphide}

Among the group III-V compound semiconductors, the boron Group V compounds are least known, mainly because of the difficulties involved in their synthesis. Boron phosphide, a member of this group, shows both physical and chemical properties that differ from the general trend of the III-V family. Due to its high melting point (approximately $3000^{\circ} \mathrm{C}$ ), high dissociation pressure and low pressure incongruent decomposition ${ }^{36}$ at elevated temperatures into phosphorus and a lower phosphide, it would be very difficult to grow boron phosphide crystals by conventional methods such as zone refining and growth from the melt. ${ }^{37}$ Thus, many of the important basic physical properties of $B P$ are not yet well established, in spite of the scientific interest in this compound stimulated by its potential as a candidate for solid-state devices and possible use as an abrasive.

Much of the earlier.synthesis was done using evacuated tubes containing boron and red phosphorus heated to about $1100^{\circ} \mathrm{C} .{ }^{38-40}$ Boron phosphide has been prepared as a microcrystalline powder by the replacement reaction of $\mathrm{BCl}_{3}$ or $\mathrm{BBr}_{3}$ and $\mathrm{Br}_{3} \mathrm{P}_{2}$ at $1000^{\circ} \mathrm{C}$ in an argon atmosphere. ${ }^{37,41}$ Thermal decomposition of halide addition compounds such as $\mathrm{BCl}_{3} \cdot \mathrm{PCl}_{5}$ has also yielded boron phosphide. ${ }^{42}$ Pressure synthesis has been successful at 100 atmospheres and $1000-1600^{\circ} \mathrm{C} .{ }^{43}$ High purity stoichiometric crystals of $\mathrm{BP}$ have been reported to crystallize from solutions under high pressure in an 
autoclave 44 at about 1500 kbar and temperatures between 1000$1500^{\circ} \mathrm{C}$; pure boron and pure phosphorus in admixture were used as the reactants with the boron content varying between $5-20 \%$ by weight. Largest crystals are reported to be obtained at process temperatures between 1200 and $1300^{\circ} \mathrm{C}$; slow cooling had no effect on the crystal growth but prolonged reaction times produced larger crystals. The growth rate of boron phosphide has been reported ${ }^{45}$ as a function of temperature, pressure and time. Temperature seems to enhance the growth rate and there appears to be an optimum duration for synthesis of larger crystals.

Boron phosphide has a large bandgap 46 and yet is neither colorless nor transparent. 37 Single crystal measurements had yielded an energy gap of $2 \mathrm{eV}$ and no strong absorption in the infrared range. 37 The low value of the bandgap had earlier been determined from the slope of log resistivity versus inverse temperature from measurements on sintered crusts. 47 The bandgap determined has been reported as being indirect. 37

The effect of neutron irradiation on boron phosphide and boron nitride is virtually unexplored. Boron by itself has been used as a thermistor for sensing thermal neutrons. 48 The only available report $^{49}$ on the effect of thermal neutrons on boron phosphide and hexagonal boron nitride is a study of the current-voltage characteristics of these compounds before and during irradiation. The current appears to be about an order of magnitude larger during irradiation. Due to the extremely small half life of the radioactive isotopes of these materials, they may be promising materials for use in neutron detectors. 


\section{METHODS AND EQUIPMENT USED}

All high pressure synthesis experiments were carried out in the 600 ton tetrahedral anvil press shown in Figure 1 . The theory and design of the original tetrahedral press is described by Hal1. 50,51 The tetrahedral press is an extension of the "twodimensional" Bridgman anvil concept to three dimensions. A "threedimensional" device is necessary to overcome the problem of the small sample size in the Bridgman anvils. In the tetrahedral press the principle of massive support is still at work but not to the same extent as in Bridgman anvils. This is so because the solid angle subtended by each anvil must decrease as the number of anvils used is increased.

In the tetrahedral press four anvils with triangular faces are driven toward a central point by hydraulic rams whose axes lie along lines normal to the triangular anvil faces. The anvil axes intersect at tetrahedral angles $\left(109.47^{\circ}\right)$ in the center of a regular tetrahedral volume enclosed by the anvil faces. The anvils are constructed of cemented tungsten carbide and are surrounded by a press-fit steel binding ring. The binding ring absorbs the tensile loads developed within the body of the tungsten carbide. The anvils are brought together by independent valves which control each ram. The position of the anvils is indicated by dial gages. In the initial stages of pressure build-up, while the gaskets are being formed, the rams are advanced individually in small incremental steps. Then all control 


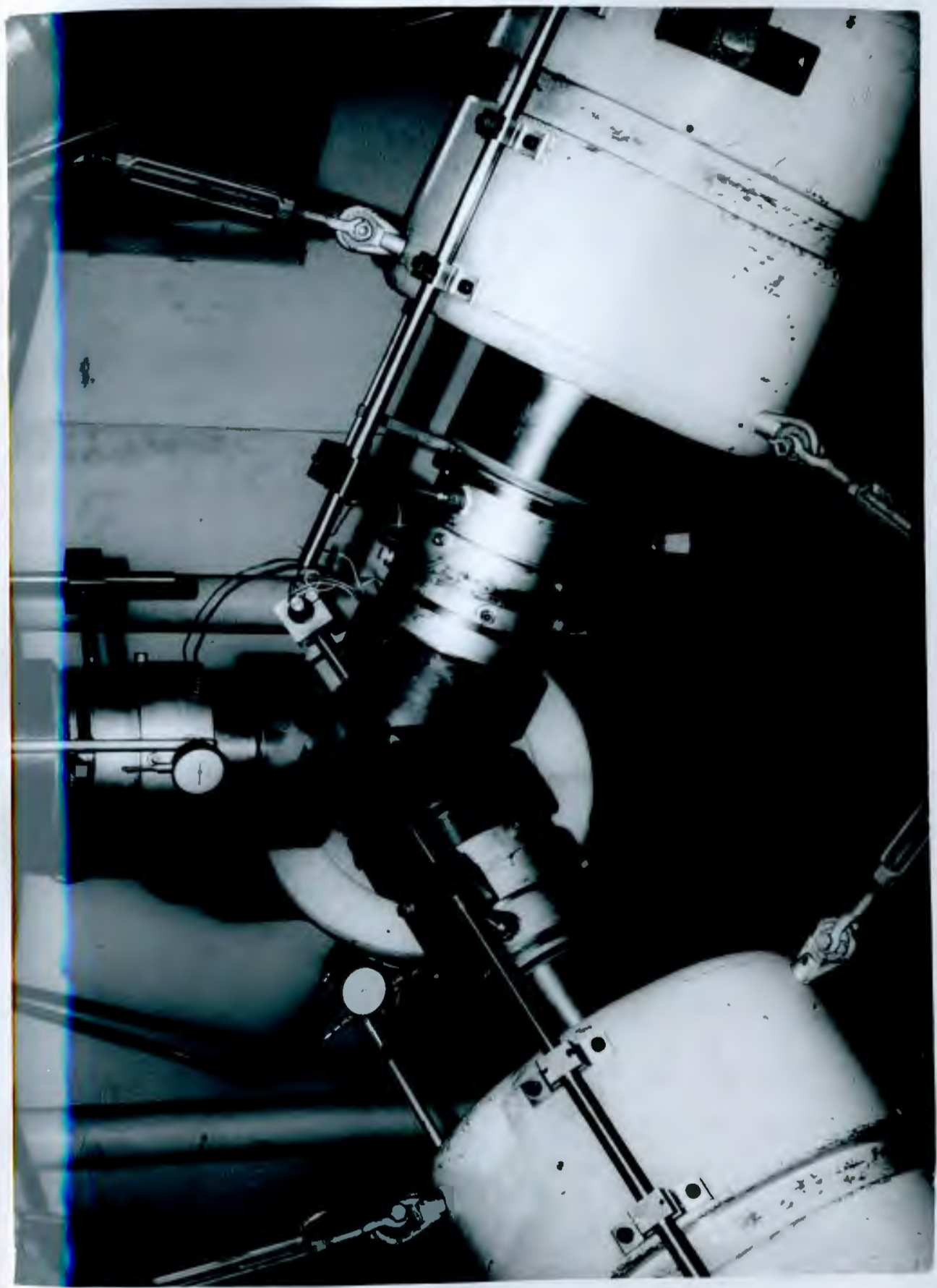


valves are opened thus supplying hydraulic oil simultaneously to the four hydraulic rams. Figure 2 shows the hydraulic flow diagram of the tetrahedral anvil press used in this study. Some tetrahedral presses are equipped with an anvil guide device ${ }^{51}$ which eliminates the need for incremental adjustment. This device causes all hydraulic rams to advance simultaneously and symmetrically toward the center of the tetrahedral press as oil pressure is applied to all four hydraulic rams from one valve.

The pyrophyllite tetrahedra used as sample holders for the high pressure runs were obtained from Maryland Lava Company, Inc., Bel Air, Maryland. The pyrophyllite transmits pressure to the sample, provides thermal and electrical insulation and, by extruding between the sloping shoulders of the advancing anvils, provides the necessary compressible gasket.

Pressure versus load calibrations were made by measuring the known abrupt resistance changes in sample cells containing extruded bismuth and thallium wire and using the transition values reported by Kennedy. 52 For this purpose, metallic bismuth was extruded cold through a steel die at about 5000 psi into a wire of 20 mils diameter and kept till used in ethylene glycol to prevent its oxidation. Bismuth rod of $20 \mathrm{mils}$ diameter and $1 / 4$ inch in length was placed into a boron nitride cylinder of $7 / 32$ inch outer diameter, 20 mils inside diameter and $1 / 4$ inch in length. Bismuth containing boron nitride cylinders were then placed inside the pyrophyllite tetrahedron of edge 1.5 inches. Figure 3 shows the sample and sample holder as used in this calibration. Two strips of copper (0.015" thick and 3/8" wide) coming from the opposite sides of the tetra- 


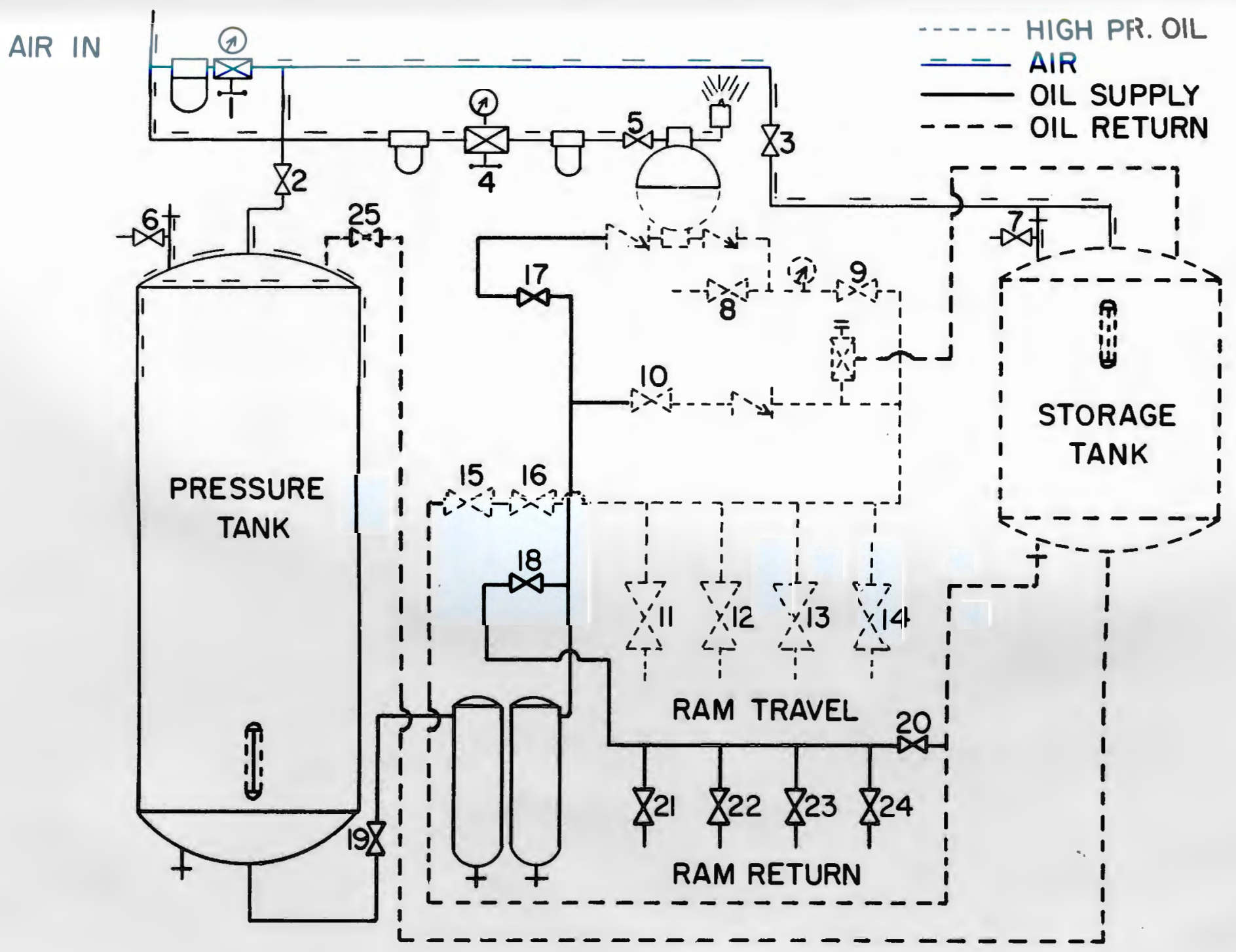




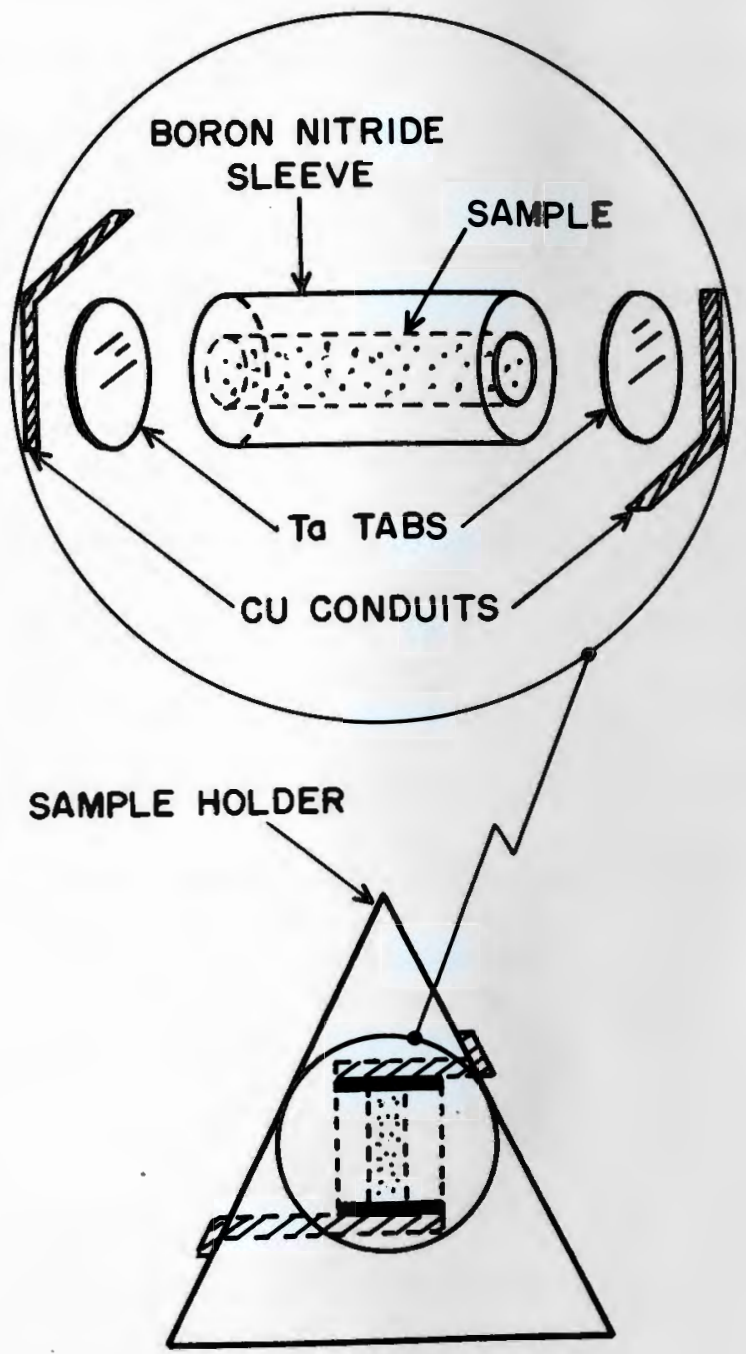


hedron make contact with the ends of the bismuth wire via tantalum taps which serve as the contact between the test specimen and the copper strips. These copper strips are bent against the surface of the tetrahedron and serve as leads for resistance measurement. Changes of resistance of the bismuth wire during high pressure compression were measured by a milliohmmeter and electrometer. ${ }^{*}$ In a similar fashion, thallium and barium were used for the determination of higher pressure points. The calibration curve is shown in Figure 4.

Temperature calibrations were made using a Pt-Pt $10 \% \mathrm{Rh}$ thermocouple. The thermocouple junction was located in the center of the cell and the leads were brought out through the edges of the tetrahedron in the space between the sloping anvil shoulders. Friction of the pyrophyllite gaskets was sufficient to hold the fine thermocouple wires in place during the high pressure operation. The effect of pressure on the emf of the thermodouple was taken into consideration using data reported by Bundy ${ }^{53}$ and corrected temperatures were computed for different power settings. Two temperature calibrations were made, one for diamond synthesis shown in Manuscript I and another for BP synthesis shown in Figure 5. For a more detailed discussion of pressure and temperature calibrations at high pressure, the reader is referred to Eatough. 54

\footnotetext{
*Keithley Instruments Inc., Cleveland, Ohio.
} 


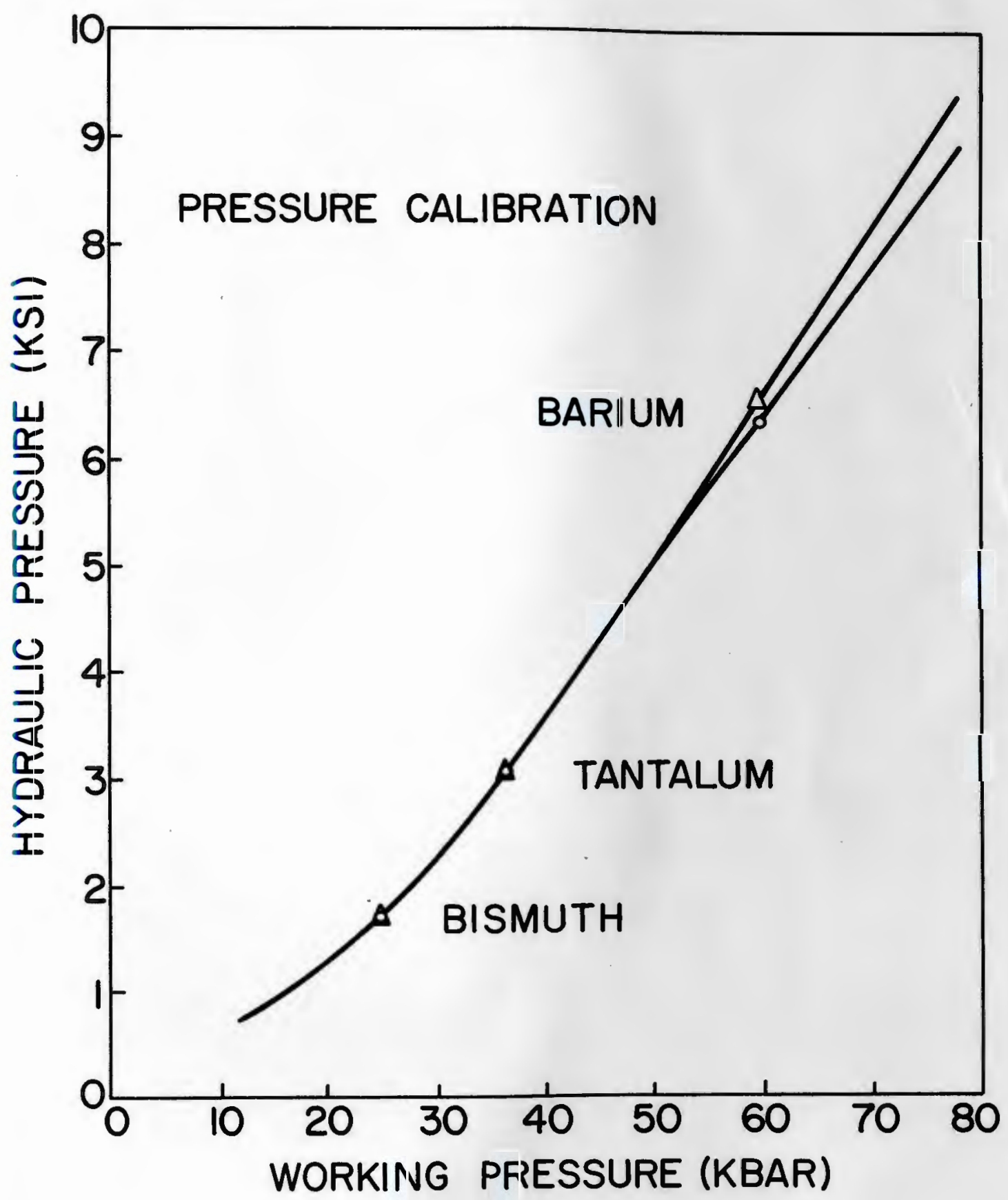




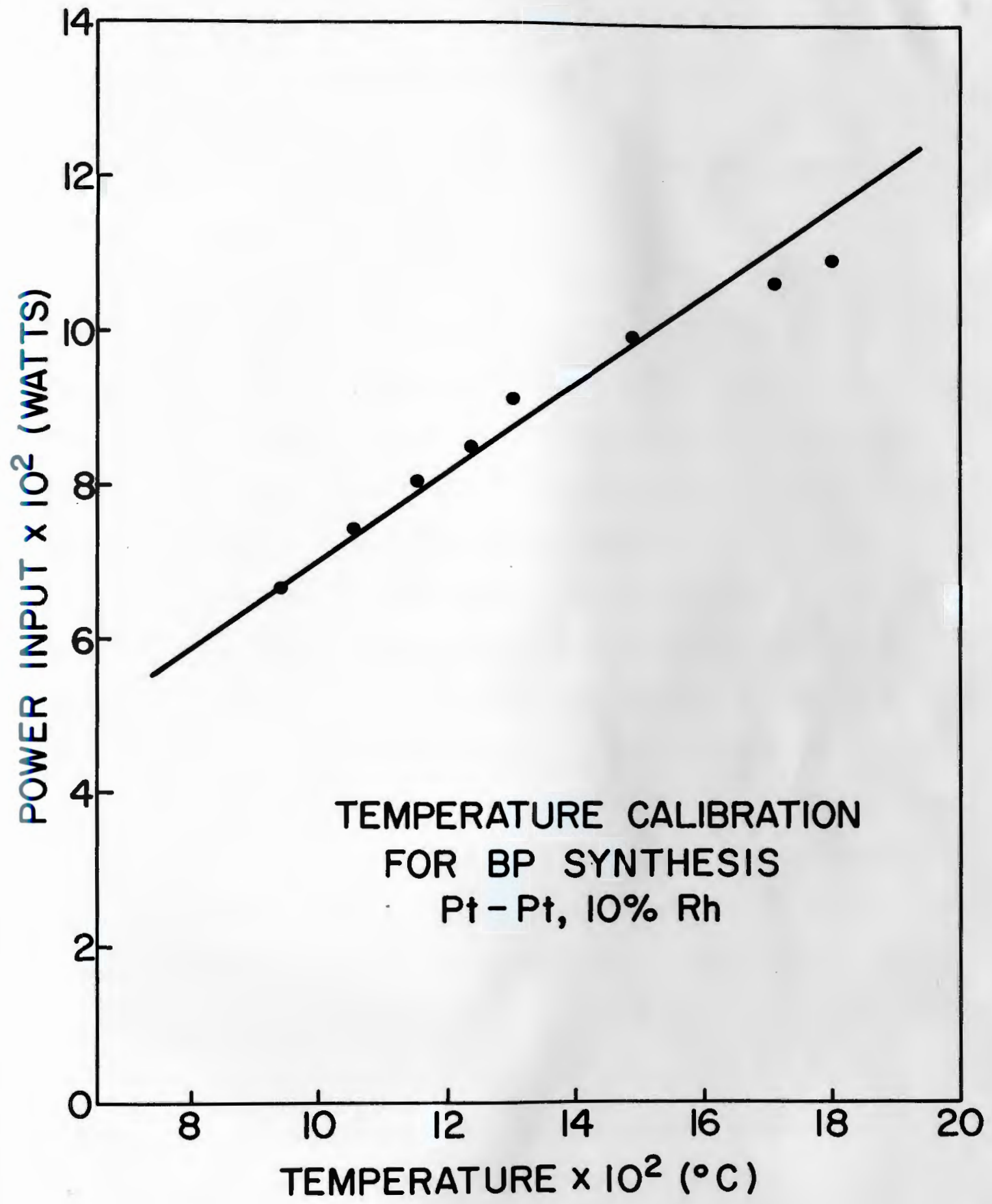




\section{SUMMARY AND PROPOSED FUTURE WORK}

In the foregoing, the synthesis and characterization of diamond and boron phosphide have been discussed.

The end product of the synthesis is affected by a variety of parameters; the significant ones in the case of diamond are pressure, temperature, nature of the metal catalyst-solvent and type and quantity of dopant used. Since the objective has been to synthesize small crystallites of diamond, widespread nucleation has been induced by using higher pressures within the growth regime.

For boron phosphide synthesis, pressure, temperature and time have been the main controlling factors. While higher temperatures and greater time durations have a favorable effect on the crystal size, pressure does not seem to greatly alter the end product. However, high pressures of the order of 20 kbar have been found necessary in order to retain the phosphorus in the melt at the temperatures encountered. From the growth-rate measurements an "activation energy of growth" has been determined. Optical micrographs illustrating the change in crystal size with time are shown. Scanning electron micrographs have been taken to study the morphology of the crystals synthesized and they reveal homogeneously scattered voids throughout the crystals under all conditions of temperature and pressure.

Some of the properties of diamond and boron phosphide have also been studied as part of this investigation. For diamond, the 
electrical conductivity of heavily doped specimens has been worked out and the effect of proton irradiation investigated.

The mechanism of electrical conduction in diamond heavily doped with boron, aluminum and titanium appears to be due to the formation of impurity bands as opposed to the hopping of charge carriers. The activation energies of the impurity levels have been determined from an analysis of the $\log R$ versus $1 / T$ curves. For boron doped diamond, due to the 'kink' in the $\log \mathrm{R}$ versus $1 / \mathrm{T}$ curves, which is unusual, the activation energy has been determined by assuming a "two-impurity" model with boron as majority impurity and nitrogen as minority impurity. For aluminum and titanium doped samples, which do not show any anomalies up to $200^{\circ} \mathrm{K}$, the analytical data could be fitted very well with experimental data.

Type I diamond irradiated with high energy protons shows an increase in the lattice constant which has been detected from Raman spectral measurements. The infrared absorption spectra before and after irradiation reveal a characteristic absorption at 6.92 microns in the irradiated sample. This could be a manifestation of defects induced as a result of irradiation or some possible transmutation of carbon to boron as explained earlier in the text. However, the band edge remained the same even after irradiation.

Boron phosphide has been synthesized. The morphology and the effect of thermal neutron irradiation have been investigated. Optical absorption measurements have been made and the fundamental absorption edge has been found.

Thermal neutron irradiation appears to increase the current 
at fixed voltages in detectors made of boron phosphide, boron oxide and hexagonal boron nitride. Boron phosphide seems to be more suited than the other compounds for detector applications at high voltages due to 1 ts tendency to be more sensitive in this region. The increase in current during irradiation has been explained as resulting from defects (trapping levels) induced as a result of neutron irradiation.

Even though proton irradiation, at energies used in these investigations, should not have induced electrical conductivity in type I diamond, it is strongly felt that irradiation at higher energy levels would cause sufficient transmutation of carbon into boron and result in semiconducting diamond. Future work is being directed towards irradiating single crystal diamond at proton energies of about $100 \mathrm{MeV}$ and then characterizing them for their electrical and optical properties. Graphite samples, irradiated at $100 \mathrm{MeV}$ proton energies, will also be used in the synthesis of semiconducting diamond.

In the area of boron phosphide, efforts are being made to synthesize "voldless" single crystals using new growth techniques. The generation of well-developed homogeneous single crystals will enable more reliable measurements on the fundamental absorption edge and facilitate conductivity studies which are meager at this point for this compound. For thermal neutron detection boron phosphide seems to be a definite possibility. More quantitative experiments are being planned to resolve the actual neutron flux striking the target (by accounting for contribution due to $\gamma$ radiation) in order to calculate the neutron absorption efficiency and 
neutron-induced carriers which lead to enhanced electrical conductivity. 
1. Lax, B. "Semiconductor Diode Lasers", Solid State Design, $\underline{4}$, No. 11 (1963)

2. Gielisse, P. J., and Doser, M. "Thermistor Device and Method of Producing Said Device" U. S. Patent No. 3,435,399. March 1969.

3. Berman, R., Sir Francis Simon. Zeitschrift fulr Elektrochemie, 59, $333(1955)$

4. Bundy, F. P. J. Chem. Phys., 38, 631 (1963)

5. Strong, H. M., and Hanneman, R. E. G. E. Report No. 66-C-038, March 1966.

6. Strong, H. M. , and Hanneman, R. E. G. E. Report No. 66-C-408, December 1966.

7. Peters, E. T., Kaufman, L., and Ryan, J. J. AFCRL-65-168, February 1965.

8. Giardini, A. A., and Tydinges, J. E. Amer. Mineralogist, 47, 1393 (1962)

9. Litvii, Yu. A. Izv." Akad. Nauk.SSSR, Neorgan. Mat., 4, 175 (1968)

10. Cannon, P. G. E. Report No. 62-RL-(3049 C), June 1962.

11. Vereschagin, L. F., Kalashnikov, Ya. A., Feklichev, E. M., Nikol'Shaya I. V., and Tikhomirova, L. M. Dok1. Akad. Nauk. SSSR, 162, 1027 (1965)

12. DeCarlie, P. S., and Jamieson, J. C. Science, 133, 1821 (1961)

13. Klebanov, Yu. D. Izv. Akad. Nauk. SSSR, Neorgan. Mat., 6 , $1729(1970)$ 
14. Bovenkerk, H. P., Bundy, F. P., Hall, H. T., Strong, H. M., and Wentorf, R. H. Nature, 184, 1094 (1959)

15. Wentorf, R. H., and Bovenkerk, H. P. J. Chem. Phys., $\underline{36}, 1987$ (1962)

16. Bovenkerk, H. P. "The Physics and Chemistry of High Pressures" Society of Chemical Industry, London, 191 (1963)

17. Wentorf, R. H., and Darrow, K. A. Phys. Rev., 137, 1614 (1965)

18. Vavilov, V. S., Guseva, M. I., Konorova, E. A., Sergienko, V. F. Soviet Physics - Semiconductors, 4 , 6 (1970)

19. Vavilov, V. S., Guseva, M. I., Konorova, E. A., Krasnopevtsev, V. V., Sergienko, V. F., and Tutov, V. V. Soviet Physics, Solid State, $\underline{8}, 1560$ (1966)

20. Hung, C. S., and Gliessman, J. R. Phys. Rev., 79, 726 (1950)

21. Hung, C. S. Phys. Rev., 79, 727 (1950)

22. Tsay, Y. F., Ananthanarayanan, K. P., Gielisse, P. J. and Mitra, S. S. J. Appl. Phys. May 1972 (to be published).

23. Conwe11, E. Phys. Rev., 103, 51 (1956)

24. Mott, N. F. Can. J. Phys., 34, 1356 (1956)

25. Fritzsche, H. J. Phys. Chem. Solids, $\underline{6}$, 69 (1958)

26. Wilson, w. B. Phys. Rev., 127, 1549 (1962)

27. Miller, A., and Abrahams, E. Phys. Rev., 120, 745 (1960)

28. Stephen, M. J. Phys. Soc. Proc., 71, 485 (1958)

29. Collins, R. J., and Fan, H. Y. Phys. Rev., 93, 674 (1954)

30. Smith, S. D. and Hardy, J. R. Phil. Mag., $\underline{5}, 1311$ (1960)

31. Dyer, H. B., and Du Preez, L. J. Chem. Phys., 42, 1898 (1965)

32. Ananthanarayanan, K. P., Borer, W. J., Plendl, H. S., and Gielisse, P. J. Radiation Effects (to be published).

33. Wedepoh1, P. T. Ph.D. Thesis, University of Reading, (1958) 
34. Clark, C. D., Kemmey, P. J., and Mitche11, E. W. J. Discussions of the Faraday Soc., No. 31 (1961)

35. Kemmey, P. J., Mitchel1, E. W. J. Proc. of the Int1. Conf. on Semiconductor Physics, New York, N. Y.: Academic Press, p. 919 (1961)

36. Matkovich, V. I. Acta Cryst., 14, 93 (1961)

37. Wang, C. C., Cardona, M., and Fischer, A. G. RCA Rev., 159 (June 1964)

38. Popper, P., and Ingles, T. A. Nature, 179, 1075 (1957)

39. Williams, F. V., and Ruehrwein, R. A. J. Am. Chem. Soc., $\underline{82}$, $1330(1960)$

40. Perri, J. A., LaPlaca, S., and Post B. Acta Cryst., 11, 310 (1958)

41. Armington, A. F., Weiner, J. R., and Moates, G. H. Inorg. Chem,, $\underline{5}, 483(1966)$

42. Vickery, R. C. Nature, 184, 268 (1959)

Matkovich, V. I., and Peret, J. L. "Method of preparing cubic boron phosphide", U.S. Patent No. 3,251,651. May 17, 1966.

43. Grayson, P. E., Buford, J. T., and Armington, A. F. Electrochem. Tech., 3 , 338 (1965)

44. Niemyski, T., Mierzejewska-Appenheimer, S., and Majewski, J. Proc. of the Int1. Conf. on Crystal Growth, ed. by H. Peiser, p. 585 (1966)

45. Ananthanarayanan, K. P., and Gielisse, P. J. (to be published)

46. Stone, B., and Hill, D. Phys. Rev. Lett., No. 6,282 (1960)

47. Fischer, A. G. Thesis, Electroluminescence, University of Giessen, Germany (1957)

48. Gaule, G. K. Boron - Volume 2 New York, N. Y.: Plenum Press (1965) 
128

49. Ananthanarayanan, K. P., Choudry, A., and Gielisse, P. J. (to be published)

50. Ha11, H. T. Sci. Amer., 201, 61 (1959)

51. Hall, H. T. Rev. Sci. Instr., 33, 1278 (1962)

52. Kennedy, G. C., and LaMori, P. N. Progress in Very High Pressure Research. New York, N.Y.: John Wiley and Sons. p. 304 (1961)

53. Bundy, F. P. Progress in Very High Pressure Research. New York, N. Y.: John Wiley and Sons. p. 256 (1961)

54. Eatough, N. L. Ph.D. Thesis, Department of Chemistry, Brigham Young University (1970) 